\title{
Expected Warning Times from the ShakeAlert(B Earthquake Early Warning System for Earthquakes in the Pacific Northwest
}

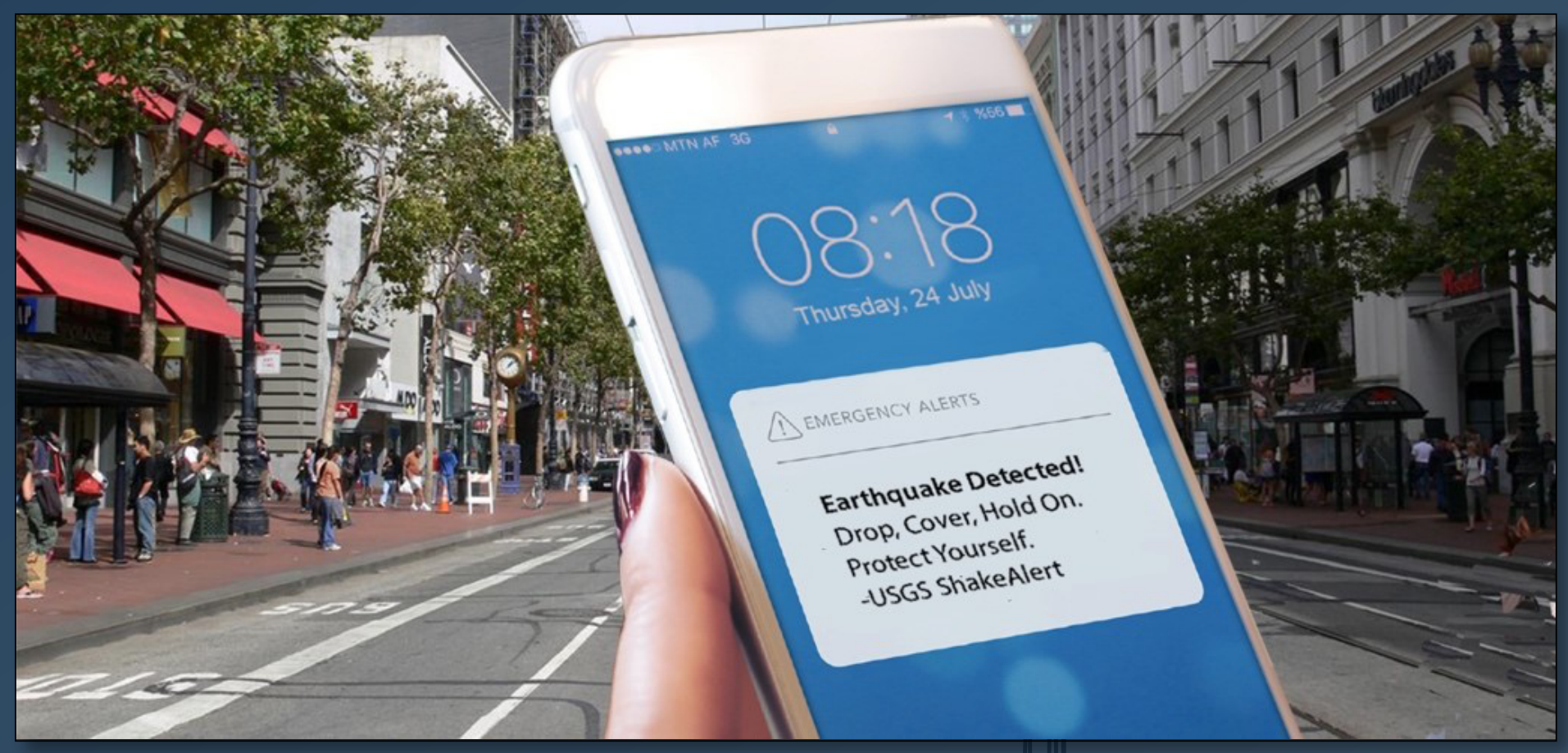

Open-File Report 2021-1026

Version 1.1, March 2021

U.S. Department of the Interior U.S. Geological Survey 
Cover. Photograph of a smartphone that has received a ShakeAlert Message. Photograph by Jenda Johnson, Incorporated Research Institutions for Seismology, used with permission. The seismogram is from downtown Seattle (Pacific Northwest Seismic Network station TKCO) during the 2001 Nisqually earthquake. It is 40 seconds long and begins at the earthquake origin time. The peak shaking, instrumental Modified Mercalli Intensity of about 7, occurs at about 26 seconds after origin time. Calculations in this study show that the first ShakeAlert Message would be published about 11-12 seconds after origin time, which is just before the first seismic waves arrive at this location. 


\section{Expected Warning Times from the ShakeAlert ${ }^{\circledR}$ Earthquake Early Warning System for Earthquakes in the Pacific Northwest}

By Jeffrey J. McGuire, Deborah E. Smith, Arthur D. Frankel, Erin A. Wirth, Sara K. McBride, and Robert M. de Groot

Open-File Report 2021-1026

Version 1.1, March 2021 


\section{U.S. Geological Survey, Reston, Virginia \\ First release: 2021 \\ Revised: March 24, 2021 (ver. 1.1)}

For more information on the USGS - the Federal source for science about the Earth, its natural and living resources, natural hazards, and the environment-visit https://www.usgs.gov or call 1-888-ASK-USGS (1-888-275-8747).

For an overview of USGS information products, including maps, imagery, and publications, visit https://store.usgs.gov.

Any use of trade, firm, or product names is for descriptive purposes only and does not imply endorsement by the U.S. Government.

Although this information product, for the most part, is in the public domain, it also may contain copyrighted materials as noted in the text. Permission to reproduce copyrighted items must be secured from the copyright owner.

Suggested citation:

McGuire, J.J., Smith, D.E., Frankel, A.D., Wirth, E.A., McBride, S.K., and de Groot, R.M., 2021, Expected warning times from the ShakeAlert earthquake early warning system for earthquakes in the Pacific Northwest (ver. 1.1, March 24, 2021): U.S. Geological Survey Open-File Report 2021-1026, 37 p., https://doi.org/10.3133/ofr20211026.

ISSN 2331-1258 (online) 


\section{Acknowledgments}

Thanks to Julian Bunn (California Institute of Technology), Andrew Good (California Institute of Technology), and Minh Huynh (USGS) for extensive efforts to program the warning time calculations into the ShakeAlert system testing-processing stream. We thank Steve Hickman (USGS), Joan Gomberg (USGS), Paul Bodin (University of Washington), Jen Andrews (California Institute of Technology), and Doug Toomey (University of Oregon) for helpful reviews. We thank Maren Böse (ETH Zurich) for providing the extended FinDer template set used in the results presented in figures 12-14.

\section{Contents}

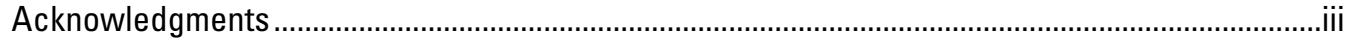

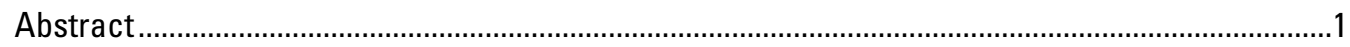

The ShakeAlert Earthquake Early Warning System..........................................................................

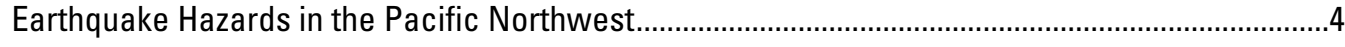

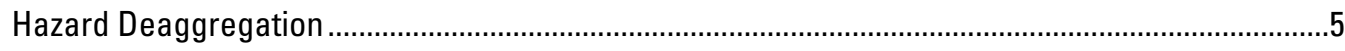

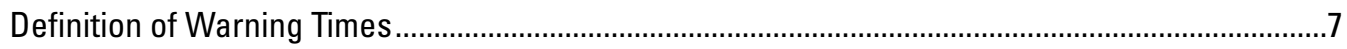

Warning Times for Shallow Crustal Events .....................................................................................

Warning Times for Deep Instraslab Earthquakes.............................................................................10

Warning Times for Offshore M7-9 Megathrust Earthquakes ........................................................13

The Current ShakeAlert Production System ............................................................................14

The Future ShakeAlert Production System ................................................................................17

Implications for EEW Users in the Pacific Northwest........................................................................21

Effects on Protective Actions and the ShakeAlert Warning Message..................................23

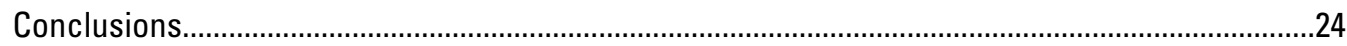

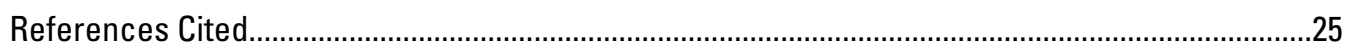

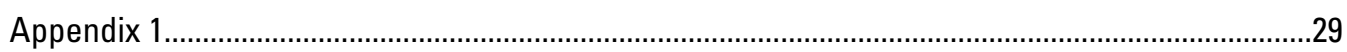




\section{Figures}

1. Three-dimensional schematic diagram showing the types of earthquakes in the Pacific Northwest

2. Maps and plot showing the variability in the time to alert for the real-time production ShakeAlert system for magnitude 3.5 or greater earthquakes

3. Plots showing the probability of generating a ShakeAlert Message as a function of the closest distance to the fault.

4. Plots showing the performance of the real-time ShakeAlert system during the 2019 magnitudes 6.4 and 7.1 Ridgecrest earthquakes

5. Plots showing the empirical cumulative distribution functions of the warning times for the seismic stations that observed the 2019 magnitudes 6.4 and 7.1 Ridgecrest earthquakes.....10

6. Maps of peak shaking and warning times from ShakeAlert for the 2001 Nisqually earthquake in Washington

7. Plots showing warning times for the 2001 Nisqually earthquake in Washington............12

8. Maps of peak shaking and warning times from ShakeAlert for the 2003 Tokachi-Oki earthquake offshore Hokkaido, Japan

9. Ensemble ShakeMap for 30 magnitude 9 megathrust rupture scenarios on the Cascadia subduction zone.

10. Maps of the western Cascadia region showing the time between the origin of the earthquake and when locations of ShakeAlert seismic stations reached instrumental Modified Mercalli Intensity level 4.5 in five magnitude 9 Cascadia earthquake scenarios ....16

11. Maps of the western Cascadia region showing warning times for the simulated csz025 earthquake scenario

12. Maps of the western Cascadia region showing warning times for five magnitude 9 earthquake scenarios with an alert threshold of 2.5

13. Maps of the western Cascadia region showing warning times for five magnitude 9 earthquake scenarios with an alert threshold of 3.5 .

14. Maps of the western Cascadia region showing warning times for five magnitude 9 earthquake scenarios with an alert threshold of 4.5

15. Schematic cartoon showing drop, cover, and hold on actions

\section{Tables}

1. Criteria used by current delivery mechanisms to determine which users will receive alerts on their cell phones.

2. Probability of exceeding peak ground acceleration of $0.045 \mathrm{~g}$ at the indicated return time for three earthquake types

3. Probability of exceeding peak ground acceleration of $0.013 g$ at the indicated return time for three earthquake types.

4. Probability of exceeding peak ground acceleration of $0.003 g$ at the indicated return time for three earthquake types.

5. Alert history for the 2001 magnitude 6.8 Nisqually and 2019 magnitude 7.1 Anchorage earthquakes from offline runs of the ShakeAlert production system in summer $2020 . .11$ 


\section{Abbreviations}

$\begin{array}{ll}\text { EEW } & \text { earthquake early warning } \\ \text { FEMA } & \text { Federal Emergency Management Agency } \\ \boldsymbol{g} & \text { gravitational acceleration } \\ \text { IPAWS } & \text { Integrated Public Alert and Warning System } \\ \text { JCCEO } & \text { Joint Committee for Communication, Education, and Outreach } \\ \text { km } & \text { kilometer } \\ M & \text { magnitude } \\ \text { MMI } & \text { instrumental Modified Mercalli Intensity } \\ \text { NSHM } & \text { National Seismic Hazard Maps } \\ \text { PGA } & \text { peak ground acceleration } \\ \text { USGS } & \text { U.S. Geological Survey } \\ \text { WEA } & \text { Wireless Emergency Alert }\end{array}$





\title{
Expected Warning Times from the ShakeAlert ${ }^{\circledR}$ Earthquake Early Warning System for Earthquakes in the Pacific Northwest
}

\author{
By Jeffrey J. McGuire, Deborah E. Smith, Arthur D. Frankel, Erin A. Wirth, Sara K. McBride, and Robert M. de Groot
}

\section{Abstract}

The ShakeAlert ${ }^{\circledR}$ earthquake early warning system has been live since October 2019 for the testing of public alerting to mobile devices in California and will soon begin testing this modality in Oregon and Washington. The Pacific Northwest presents new challenges and opportunities for ShakeAlert owing to the different types of earthquakes that occur in the Cascadia subduction zone. Many locations in the Pacific Northwest are expected to experience shaking from shallow crustal earthquakes (similar to those in California), earthquakes that occur deep within the subducted slab, and large megathrust earthquakes that occur primarily offshore. The different geometries and maximum magnitudes associated with these types of earthquakes lead to a range of warning times that are possible between when the initial ShakeAlert Message is issued and when a user experiences strong shaking. After an earthquake begins, the strategy of the ShakeAlert system for public alerting is to warn people who are located close enough to the fault that the system estimates they will experience at least weak to moderate shaking. By alerting the public at these low levels of expected shaking, it is possible to provide sufficient warning times for some users to take protective actions before strong shaking begins. In this study, we present an analysis of past ShakeAlert Messages as well as simulations of historical earthquakes and potential future Cascadia earthquakes to quantify the range of warning times that users who experience strong or worse shaking are likely to receive. Additional applications for ShakeAlert involve initiation of automatic protective actions prior to the onset of shaking, such as slowing trains, shutting water supplies, and opening firehouse doors, which are beyond the scope of this paper. Users in the Pacific Northwest should expect that the majority of alerts they receive will be from shallow crustal and intraslab earthquakes. In these cases, users will only have a few seconds of warning before strong shaking begins. This remains true even during infrequent, offshore great (magnitude $\geq 8$ ) megathrust earthquakes, where warning times will generally range from seconds to tens of seconds, depending on the user's location and the intensity of predicted shaking that a user chooses to be alerted for, with the longest warning times of 50-80 seconds possible only for users located at considerable distance from the epicenter. ShakeAlert thus requires short, readily understood alerts stating that earthquake shaking is imminent and suggesting protective actions users should take. Extensive education and outreach efforts that emphasize the need to take actions quickly will be required for ShakeAlert to successfully reduce injuries and losses.

\section{The ShakeAlert Earthquake Early Warning System}

Earthquake early warning (EEW) systems, first developed in Mexico and Japan, seek to detect the initial seismic waves at the beginning of an earthquake and notify users that shaking is imminent at their location (see Allen and Melgar, 2019, for a review). The ShakeAlert EEW system has been live for the testing of public alerting to wireless devices in California since fall of 2019 and similar testing will begin in Oregon and Washington in 2021. Alert delivery to devices that trigger automated actions has been underway in California, Oregon, and Washington since 2018. The system uses a network of more than a thousand seismometers throughout the West Coast to detect the initial seismic waves from an earthquake, estimate its magnitude and peak shaking, and issue a ShakeAlert Message as rapidly as possible (Given and others, 2014, 2018; Hartog and others, 2016; Kohler and others, 2018; Chung and others, 2020). More than 60 ShakeAlert technical partners use ShakeAlert Messages issued by the U.S. Geological Survey (USGS) to develop and deliver alerts to end users. A key need in ensuring the effectiveness of EEW in promoting public safety is understanding how much warning time will be available and how that varies with different alerting criteria, tectonic regimes, and alert delivery mechanisms (Minson and others, 2018; Wald, 2020). All of these factors contribute to determining the amount of warning an individual at a particular location will receive from a particular earthquake, which can vary significantly between users. Moreover, educating end users ahead of time about the range of possible warning times will be key for ensuring that appropriate protective and (or) automated actions are taken (McBride and others, 2020). 
For every earthquake, there is a zone near the epicenter where there is no warning time before shaking is felt because it takes time, often just seconds, for the ShakeAlert system to detect the shaking and issue the first ShakeAlert Message. Moreover, individual end users will receive different amounts of warning time for different earthquakes that they are likely to experience. In the Pacific Northwest, the Cascadia subduction zone produces three primary classes of earthquakes: shallow crustal, deep intraslab, and offshore plate boundary megathrust ruptures (fig. 1). Each of these presents a different scenario for EEW because of the timing, intensity, and spatial extent of the shaking that they produce. One key feature of earthquakes is that although they start at a point, the rupture takes time to spread out over the fault. Large magnitude 8-9 earthquakes can rupture hundreds of kilometers along a major fault and this takes tens of seconds to minutes to occur. Thus, for the largest of earthquakes, there is a higher potential for long warning times than there is for smaller earthquakes. The goal of this study is to help ShakeAlert technical providers, emergency managers, end users, and others to understand the range of possible warning times based on the types of earthquake sources that occur in the Pacific Northwest to inform the most effective protective actions.

Given these complexities and based on experiences during past earthquakes, EEW messaging strategies must be thoughtfully constructed to reduce injuries and consider human behavior, injury patterns, and message interpretation in order to spur immediate protective action. Earthquake-related injuries most frequently occur when people are attempting to move during and immediately after shaking (Peek-Asa and others, 2003; Johnston and others, 2014; McBride and others, 2019; Horspool and others, 2020). In the Pacific Northwest, although severe injuries were reported during the 2001 Nisqually, Washington, earthquake

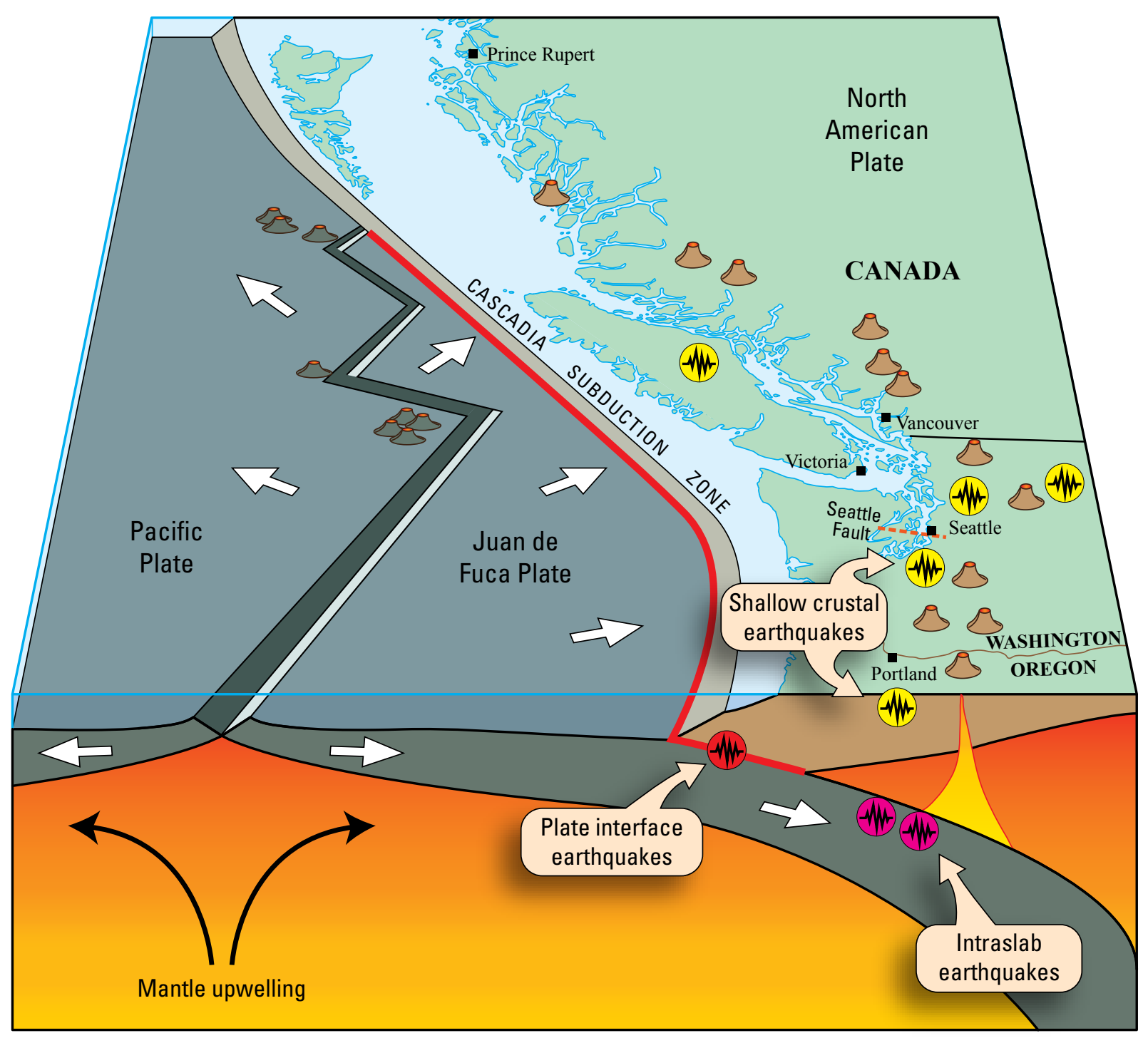

Figure 1. Three-dimensional schematic diagram showing the types of earthquakes in the Pacific Northwest: shallow crustal earthquakes, deep intraslab earthquakes, and offshore plate interface (megathrust) earthquakes. The oceanic Juan de Fuca Plate (shown in gray) subducts beneath the North American Plate. From Given and others (2018), reproduced without modification. 
(1 death, 400 injuries), there was no evidence that severe injuries occurred from collapsed structures. Falls were the main reason for reported injuries (Kano, 2005) and hospitalizations in the Nisqually earthquake, and were most commonly associated with exiting from a building; these findings are consistent with other earthquake injury analyses (Peek-Asa and others, 2003, p. 462, 464). Reports from the Nisqually earthquake indicate that there were also head injuries and crushing caused by falling bricks after people exited a building during the earthquake (staff of the Pacific Northwest Seismic Network, 2001). To limit confusion and reduce the potential for such injuries, short directive messaging based on the range of likely warning times, combined with prior education and training on actions people should take after receiving an alert, is critical to developing appropriate warning message strategies.

To produce a ShakeAlert Message, the system first detects the earthquake, estimates its location and magnitude, computes the area that is expected to experience different intensities of shaking, and then issues ShakeAlert Messages (Given and others, 2018; Chung and others, 2020; Kohler and others, 2020). The time between when the earthquake starts and when the first ShakeAlert Message is issued ranges from about 4 to 20 seconds, depending on the particular type of fault, the depth of the earthquake hypocenter, and the seismic station density near its epicenter (fig. 2). The ShakeAlert sensor distribution is densest in urban areas and least dense offshore, resulting in a range of initial alerting times of 4-20 seconds. Of the three earthquake types, the time until the first ShakeAlert Message is issued can be the longest for offshore earthquakes in the Cascadia subduction zone because few seismic stations are located offshore (fig. 2).
Once the ShakeAlert Messages are issued by the USGS, alerts are delivered to EEW end users by ShakeAlert technical partners via a variety of mechanisms that fall into three broad categories. Firstly, machine-to-machine delivery via the internet is generally the fastest and can be used to initiate pre-recorded messages on loud speaker systems, slow trains, close valves, or alert cell phones connected to Wi-Fi. Secondly, users can receive alerts powered by ShakeAlert on their cell phone either by downloading an application (commonly referred to as an app) or via the Android operating system. In California, QuakeAlertUSA (available from Early Warning Labs), MyShake (from University of California Berkeley), and the City of Los Angeles (app no longer available) have partnered with the USGS to test the delivery of alerts through cell phone apps. Thirdly, for potentially damaging earthquakes, Wireless Emergency Alerts (WEA) delivered by the Integrated Public Alert and Warning System (IPAWS), operated by the Federal Emergency Management Agency (FEMA), will deliver alerts via cell broadcast to all cell phones in the affected area. Each of these mechanisms uses different criteria, some of which the user can select, for deciding when a particular user should be alerted. They also take different amounts of time to deliver the alert to a particular device and the delivery times depend on whether the device is connected to Wi-Fi or to the cellphone carrier's broadcast signal. These varying alert delivery times for the different mechanisms are still being tested and improved. They can vary from as little as less than 1 second for the fastest machine-to-machine and app alerts via $\mathrm{Wi}-\mathrm{Fi}$, to several tens of seconds or no alert for WEA, which in some cases is the slowest delivery pathway.
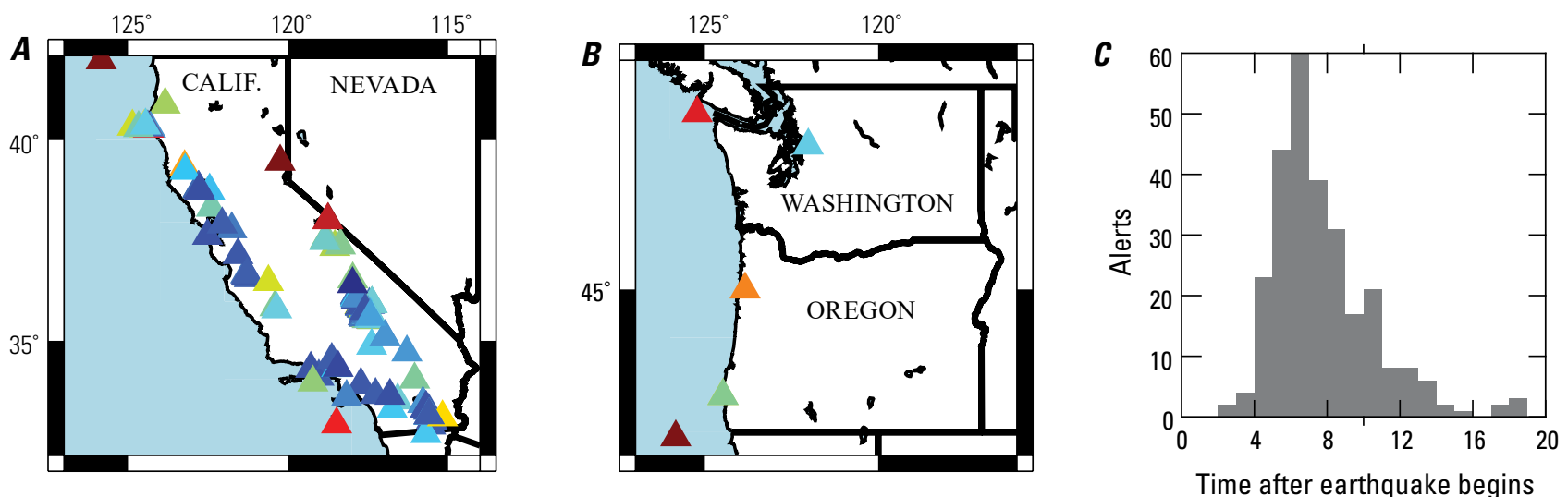

Time after earthquake begins
until alert is issued, in seconds

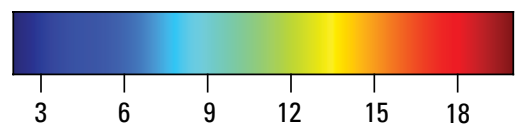

Time after earthquake begins until alert is issued, in seconds

Figure 2. Maps and plot showing the variability in the time to alert for the real-time production ShakeAlert system from January 1 , 2019, to October 31, 2020, for magnitude 3.5 or greater earthquakes (locations marked by triangles). $A$, Map of California; $B$, map of Oregon and Washington; $C$, histogram of alert times. The time until the first ShakeAlert Message is issued is generally longer for offshore earthquakes than onshore earthquakes. These times include latencies from the data telemetry delivery of the seismic data to the ShakeAlert processing centers and from all of the ShakeAlert software computations necessary to produce ShakeAlert Messages. 
Whether a particular user will receive an alert via a specific delivery mechanism is currently determined by a combination of the real-time estimates of earthquake magnitude $(M)$ and the shaking intensity that will be experienced at the user's location. ShakeAlert provides the estimated shaking intensity using the Modified Mercalli Intensity scale (MMI) predicted by a ground motion to intensity conversion equation (Worden and others, 2012) and a ground motion prediction equation (Chiou and Youngs, 2008; Thakoor and others, 2019). The combinations of magnitude and intensity that are used as criteria for issuing an alert to a particular user via the different delivery mechanisms (as of spring 2021) are given in table 1. The ShakeAlert system produces a contour product, which contains polygons that approximate the area where the expected median intensity ground motion corresponds to specific levels of MMI (Given and others, 2018; Thakoor and others, 2019). The delivery mechanisms then determine if a particular user is within its specified alert polygon before issuing the user an alert. Currently, the shaking intensity values used by different delivery mechanisms range from weak (MMI 3) to moderate (MMI 5) shaking. The strategy of the ShakeAlert system is to issue alerts for weak to moderate shaking to maximize warning times for the regions that will eventually experience strong or worse shaking. This strategy means that many users who receive alerts will not experience strong shaking. Moreover, the majority of alerts will be for earthquakes in the $M 4-5$ range, given the current alerting criteria. In this study, we focus on the warning times for users who will experience strong (MMI 6) or worse shaking from large (about M6.5 or greater) earthquakes.

For large earthquakes, alerts are sent to an area that expands over time as the system's estimate of the earthquake magnitude and rupture length grow (Chung and others, 2020). The first ShakeAlert Messages issued are typically based on only the first few seconds or less of data and tend to be small (for example, about $M 4-6$ ) because the rupture has not had time to grow into a large earthquake. For reference, in the Pacific Northwest, a first alert for a M5.5 earthquake would go out to radii of about 200, 75 , and 20 kilometers $(\mathrm{km})$ for delivery mechanisms that alert for MMI 2.5, 3.5, and 4.5, respectively. As the magnitude estimates grow to $M 6.5$ or 7.0 , these distances increase to approximately 450 to 530,225 to 300 , and 80 to $120 \mathrm{~km}$, respectively. Thus, whether the first ShakeAlert Message issued for an earthquake covers a particular region will be highly variable depending on the specific earthquake and user's location, the initial magnitude estimate, and the choice of delivery mechanism.

The time after a ShakeAlert Message is issued by the USGS until the time when a technical partner delivers an alert to an individual user by any mechanism is variable. The fastest alerts are via systems connected to the internet (for example, cell phones on Wi-Fi or public address systems), which can be delivered in less than 1 second in some cases. Alerts that arrive via cellular delivery are commonly in the range of 1 to 10 seconds, but the scaling to large numbers of users is still being tested by various apps and Android. The WEA system can be as fast as 4 seconds based on recent tests, but many users receive the alert later than 10 seconds or not at all (McBride, S.K., USGS, written commun., 2020). Individual alerts may be faster or slower than these times, and alerts may become faster in the future. For the purposes of this study, we report maximum possible warning times, which do not include the time required for the ShakeAlert technical partner to deliver the alert to end users after it is received from the USGS because we do not yet have enough information on alert delivery times via any mechanism to evaluate them in a probabilistic way.

\section{Earthquake Hazards in the Pacific Northwest}

The Pacific Northwest is susceptible to three main types of earthquake sources: shallow crustal earthquakes, deep intraslab earthquakes, and large megathrust earthquakes in the Cascadia subduction zone (fig. 1). Large deep intraslab earthquakes in the subducting Juan de Fuca Plate occur approximately every few decades, and tend to occur beneath the Puget Sound region of Washington State at 40-70 km depths (Bostock and others, 2019). The most recent deep earthquakes that inflicted significant damage include the 2001 M6.8 Nisqually, 1965 M6.5 Puget Sound, and 1949 M6.8 Olympia earthquakes. Deep earthquakes appear to be significantly less common in the subducting Juan de Fuca slab beneath Oregon (Bostock and others, 2019). Crustal earthquakes tend to have longer recurrence times in the Pacific Northwest, but they are potentially more damaging than deep intraslab earthquakes because of their shallow depths and proximity to population centers. Examples of large crustal earthquakes in the Pacific Northwest include the 1872 M6.5-7 Entiat earthquake

Table 1. Criteria used by current (as of spring 2021) delivery mechanisms to determine which users will receive alerts on their cell phones.

[Peak ground acceleration (PGA) levels are the estimated median shaking level at the polygon boundary, and individual users located inside the polygon may experience ground motion higher or lower than that value. App, application; $\mathrm{cm} / \mathrm{s}^{2}$, centimeter per square second; $g$, gravitational acceleration; GMICE, ground motion to intensity conversion equation; GMPE, ground motion prediction equation; IPAWS, Integrated Public Alert and Warning System; MMI, instrumental Modified Mercalli Intensity; WEA, Wireless Emergency Alerts]

\begin{tabular}{|c|c|c|c|c|c|}
\hline Delivery mechanism & $\begin{array}{l}\text { Minimum } \\
\text { magnitude }\end{array}$ & $\begin{array}{c}\text { Contour product } \\
\text { polygon }\end{array}$ & $\begin{array}{l}\text { Median MMI calculated } \\
\text { from GMPE and GMICE }\end{array}$ & PGA level $\left(\mathrm{cm} / \mathrm{s}^{2}\right)$ & $\begin{array}{c}\text { PGA level } \\
(g)\end{array}$ \\
\hline IPAWS WEA system & 5.0 & MMI 4 & 3.5 & 12.8 & $0.013 g$ \\
\hline Android "be aware" alerts & 4.5 & MMI 3 & 2.5 & 2.9 & $0.003 g$ \\
\hline Android "take-action" alerts & 4.5 & MMI 5 & 4.5 & 44.5 & $0.045 g$ \\
\hline MyShake app & 4.5 & MMI 3 & 2.5 & 2.9 & $0.003 g$ \\
\hline QuakeAlertUSA app & 4.5 & MMI 3, 4, 5 & $2.5,3.5,4.5$, user selectable & $2.9,12.8,44.5$ & $0.003 g, 0.013 g, 0.045 g$ \\
\hline City of Los Angeles app & 4.5 & MMI 3 & 2.5 & 2.9 & $0.003 g$ \\
\hline
\end{tabular}


(Brocher and others, 2017) and the approximately $M 7$ Seattle Fault earthquake in A.D. $900-930$ that has been inferred from geologic evidence (Nelson and others, 2003).

In addition to shallow crustal and deep intraslab events, the Cascadia subduction zone has a history of large M8-9 earthquakes on the megathrust fault offshore, which has been inferred from geologic evidence for shaking, subsidence, and tsunamis (Atwater and others, 2005), as well as by offshore turbidite records (Goldfinger and others, 2012). The last known Cascadia megathrust earthquake occurred in A.D. 1700, and full margin ruptures on the Cascadia subduction zone are estimated to occur approximately every 500 years (Goldfinger and others, 2012). Based on modeling tsunami observations in Japan, the A.D. 1700 earthquake had an estimated magnitude of 8.7-9.2 (Satake and others, 2003). Paleoseismic evidence suggests that southern Cascadia may also experience more frequent partial ruptures (for example, approximately $M 8$ ) of the Cascadia megathrust zone (Nelson and others, 2006), but evidence for smaller magnitude partial ruptures in northern Cascadia are less well constrained (Frankel and others, 2019).

\section{Hazard Deaggregation}

The USGS National Seismic Hazard Maps (NSHM; Petersen and others, 2014, 2019) provide estimates for the contribution of different types of earthquakes to the total seismic hazard in locations throughout the Pacific Northwest. Whereas seismic hazard is high throughout the region, the underlying contributions from different types of earthquakes at a particular location vary. The USGS provides the ability to deaggregate the hazard portrayed in the NSHM by shaking level and source type, and we have utilized this capability to illustrate the types of earthquakes likely to cause a ShakeAlert Message to be issued for a number of locations throughout the region.

To determine what types of earthquakes are likely to cause alerts to be delivered to a specific location, we have deaggregated the hazard according to the probability of exceeding different levels of peak ground acceleration (PGA) that correspond to the different alerting criteria in table 1. Specifically, the ShakeAlert contour product polygons in the Pacific Northwest are calculated using the ground motion prediction equation from Chiou and Youngs (2008) and the ground motion to intensity conversion equation from Worden and others (2012). As currently defined in the ShakeAlert system (Chung and others, 2020), the MMI 3, 4, and 5 contour products, correspond to PGA levels of $0.003 g, 0.013 g$, and $0.045 g$, respectively, where $g$ is gravitational acceleration. Tables 2-4 give the return time of each expected level of shaking in Seattle, Wash.; Tacoma, Wash.; Portland, Oreg.; Newport, Oreg.; and Eureka, Calif. Return time is defined such that there is a 63 percent (about 2 out of 3 ) chance of this shaking level occurring during one return time. For each level of shaking and location, the hazard is deaggregated into earthquake sources on the subducted plate interface (megathrust earthquakes), deep within the slab, and in the shallow crust. Tables 1.1-1.3 in appendix 1 show a breakdown of the shallow crustal earthquakes into those associated and not associated with specific faults in the NSHM. Since a ShakeAlert Message is issued based on the median ground motion expected for the detected earthquake at a user's location (using the appropriate ground motion prediction equation, earthquake magnitude, and distance from the ruptured fault), the hazard calculation in this analysis does not include extreme values of ground motion caused by effects such as site amplification or rupture directivity. All calculations in tables 2-4 correspond to a minimum magnitude of 5.0 set by the NSHM.

As an example, end users who live in Seattle, Portland, or Eureka and use a cell phone app powered by ShakeAlert set to alert using the MMI 3 contour product should expect to receive an alert once every 3.5, 7, or 2 years, respectively (table 4). However, for the Android take-action alerts, which use the MMI 5 contour product, users in these same locations would expect to receive this type of alert once every 24,91 , and 14 years, respectively (table 2).

Table 2. Probability of exceeding peak ground acceleration (PGA) of $0.045 \mathrm{~g}$ at the indicated return time for three earthquake types.

[PGA of $0.045 g$ corresponds to the Modified Mercalli Intensity (MMI) 5 contour product. $g$, gravitational acceleration; \%, percent; yr, year]

\begin{tabular}{lcccc}
\hline Location & $\begin{array}{c}\text { Return } \\
\text { time (yr) }\end{array}$ & $\begin{array}{c}\text { Megathrust } \\
\text { earthquake (\%) }\end{array}$ & $\begin{array}{c}\text { Deep intraslab } \\
\text { earthquake (\%) }\end{array}$ & $\begin{array}{c}\text { Shallow crustal } \\
\text { earthquake (\%) }\end{array}$ \\
\hline Seattle & 24 & 6 & 54 & 40 \\
Tacoma & 25 & 6 & 55 & 39 \\
Portland & 91 & 26 & 15 & 59 \\
Newport & 117 & 39 & 12 & 48 \\
Eureka & 14 & 4 & 4 & 92 \\
\hline
\end{tabular}

Table 3. Probability of exceeding peak ground acceleration (PGA) of $0.013 \mathrm{~g}$ at the indicated return time for three earthquake types.

[PGA of $0.013 g$ corresponds to the Modified Mercalli Intensity (MMI) 4 contour product. $g$, gravitational acceleration; \%, percent; yr, year]

\begin{tabular}{lcccc}
\hline Location & $\begin{array}{c}\text { Return } \\
\text { time (yr) }\end{array}$ & $\begin{array}{c}\text { Megathrust } \\
\text { earthquake (\%) }\end{array}$ & $\begin{array}{c}\text { Deep intraslab } \\
\text { earthquake (\%) }\end{array}$ & $\begin{array}{c}\text { Shallow crustal } \\
\text { earthquake (\%) }\end{array}$ \\
\hline Seattle & 8 & 2 & 49 & 49 \\
Tacoma & 8 & 2 & 49 & 48 \\
Portland & 25 & 8 & 25 & 67 \\
Newport & 50 & 17 & 13 & 69 \\
Eureka & 4 & 1 & 5 & 93 \\
\hline
\end{tabular}

Table 4. Probability of exceeding peak ground acceleration (PGA) of $0.003 \mathrm{~g}$ at the indicated return time for three earthquake types.

[PGA of $0.003 g$ corresponds to the Modified Mercalli Intensity (MMI) 3 contour product. $g$, gravitational acceleration; \%, percent; yr, year]

\begin{tabular}{lcccc}
\hline \multicolumn{1}{c}{ Location } & $\begin{array}{c}\text { Return } \\
\text { time (yr) }\end{array}$ & $\begin{array}{c}\text { Megathrust } \\
\text { earthquake (\%) }\end{array}$ & $\begin{array}{c}\text { Deep intraslab } \\
\text { earthquake (\%) }\end{array}$ & $\begin{array}{c}\text { Shallow crustal } \\
\text { earthquake (\%) }\end{array}$ \\
\hline Seattle & 3.5 & 1 & 35 & 64 \\
Tacoma & 4 & 1 & 37 & 62 \\
Portland & 7 & 2 & 30 & 68 \\
Newport & 12 & 4 & 11 & 84 \\
$\begin{array}{l}\text { Eureka }(0.005 g \\
\left.\text { threshold }{ }^{2}\right)\end{array}$ & 2 & 1 & 4 & 95 \\
\hline
\end{tabular}

${ }^{\text {a The }} 0.005 g$ threshold for Eureka corresponds to the shortest recurrence time modeled by the National Seismic Hazard Map. 
Table 2 also shows that these take-action alerts will be prompted by predominately deep intraslab and shallow crustal earthquakes in Seattle (94 percent) and Portland (74 percent), but for locations near the coast, such as Newport, the contribution from offshore megathrust earthquakes (39 percent) will be significantly larger.

The distribution of earthquake magnitudes that will prompt the USGS to issue a ShakeAlert Message has a strong influence on the amount of warning time that is possible. Although the strength of shaking at a given distance from
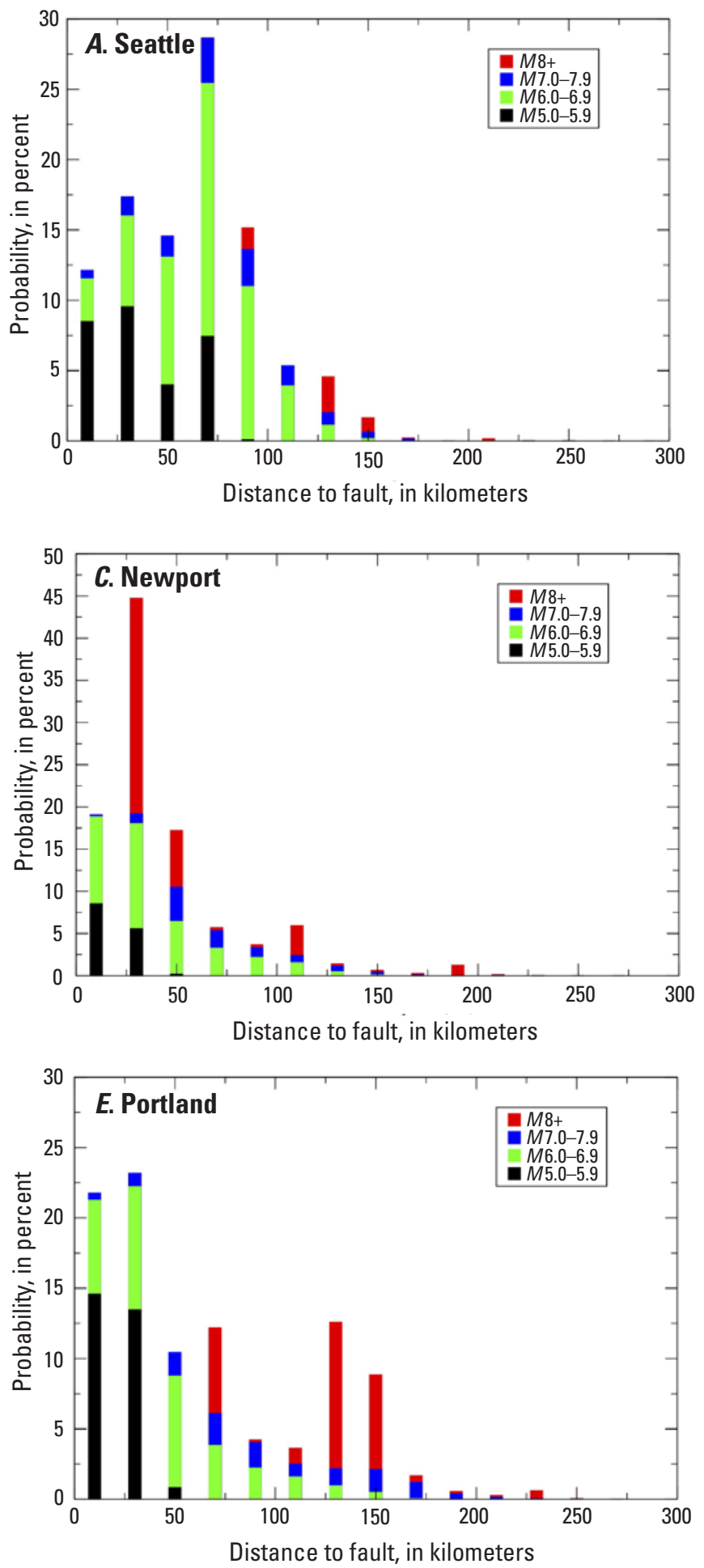

an earthquake is highly variable, for smaller magnitude earthquakes, the zone of strong shaking is generally smaller and closer to the epicenter than it is for larger events. Thus, it is inherently harder to provide long warning times for strong shaking in $M 5$ earthquakes than it is in M8 earthquakes (Meier and others, 2020). Figure 3 shows the deaggregation of the sources contributing to MMI 5 alerts in table 2 for each of the five cities as a function of magnitude and closest distance to the fault. Note these are not epicentral distances and hence cannot
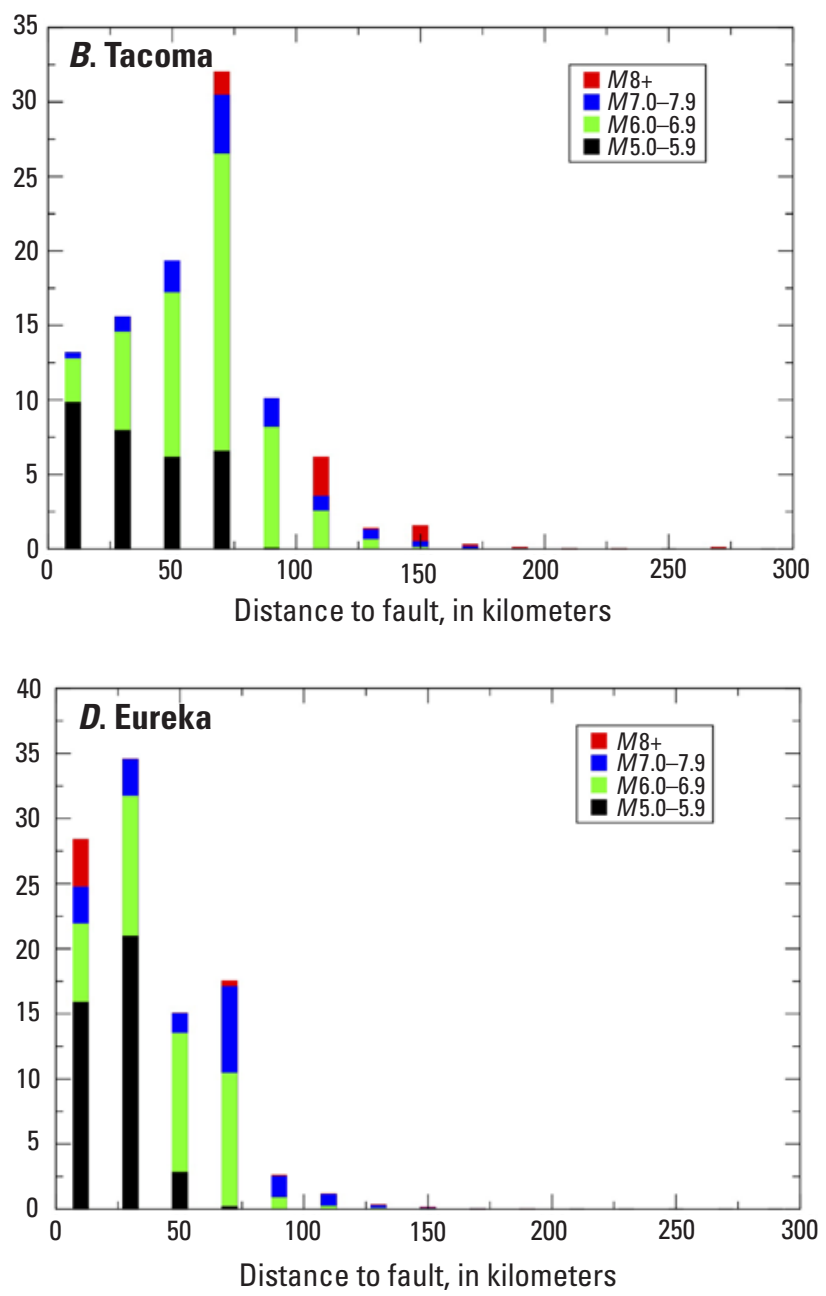

Figure 3. Plots showing the probability of generating a ShakeAlert Message as a function of the closest distance to the fault that ruptured during the earthquake for the hazard deaggregation calculations in table 2 for Seattle $(A)$, Tacoma $(B)$, Newport $(C)$, Eureka $(D)$, and Portland $(E)$. The deaggregation calculations are for a Modified Mercalli Intensity 5 contour product. Note the distance is the distance tabulated in the National Seismic Hazard Maps, which is the distance to the closest point on the fault $\left(R_{\text {rup }}\right)$, not the distance to the epicenter. Colors show the contribution of different magnitude ranges to the probabilities. $M$, magnitude. 
be simply mapped to expected warning times. In particular, for great megathrust earthquakes we do not know where the next $M 8+$ earthquake will nucleate (see the following sections for discussions of warning times in this type of earthquake). It should be noted that ground-motion intensity depends on the distance to the closest part of the fault that ruptured during the earthquake, not the distance to where the earthquake starts - its hypocenter (the epicenter is the projection of the hypocenter onto the Earth's surface).

Of particular importance in figure 3 is that, for all locations, the majority of alerts will be from moderate M5.0-7.0 earthquakes occurring within about $100 \mathrm{~km}$. Some delivery mechanisms will be even more dominated by alerts for smaller earthquakes than what is shown in tables 2-4 because they use the lower M4.5 magnitude threshold (table 1). Similar calculations for the MMI 4 contour product alerting are shown in figure 1.1 in appendix 1. In all five locations, the majority of alerts that an end user will receive will be from earthquakes smaller than $M 7.0$. In such cases, we expect warning times before strong shaking to be short, on the order of 10 seconds or less. Warnings from large $M 8.0$ or greater megathrust earthquakes will be a small fraction of the alerts received in all locations, but offer the greatest potential for a longer warning time.

\section{Definition of Warning Times}

Two choices of ground motion levels are required to specify the warning time at a particular location. In this study, we use MMI for instrumental intensity, which is computed from observed peak ground acceleration and peak ground velocity (Worden and others, 2012), rather than for macroscopic intensity, which is defined through observed non-instrumental effects of shaking (for example, damage to structures, as reported on the USGS Did You Feel It? web page, available at https://earthquake.usgs.gov/data/ dyfi). We measure the warning time by comparing the temporal evolution of the observed and the predicted ground motions at sites where seismic stations are located, following the methods of Chung and others (2020). At each site, both the observed and the predicted ground motions evolve over time. The predicted ground motions are updated repeatedly during the earthquake as the ShakeAlert system records more data and updates its earthquake magnitude and location estimates. Moreover, large earthquakes can take tens of seconds or more to rupture along a long fault and ShakeAlert attempts to track this growth, causing the predicted ground motions to update over seconds to tens of seconds or even minutes in a great earthquake. We assume that each site would be alerted as soon as the prediction, $M M I_{\text {pred }}(t)$, for that site exceeds an alerting threshold $M M I_{\text {alert }}$ One difference from the calculations of Chung and others (2020) is that they used the ShakeAlert map product, a regular grid of predicted ground motions, whereas the calculations in this study use the ShakeAlert contour product, which is used by all of the alerting mechanisms in table 1 . The difference between the two is generally minimal and include different assumptions about local site effects on expected shaking intensity. The time a user is alerted $\left(t_{\text {alert }}\right)$ is given by equation 1 , where $t$ is time.

$$
t_{\text {alert }}=t\left(M M I_{\text {pred }}(t) \geq M M I_{\text {alert }}\right) .
$$

Whether or not a site should be alerted depends on if the peak observed ground motion, $M M I_{\text {obs }}$, exceeds $M M I_{\text {alert }}$. Sending an alert to a site with $M M I_{\text {obs }}<M M I_{\text {alert }}$ is considered a false alert (false positive). Failing to alert a site with $M M I_{\text {obs }} \geq M M I_{\text {alert }}$ is considered a missed alert (false negative). Sending an alert to a site with $M M I_{\text {obs }} \geq M M I_{\text {alert }}$ is considered a correct alert if the alert was created while there was still time to take action (true positive). We define the last point in time at which an alert is still actionable $\left(t_{\text {last }}\right)$ as

$$
t_{\text {last }}=t\left(M M I_{o b s}(t) \geq M M I_{t w}\right)
$$

That is, $t_{\text {last }}$ occurs when the observed ground motion exceeds a ground motion threshold, $M M I_{\mathrm{tw}}$, where $M M I_{\mathrm{tw}} \geq M M I_{\text {alert }}$. Once shaking is stronger than $M M I_{\mathrm{tw}}$, an incoming alert is considered not useful because ground shaking has become too strong for a person to take effective protective action (such as drop, cover, and hold on) and is considered a missed alert. Warning times $\left(t_{\mathrm{w}}\right)$ can then be measured as

$$
t_{\mathrm{w}}=t_{\text {last }}-t_{\text {alert }}
$$

The different delivery mechanisms in table 1 use a variety of values for $M M I_{\text {alert }}$ and, as a result, a particular location will have different warning times depending on the alert distribution mechanism. Similarly, the proper value to use for $M M I_{\text {tw }}$ is not clear. Given that MMI 4 is felt indoors by many, it is still possible to take protective actions at that level. For this analysis, we set $M M I_{\mathrm{tw}}$ to 4.5 to represent the onset of moderate shaking where people report having difficulties standing (Stover and Coffman, 1993; Dewey and others, 1995). Given the variety of values that can be relevant for $M M I_{\text {tw }}$ (accounting for variations in the appropriate protective action, which depend on whether someone is inside a building, driving a car, has limited mobility, and so on) and for $M M I_{\text {alert }}$, we show alternate versions of most figures in appendix 1 to allow the reader to see the effect of different chosen values. We note that damage is minimal in well designed infrastructure for shaking below MMI 8, and as a result, a higher value of $M M I_{\mathrm{tw}}$ may be appropriate for automated machine-tomachine actions in these cases, which would correspond to longer actionable warning times in many cases.

Here we present a combination of results from the realtime ShakeAlert system in California as well as offline runs of the ShakeAlert software on historical or synthetic earthquakes. The real-time system performance includes the latency for data transmission from seismic stations to ShakeAlert servers, which is typically 0-2 seconds but can be larger during some earthquakes (Chung and others, 2020). For the purposes of this study, we report maximum possible warning times that do not include the time to deliver the alert via a particular mechanism once the 
USGS ShakeAlert Message is received by the alert distribution partner. This delivery time can range from less than a second (for internet connections or cell phones connected to Wi-Fi) to not receiving the alert at all (in some cases). We do not yet have enough information on alert delivery times via any mechanism to evaluate them in a probabilistic way. Values of 1 second for alerts delivered via the internet or to cell phone apps and Android phones via Wi-Fi, 4 seconds for alerts delivered to cell phone apps or Android phones via cellular connections, and 8 seconds for WEA are within the range of latencies reported to ShakeAlert by various partners during testing in 2019 and 2020 and our own WEA tests (McGuire and others, 2019; McBride, S.K., USGS, written commun., 2020). However, individual alerts may be faster or slower than these values.

Particularly for shallow crustal and offshore megathrust earthquakes, many sites experience their strongest shaking during passage of the seismic surface waves and, thus, approaches that assume the peak shaking occurs at the time of the S-wave arrival from the hypocenter are oversimplified. All of the warning times discussed in the following three sections have been calculated from actual MMI exceedance times from either recorded historical earthquakes or numerical simulations of large earthquakes on the Cascadia megathrust. We use synthetic earthquakes for the megathrust events because there are no recorded great earthquakes in the Cascadia region. We compare these to results from wellrecorded events in Japan that have previously been studied for EEW by others.

\section{Warning Times for Shallow Crustal Events}

Tables 2-4 show that more than 40 percent of alerts received will be from shallow crustal earthquakes for most combinations of delivery mechanism and location in the Pacific Northwest. ShakeAlert is developing a solid understanding of warning times for these types of onshore earthquake sources from data collected on frequent moderate and occasional large magnitude events in California (for example, Chung and others, 2020). As the seismic network in the Pacific Northwest is built out over the coming years to match the ShakeAlert implementation plan (Hartog and others, 2016; Given and others, 2018), we expect the capabilities of the system in Oregon and Washington to approximately resemble those in many parts of California for shallow crustal events. Warning times for strong, or worse, shaking (MMI 6 or greater) in shallow crustal earthquakes are inherently short because for all but the largest earthquakes, this level of shaking is concentrated relatively close to the epicenter (Wald, 2020). Even for large propagating ruptures, it is inherently difficult to achieve long warning times for high-intensity shaking because such shaking requires knowing the current length of the rupture and is only expected within a few tens of kilometers of the fault. Thus, to get long warning times for large crustal earthquakes (on the order of tens of seconds), users must be willing to take action at non-damaging levels of shaking (for example, MMI 3-4) for training purposes or in anticipation that the earthquake may grow to become larger (Minson and others, 2018).

The ShakeAlert system consists of a series of algorithms that estimate an earthquake's location, magnitude, rupture length, and expected shaking. During a large earthquake, the size and fault location estimates will evolve as the earthquake grows and the system receives more data about the shaking. Typically, the current ShakeAlert system starts when the EPIC point-source algorithm (Chung and others, 2019) detects the earthquake and produces an initial estimate of the magnitude and epicenter. The FinDer algorithm then starts to produce an estimate of fault length and a corresponding magnitude, which is continually updated until the earthquake rupture stops. These parameters are combined by the solution aggregator algorithm, and the result is used by the EqInfo2GM algorithm to produce estimates of expected peak shaking, which is published by the decision module (see fig. 6 of Given and others, 2018). The system is further described by Kohler and others (2018) and Chung and others (2020). The warning times described below result from running the full system (as of fall 2020) through to the predicted ground motion calculation; they result from a combination of these algorithms.

Shallow crustal earthquakes of moderate size are a difficult case for EEW to provide long warning times (Minson and others, 2018; Meier and others, 2020; Wald, 2020). Tables 2-4 and figure 3 show that approximately 40-70 percent of the alerts received in Portland and Seattle will likely come from nearby crustal earthquakes of M4.5-7. The ShakeAlert system recently issued ShakeAlert Messages for the 2019 M6.4 and M7.1 Ridgecrest earthquakes, and these events offer useful insights into the warning times possible in the Pacific Northwest for crustal earthquakes. The distance that strong shaking (MMI 6) is typically felt from a $M 7.1$ earthquake is large (about $100-150 \mathrm{~km}$; for example, see fig. $4 B$ ) compared to a $M 5.0$ earthquake (about $10 \mathrm{~km}$ ). Figures 4 and 5 show the warning times as a function of the eventual shaking level that end users with a cell phone app set to alert for MMI 3 shaking (corresponding to a median $M M I_{\text {alert }}$ of 2.5 ; see table 1) would have received if cell phone apps had been delivering alerts at this level during the Ridgecrest earthquakes (Chung and others, 2020). The warning time for all possible values of $M M I_{\mathrm{tw}}$ at a particular location are shown in figure 4 as a vertical column of symbols at a given distance. Even within $50 \mathrm{~km}$ of the epicenter, it can take 10 seconds or more for the shaking at a particular location to increase from when it is first felt until it reaches its highest intensity. In contrast, figure 5 (as well as figs. $6,7 B, D, F, 8$, and 11-14) assumes that when shaking reaches $M M I_{\mathrm{tw}}=4.5$ an alert becomes no longer useful because the shaking is already strong enough that it is too difficult to take a protective action. Although $M M I_{\mathrm{tw}}=4.5$ may be a relevant value for drop, cover, and hold on actions, we note that some automated actions in industrial settings could likely still continue at higher levels of shaking and as a result have somewhat longer actionable warning times (as is seen in the location with the strongest shaking [MMI 8.5] in fig. 4).

For regions that experienced potentially damaging shaking in the M7.1 earthquake (MMI 6; yellow curves in fig. 5B), 25 percent of sites would have received warning times of more than 20 seconds, 25 percent would have received warning 

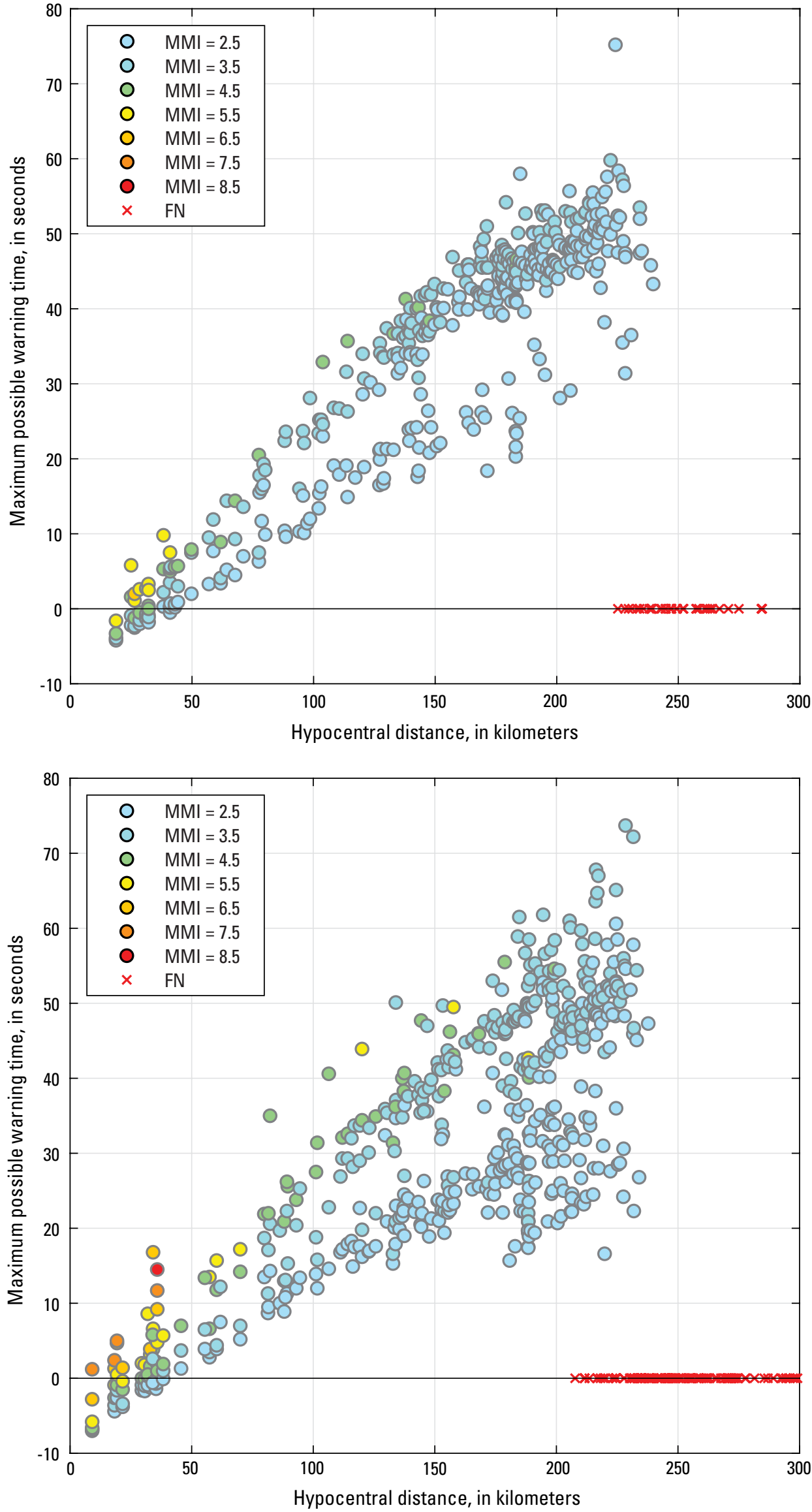

Figure 4. Plots showing the performance of the real-time ShakeAlert system during the 2019 magnitudes 6.4 (left) and 7.1 (right) Ridgecrest earthquakes. The time at which different instrumental Modified Mercalli Intensity (MMI) threshold levels are exceeded by the observed ground motion at each seismic station relative to the time when the site is alerted $\left(t_{\text {alert }}\right)$ for an alert threshold ( $M \mathrm{MI}_{\text {aler }}$ ) of 2.5 is plotted versus distance from the hypocenter. Each station has a symbol plotted for each MMI level that it exceeded. The highest MMI threshold for which there is a warning time measurement shows the approximate peak ground-motion level for each site. False negatives (FN) - sites for which an alert should have been generated but was not-are also shown. Warning times in this figure do not include delivery times for the different delivery mechanisms and are therefore maximum values. However, they do include all data transmission and computational latencies in the real-time system during July 2019. Sites for which peak observed intensities are less than 2.5 are not shown. Modified from Chung and others (2020). 

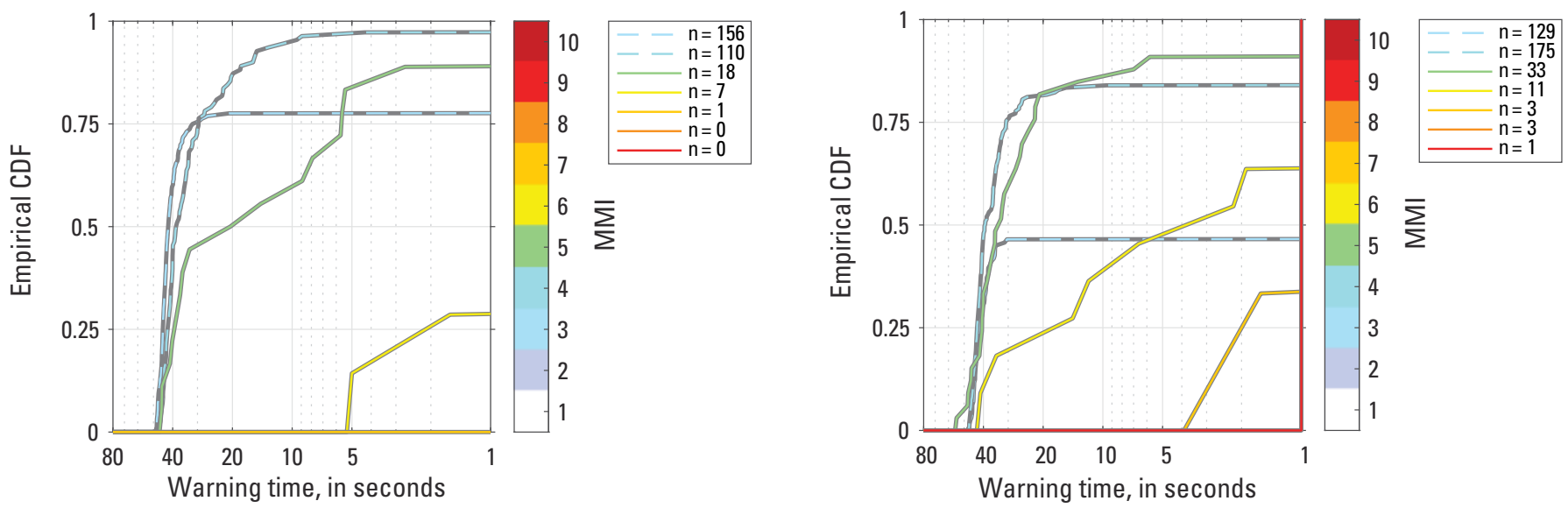

Figure 5. Plots showing the empirical cumulative distribution functions (CDF) of the warning times for the seismic stations that observed the 2019 magnitudes 6.4 (left) and 7.1 (right) Ridgecrest earthquakes (these are a subset of the warning times shown in fig. 4). Stations do not have a uniform spatial sampling. These plots use an alerting threshold ( $M M I_{\text {alert }}$ of 2.5 and observed ground-motion threshold $\left(M M I_{\text {tw }}\right)$ of 4.5; see Chung and others (2020) for other combinations of $M M I_{\text {alert }}$ and $M M I_{\text {tw. }}$. The number (n) of alerts for each instrumental Modified Mercalli Intensity (MMI) level is shown. Modified from Chung and others (2020).

times of 5-20 seconds, and 50 percent would have received warning times of 5 seconds or less (with many of these sites receiving no advance warning at all). Moreover, the regions that experienced the strongest shaking close to the fault (MMI 7-9) received no warning before they experienced shaking, but could have received as much as about 10 seconds of warning before peak shaking (Chung and others, 2020). Warning times of 20-40 seconds were possible in this event primarily for sites that experienced light to moderate shaking (MMI 3-5; blue curves in fig. $5 B$ ). Note that for the M6.4 Ridgecrest earthquake, the zone that experienced MMI 6 shaking was limited to within about $50 \mathrm{~km}$ of the epicenter (fig. $4 A$ ) and warning times longer than 5 seconds were not possible even with alerting at the MMI 3 contour product level (fig. $5 \mathrm{~A}$ ). Warning times are significantly longer for the $M 7.1$ earthquake than the $M 6.4$ earthquake for regions that experienced MMI 6 or greater shaking.

About 40-95 percent of the alerts at various locations in the Pacific Northwest are expected to be issued for shallow crustal earthquakes with various alerting thresholds (tables 2-4). Many of these alerts will be for M4.5-6.5 earthquakes where warning times from strong (MMI 6) or larger shaking are expected to be short (less than 10 seconds; for example, see fig. $5 A$ ). Less frequent $M 7$ or greater shallow crustal earthquakes are potential contributors to alerts in all regions of Cascadia, and in these earthquakes, actionable warning times for sites that experience strong shaking (or worse) are possible (Chung and others, 2020) (figs. $4 B$ and $5 B$ ). However, as illustrated in figure $5 B$, these warning times will be short, usually less than 10 seconds for MMI 6 or greater shaking, with warning times as long as several tens of seconds possible only for felt but non-damaging shaking (that is, MMI 3-4). End users should take immediate protective actions when receiving alerts from shallow crustal earthquakes regardless of their alerting thresholds, in anticipation that the earthquake could grow to become damaging (Porter and Jones, 2018).

\section{Warning Times for Deep Instraslab Earthquakes}

Tables 2-4 indicate that deep intraslab earthquakes will make up approximately $30-55$ percent of the alerts for the Seattle, Tacoma, and Portland metropolitan areas. These types of earthquakes, similar to the 2001 M6.8 Nisqually earthquake near Olympia, Wash., are also quite challenging for ShakeAlert. Because of their large depth, typically about $50 \mathrm{~km}$ beneath Seattle and the surrounding region, the $\mathrm{P}$-wave reaches the surface over a wide area nearly simultaneously, followed a few seconds later by the S-wave. Moreover, because of their depth, the strongest shaking typically arrives with the S-wave, rather than surface waves, meaning that the warning time is mostly dictated by the short separation between the P- and S-waves. In these cases, ShakeAlert actually may have less time to issue ShakeAlert Messages effectively than in a shallow crustal event of comparable magnitude. For instance, in the $M 7.1$ Ridgecrest mainshock, there was about 19 seconds between when the first P-wave was detected on the surface and when the strongest shaking was recorded by seismometers (Chung and others, 2020). In contrast, for the 2019 M7.1 Anchorage, Alaska, intraslab earthquake, the difference is about 16 seconds. In general, we expect warning times for strong shaking from deep intraslab earthquakes to be comparable to those for shallow crustal events.

The ShakeAlert testing effort has analyzed performance using data from two well-recorded, large, intraslab earthquakes: the 2001 M6.8 Nisqually and 2019 M7.1 Anchorage earthquakes. In these earthquakes, P-wave shaking was first detected on the surface about $7-9$ seconds after the rupture began. Table 5 gives the evolution of the magnitude estimates for the current version of the ShakeAlert system for the Nisqually and Anchorage 
earthquakes. In both earthquakes, by about 11-13 seconds after each event begins, the magnitude estimates reach about M6.0 and ShakeAlert Messages would be used to issue alerts to locations within a few hundred kilometers radius for delivery mechanisms that use $M M I_{\text {alert }}=2.5$ (table 1). However, for higher values of $M M I_{\text {alert }}$, the initial ShakeAlert Messages would cover a much smaller region. Figure 6 shows the distribution of shaking and the maximum possible warning times for different values of $M M I_{\text {alert }}$ in the Nisqually earthquake. Owing to the time it takes for the ShakeAlert magnitude estimate to reach near peak values, the amount of warning time depends strongly on the choice of $M M I_{\text {alert }}$. The warning times in figures $6 B$ and $6 C$ do not include data transmission times from seismic stations or alert dissemination times. Thus, the maximum possible warning time for EEW users in the MMI 6 and stronger shaking regions would be about 15 seconds for $M M I_{\text {alert }}$ of 2.5 and 3.5, and 50 percent of users would receive 10 seconds or less of warning (fig. $7 B, D$ ). For $M M I_{\text {alert }}$ of 4.5 this drops to a maximum warning time of about 7 seconds, and 50 percent of users would receive 5 seconds or less of warning (fig. $7 F$ ).
Table 5. Alert history for the 2001 magnitude 6.8 Nisqually and 2019 magnitude 7.1 Anchorage earthquakes from offline runs of the ShakeAlert production system in summer 2020.

[New alerts were issued in response to evolving estimates of earthquake magnitudes at the elapsed times indicated (relative to the time the rupture began). $M$, magnitude; s, second]

\begin{tabular}{ccc}
\hline Alert & Nisqually & Anchorage \\
\hline 1 & $11 \mathrm{~s}, M 6.1$ & $8.5 \mathrm{~s}, M 5.2$ \\
2 & $12 \mathrm{~s}, M 5.9$ & $11 \mathrm{~s}, M 5.1$ \\
3 & $13 \mathrm{~s}, M 6.4$ & $12 \mathrm{~s}, M 5.4$ \\
\hline 4 & $13 \mathrm{~s}, M 6.4$ & $12 \mathrm{~s}, M 5.8$ \\
\hline 5 & $17 \mathrm{~s}, M 6.7$ & $13 \mathrm{~s}, M 6.0$ \\
6 & $20 \mathrm{~s}, M 6.8$ & $14 \mathrm{~s}, M 6.1$ \\
7 & $27 \mathrm{~s}, M 6.9$ & $15 \mathrm{~s}, M 6.3$ \\
\hline 8 & & $17 \mathrm{~s}, M 6.4$ \\
9 & & $20 \mathrm{~s}, M 6.6$ \\
10 & & $23 \mathrm{~s}, M 6.7$ \\
11 & & $29 \mathrm{~s}, M 6.9$ \\
12 & & $52 \mathrm{~s}, M 7.1$ \\
\hline
\end{tabular}
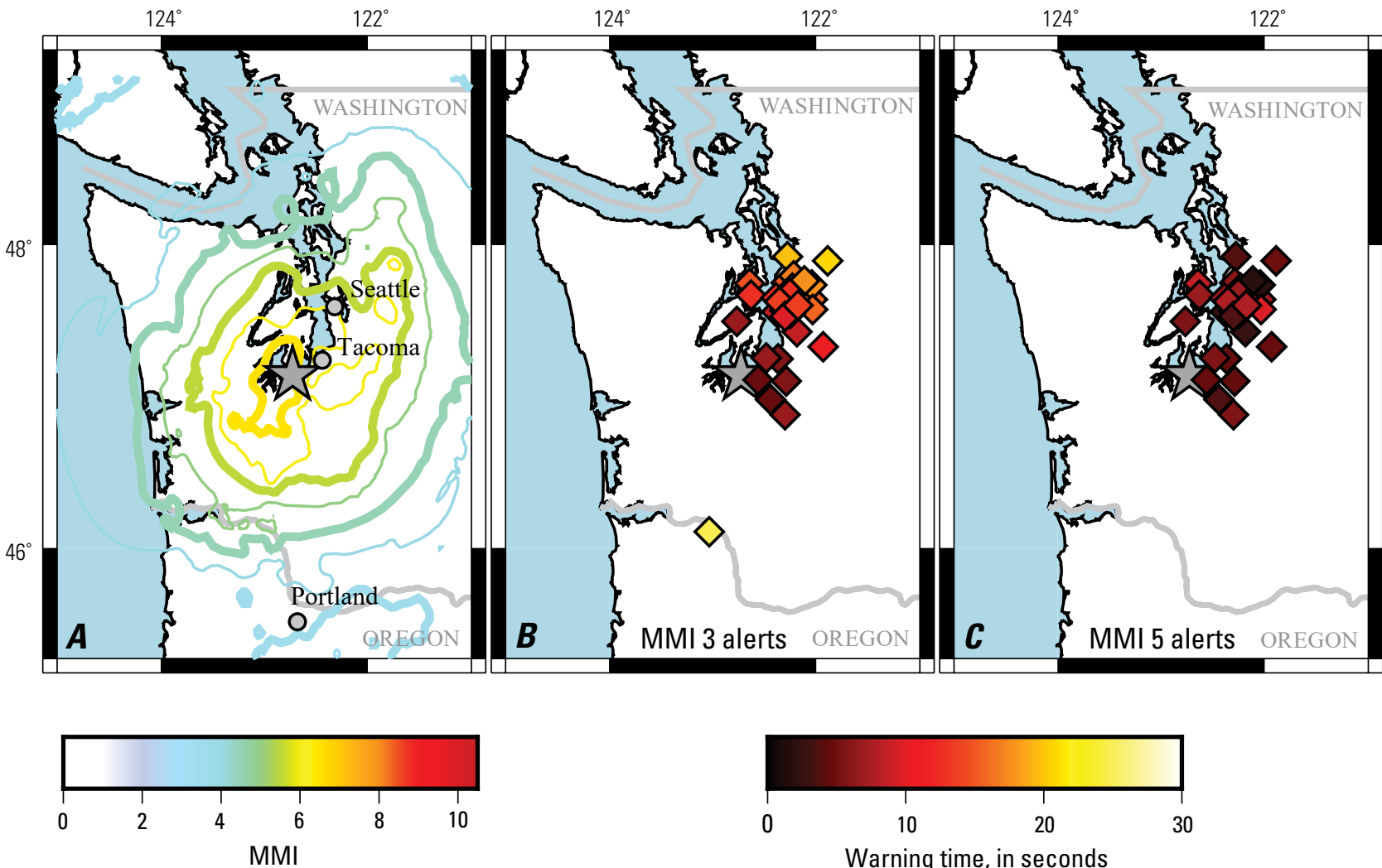

Figure 6. Maps of peak shaking and warning times from ShakeAlert for the 2001 Nisqually earthquake in Washington (assuming a ground-motion threshold [MMI ] of 4.5). A, U.S. Geological Survey ShakeMap showing contours of instrumental Modified Mercalli Intensity (MMI) values. $B$, Map showing warning times for an alert threshold (MMI $\left.I_{\text {alert }}\right)$ of 2.5. $C$, Map showing warning times for an $M M I_{\text {alert }}$ of 4.5 . Diamond symbols mark seismic stations operational at the time and the gray star shows the epicenter. 

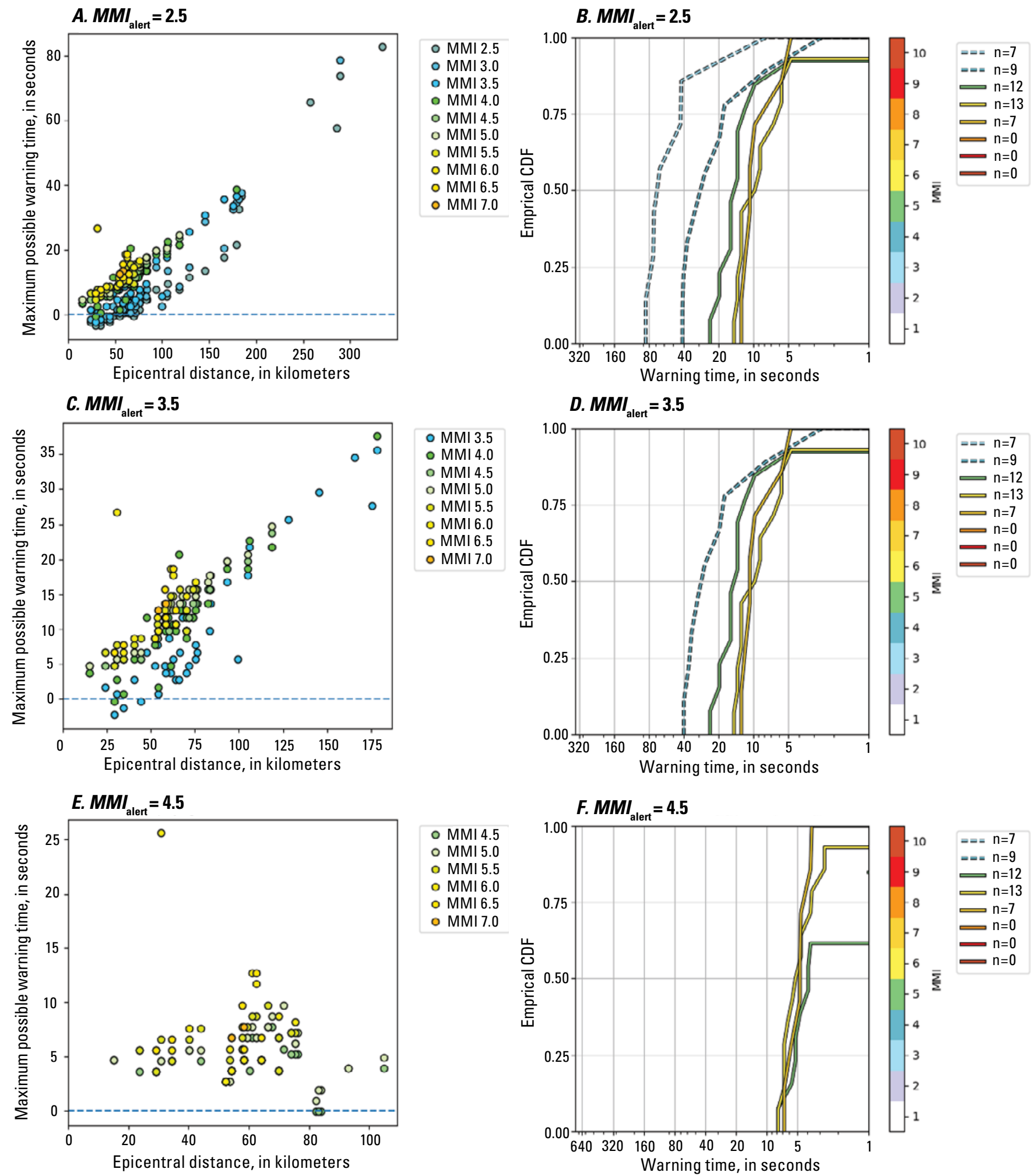

Figure 7. Plots showing warning times for the 2001 Nisqually earthquake in Washington. The left column shows warning time as a function of epicentral distance for three different alert thresholds $\left(M M I_{\text {alert }}\right)$. Only seismic stations that exceeded instrumental Modified Mercalli Intensity (MMI) 2.5 are shown. The right column shows the cumulative distribution functions (CDF) of warning times. Warning times are for an observed ground-motion threshold $\left(M M I_{t w}\right.$ ) of 4.5 in all plots. The number $(n)$ of alerts that have warning times $>1$ second for each MMI level is shown. The seismic network at the time of the Nisqually earthquake was concentrated in the Seattle-Tacoma urban area (fig. 6) and this figure is specific to that dataset. These warning times are maximum possible warning times because they do not include the data telemetry latency, which usually varies from 1 to 2 seconds, or the time to deliver the alert. Therefore, actual warning times will be shorter by at least a few seconds. 
Figure 1.2 of appendix 1 shows similar results for the 2018 M7.1 Anchorage intraslab earthquake. Again, the amount of warning time depends strongly on the value of $M M I_{\text {alert }}$ owing to the few seconds that it takes for the magnitude estimate to grow from M5.2 into the M6.0-6.4 range. Although warning times of as much as about 10 seconds are expected for $M M I_{\text {alert }}$ of 2.5, 3.5, and 4.5 at MMI 6 and above, the majority of EEW users in the locations that receive strong or worse shaking would have received less than 5 seconds of warning (fig. 1.2B, $D, F$ ). The amount of warning during $M 7$ intraslab earthquakes depends strongly on the value of $M M I_{\text {alert }}$ and the delivery mechanism (figs. 7 and 1.2). Moreover, latencies from both the data telemetry (1-2 seconds) and alert delivery (1-10+ seconds) will likely consume a significant fraction of the possible warning time for areas that experience strong (or greater) shaking in $M 7$ intraslab events (making warning times less than those shown in figs. 7 and 1.2). In summary, the majority of end users should expect very short warning times (less than 10 seconds) before moderate shaking begins if they are in a location that will experience strong or greater shaking during an intraslab earthquake.

\section{Warning Times for Offshore M7-9 Megathrust Earthquakes}

The Cascadia subduction zone is known from paleoseismology studies to produce M8-9 earthquakes every few hundred years (Goldfinger and others, 2012). Considerable effort has been put into understanding what these earthquakes will look like in terms of their shaking and tsunami hazards (Witter and others, 2013; Frankel and others, 2018; Wirth and others, 2018). Unfortunately, there are many things we do not know about the next great earthquake in Cascadia. On the basis of geodetic and paleoseismic studies, we anticipate that much of the fault slip will occur offshore, but some could propagate onshore, particularly under the Olympic Peninsula in Washington (Wang and Tréhu, 2016; Frankel and others, 2019). Although the Cascadia subduction zone is clearly capable of generating $M 8-9$ ruptures, it is not clear whether the next megathrust event could be smaller (for example, M7-8). Moreover, we have no information on where an earthquake rupture is likely to begin. To account for these unknowns, we discuss a series of studies, including evaluations of the ShakeAlert algorithms during past earthquakes in Japan, as well as synthetic earthquakes generated for the Cascadia subduction zone.

EEW can perform well for subduction zone events that occur primarily offshore, but it has difficulty providing long warning times for strong (or greater) shaking. Meier and others (2020) performed a comprehensive study of how the EEW algorithms used in ShakeAlert performed on replays of a large dataset of Japanese earthquakes, including many $M 7$ or greater subduction zone events. Figure 8 shows an example of similar results from the ShakeAlert testing program for the well-recorded M8.3 Tokachi-Oki earthquake offshore of Hokkaido, Japan. The simulation uses only onshore strong motion seismic data even though an offshore cabled observatory was operating during this earthquake that could have improved warning times (McGuire and others, 2008). The EPIC algorithm rapidly detects the earthquake after the P-waves reach the shore and within 22 seconds issues a M6.6 warning. The system continues to update the magnitude and rupture length estimates and eventually reaches $M 7.7$ (fig. 1.4 of appendix 1). This test was done with the current ShakeAlert ver. 2.1.4 production version of the FinDer algorithm (Böse and others, 2012, 2015, 2018), which uses ground motion templates that are appropriate for crustal strike slip faults to track the growing length of the best-fit line source to the PGA field. This set of templates leads to the underestimate of the final magnitude ( $M 7.7$ versus $M 8.3$ ). For locations along the coast and closest to the epicenter, the initial alerts are sufficient to trigger both MMI 3 and 5 alerts, but for regions farther away, only the MMI 3 alert is triggered initially (fig. 1.4 of appendix 1). These farther locations are not alerted at higher MMI values until the magnitude estimate has increased. Thus, there is a significant difference in the warning times between using MMI 3 and 5 alerts (fig. 8). In general, the regions that experienced MMI 7 or greater shaking, including inland regions, and were alerted for MMI $3\left(M M I_{\text {alert }}=2.5\right)$ could have received a maximum of about 30 seconds of warning after accounting for the delays from data telemetry and alert delivery. Interestingly, there are a number of locations where violent shaking (MMI 8-9) was experienced at far distances from the epicenter (more than $100 \mathrm{~km}$ ) because of local site conditions and rupture propagation effects. These locations could have had 10-30 seconds of warning before moderate shaking began using the MMI 3 alert level even after accounting for typical delivery latencies. Another key feature of figure 8 is that EEW users using the MMI 5 alert level $\left(M M I_{\text {alert }}=4.5\right)$ along the coast should expect very short warning times (less than 10 seconds) even at large distances from the epicenter of a $M 8$ event. Observations from the Tokachi-Oki earthquake seismograms indicate that automated industrial applications that can continue up to higher intensity shaking (for example, $M M I_{\mathrm{tw}}=7$ ) would have an additional 10-20 seconds of actionable warning time in many locations (fig. 1.3 of appendix 1).

Magnitude 9 earthquakes on the Cascadia megathrust will cause strong shaking over a wide region but the amount of warning time at a particular location depends strongly on where the earthquake begins. Frankel and others (2018) and Wirth and others (2018) simulated dozens of different $M 9$ earthquake scenarios with different hypocenter locations, down-dip rupture extents, slip distributions, and locations of high-stress-drop subevents that generate strong ground motions. This suite of simulations encapsulates many of the unknown aspects of the shaking expected in a megathrust Cascadia earthquake. Figure 9 shows a composite map of the median expected shaking from $30 M 9$ earthquake simulations (Wirth and others, 2020). In general, inland regions such as Portland, Tacoma, and Seattle can 

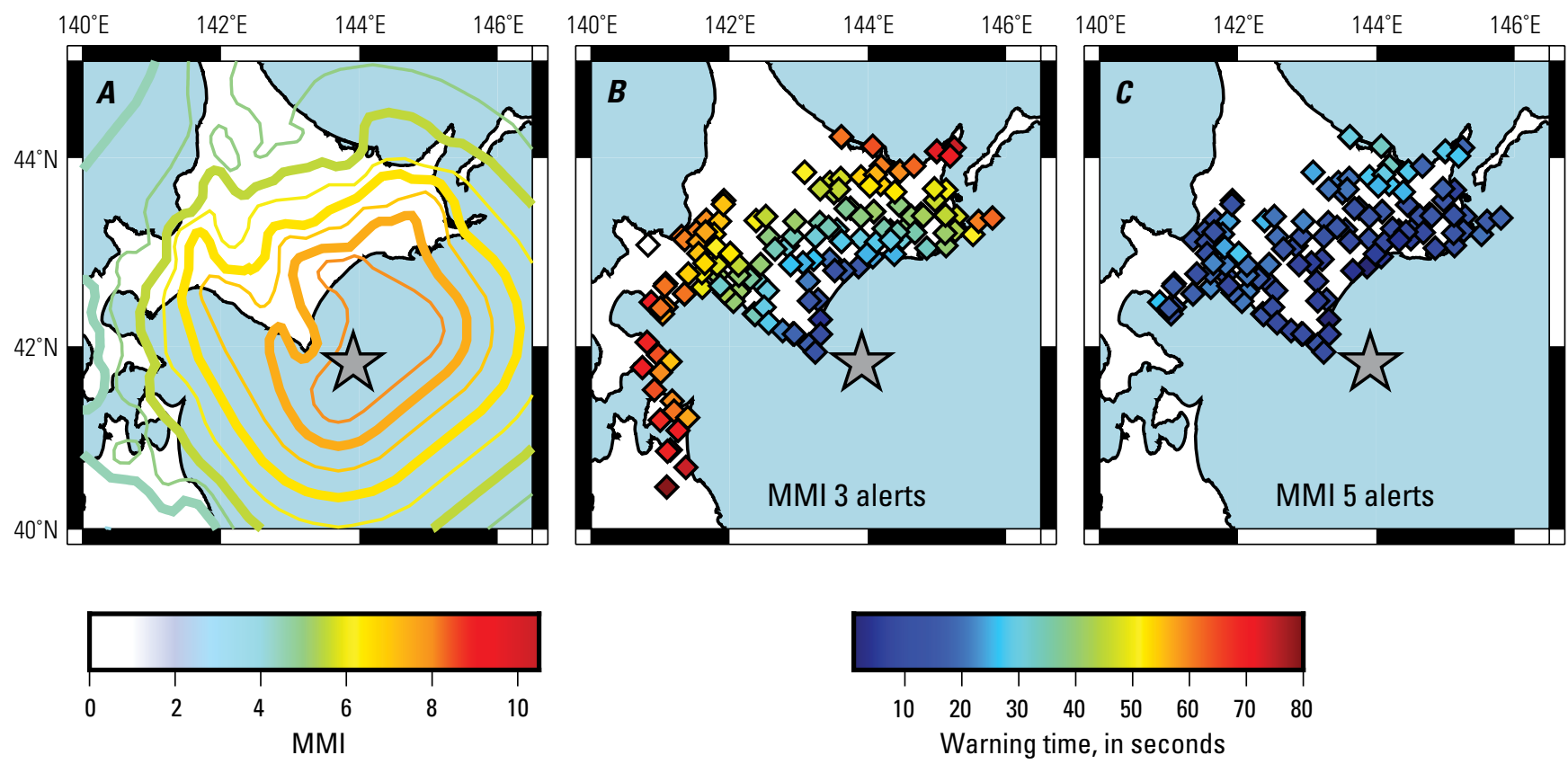

Figure 8. Maps of peak shaking and warning times from ShakeAlert for the 2003 Tokachi-Oki earthquake offshore Hokkaido, Japan. A, U.S. Geological Survey ShakeMap showing contours of Modified Mercalli Intensity (MMI) values. B, Map showing warning times for an alert threshold ( $M M I_{\text {alert }}$ ) of 2.5. C. Map showing warning times for an $M M I_{\text {alert }}$ of 4.5. Diamond symbols mark seismic stations; gray star shows the epicenter. Alerts were calculated by using version 2.1.2 of the ShakeAlert software, current as of summer 2020. The warning times do not include data telemetry or alert delivery latencies. Warning times are for an observed ground-motion threshold $\left(M M I_{\text {tw }}\right)$ of 4.5 in all plots.

experience MMI 7-9 shaking several tens of seconds to a few minutes after the earthquake begins. Figure 10 shows the time when a particular location experiences moderate (MMI 5) shaking for five of these $M 9$ Cascadia earthquake scenarios with different rupture characteristics (see Frankel and others, 2018, for details). Although these times range from 0 to 300 seconds, they are not warning times because they do not account for the growth of the alert polygons during the rupture. Next we consider what may be possible for ShakeAlert to produce in terms of warning times for M9 Cascadia earthquakes.

We selected five different $M 9$ Cascadia earthquake scenarios to test using ShakeAlert (fig. 10). We used synthetic seismograms that were produced using a hybrid approach, in which low frequency $(\leq 1$ hertz) seismograms are produced from three-dimensional numerical simulations and are combined with high frequency ( $\geq 1$ hertz) stochastic synthetic signals (Frankel and others, 2018) at sites with existing or planned ShakeAlert seismic stations. Three of these earthquake scenarios use a locking contour of 1 centimeter per year to define the down-dip rupture extent of the earthquake. This produces an earthquake rupture that ends approximately near the coastline (that is, the rupture is almost entirely offshore), and has been shown to provide a good match to paleoseismic estimates of coastal subsidence from the A.D. 1700 Cascadia earthquake (Wirth and Frankel, 2019). Of these, simulation csz004 has a hypocenter located offshore Oregon in central Cascadia, csz005 has a hypocenter located beneath northwest coastal Washington, and csz020 has a hypocenter located offshore northern California.
We also test a $M 9$ earthquake scenario with a rupture that extends farther inland (that is, to the top of the non-volcanic tremor zone) and a hypocenter located beneath central coastal Oregon (csz010), as well as a scenario with a shallow rupture extent that is entirely offshore and has a hypocenter located offshore coastal Washington (csz025). Scenario csz025 is also characterized by particularly strong rupture propagation (directivity) effects and ground-motion amplification in the Puget Lowland sedimentary basins, which will increase shaking intensity in the populous Seattle region.

\section{The Current ShakeAlert Production System}

Figure 11 shows an approximation of how the current ShakeAlert system (ver. 2.1.4) would perform in a $M 9$ earthquake using the csz025 simulation. This is not an exact run of the current production system because it has not yet been updated to work well with offshore megathrust earthquakes. In particular, to create figure 11, we expanded the FinDer algorithm alerting region to match the ShakeAlert decision module reporting boundary in order to include offshore events. We also adjusted the parameters for the solution aggregator algorithm, which combines the FinDer and EPIC algorithm results, so that FinDer could generate an alert by itself. The current system requires a FinDer alert to associate with an EPIC alert, within certain tolerances, for FinDer to contribute to the solution. The current production system tolerances between the FinDer and EPIC algorithms are a 


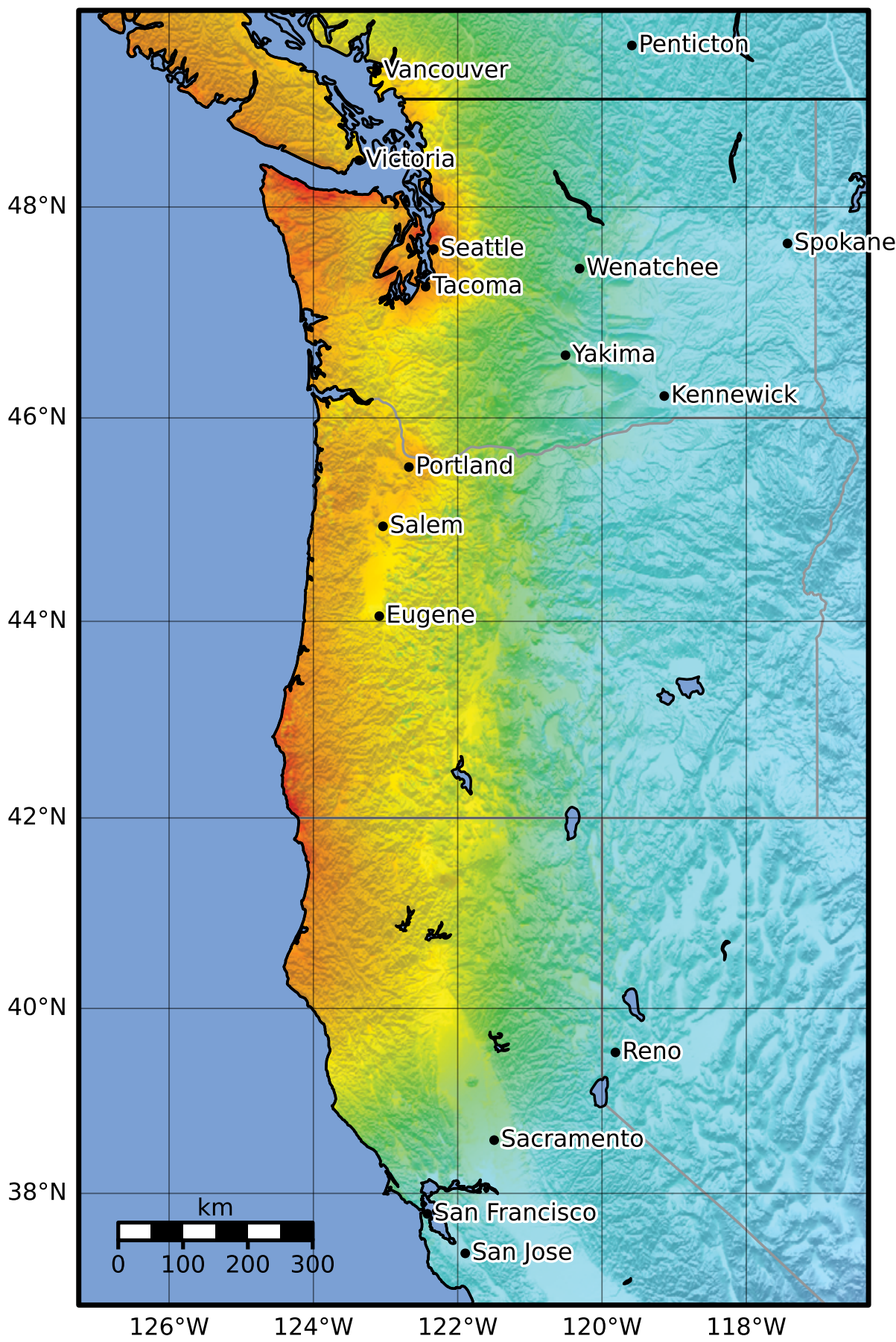

\begin{tabular}{|c|c|c|c|c|c|c|c|c|c|}
\hline SHAKING & Not felt & Weak & Light & Moderate & Strong & Very strong & Severe & Violent & Extreme \\
\hline DAMAGE & None & None & None & Very light & Light & Moderate & Moderate/heavy & Heavy & Very heavy \\
\hline PGA $(\% g)$ & $<0.0464$ & 0.297 & 2.76 & 6.2 & 11.5 & 21.5 & 40.1 & 74.7 & $>139$ \\
\hline PGV(cm/s) & $<0.0215$ & 0.135 & 1.41 & 4.65 & 9.64 & 20 & 41.4 & 85.8 & $>178$ \\
\hline INTENSITY & $\mathbf{I}$ & II-III & IV & $\mathbf{V}$ & $\mathbf{V I}$ & VII & VIII & IX & Xft \\
\hline
\end{tabular}

Scale based on Worden et al. (2012)

Figure 9. Ensemble ShakeMap for 30 magnitude 9 megathrust rupture scenarios on the Cascadia subduction zone. From Wirth and others (2020). km, kilometer; PGA, peak ground acceleration; \%, percent; $g$, gravitational acceleration; PGV, peak ground velocity; $\mathrm{cm} / \mathrm{s}$, centimeter per second. 


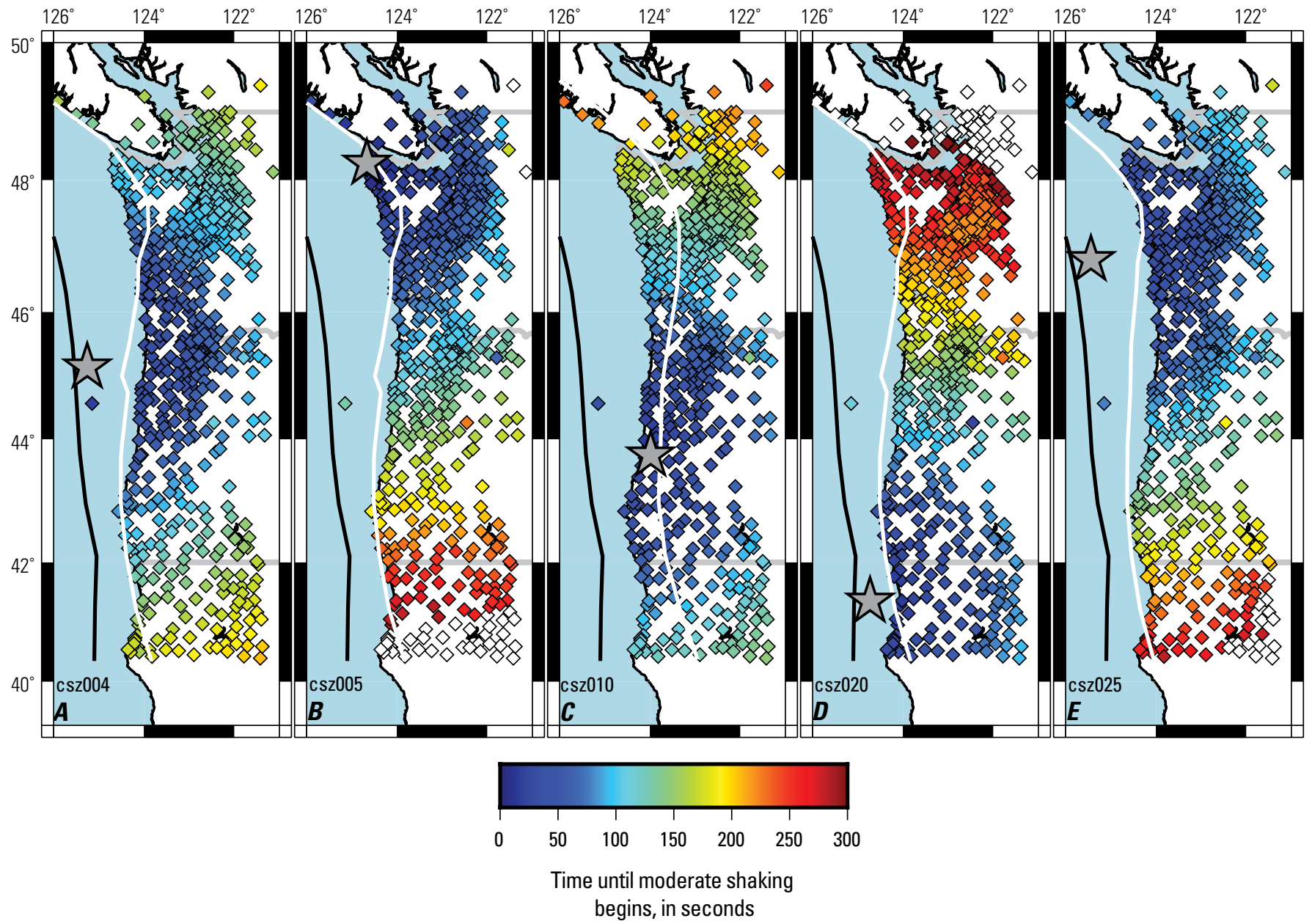

Figure 10. Maps of the western Cascadia region showing the time between the origin of the earthquake and when locations of ShakeAlert seismic stations (existing and planned) reached instrumental Modified Mercalli Intensity (MMI) level 4.5 in five magnitude 9 Cascadia earthquake scenarios from Frankel and others (2018) and Wirth and others (2018). The five scenarios shown are csz004 $(A), \operatorname{csz005}(B), \operatorname{csz010}(C), \operatorname{csz020}(D)$, and csz025 $(E)$. Gray stars mark the epicenter of the rupture; thick black and white lines mark the updip and downdip limits of slip, respectively. Diamonds denote the locations of current or planned ShakeAlert stations colored by the time after origin at which they exceed MMI 4.5. White diamonds denote locations that did not exceed MMI 4.5 before the end of the simulation. For ruptures that begin on one end of the subduction zone, it can take as long as 5 minutes for moderate shaking to begin on the opposite end. For any particular location, the amount of time between the beginning of the earthquake and when shaking reaches moderate levels is highly dependent on distance to the epicenter.

maximum difference of 30 seconds for the origin time and $100 \mathrm{~km}$ for the earthquake location. As the FinDer centroid moves away from the EPIC epicenter estimate, or if they have significant location errors, it is very possible that the current system will not associate the FinDer and EPIC alerts and this could prevent the ShakeAlert system from using FinDer at all for offshore earthquakes. In the simulation shown in figure 11, the magnitude estimates from EPIC and FinDer evolve for about 60 seconds after the earthquake begins until FinDer stabilizes at its maximum magnitude of M8.0. For this magnitude limit, alerts issued for the MMI 3 contour product reach all of Cascadia and the warning times are as high as 200 seconds at the very southern end of the region. However, even for alerting at this very low threshold, the
Seattle and Portland areas receive less than 50 seconds of warning. For the MMI 4 alerts, the alerted region is smaller and warning times are shorter. For MMI 5, the alerted region is only about half of Cascadia, warning times are short, and there is a substantial region along the coast where moderate shaking is exceeded before an alert is issued. It is unclear if this large late-alert zone is realistic or not because synthetic seismograms are not ideal for triggering the EPIC algorithm. For instance, no such late-alert zone is seen in figure 8, which uses real data from an offshore $M 8$ earthquake in Japan. As of the writing of this report, the ShakeAlert system is not yet able to accurately characterize a $M 9$ rupture in terms of length or magnitude, but research is ongoing on this topic and we expect several updates in 2021 to improve performance. 
Figure 11. Maps of the western Cascadia region showing warning times for the simulated csz025 earthquake scenario. Simulations are shown for different alerting thresholds ( $M M I_{\text {alert }}$, which correspond to the different alerting mechanisms: $A, M M I_{\text {alert }}=2.5$; $B, M M I_{\text {alert }}=3.5$; and $C, M M I_{\text {alert }}=4.5$, and the observed ground motion threshold ( $M M I_{\text {tw }}$ ) is set to 4.5. Gray stars mark the epicenter of the rupture; thick black and white lines mark the updip and downdip limits of slip, respectively. Diamonds denote the locations of current or planned ShakeAlert seismic stations colored by the warning time. Warning times were calculated by using the ShakeAlert production system as of October 2020, except that the FinDer algorithm was allowed to alert alone and the FinDer region was expanded to match the decision module reporting boundary. Alerts from both the EPIC and FinDer algorithms were combined to determine the warning times (see text). Light gray diamonds show locations that were outside of the alert polygons and as a result received no warning because the earthquake magnitude and rupture length were underestimated. Dark gray diamonds show locations that had already exceeded the shaking threshold before they were within the alerting area-late alerts. Contour lines are shown for every 25 seconds of warning time, starting from the gray line ( 25 seconds); subsequent contours are black. MMI refers to instrumental Modified Mercalli Intensity levels.

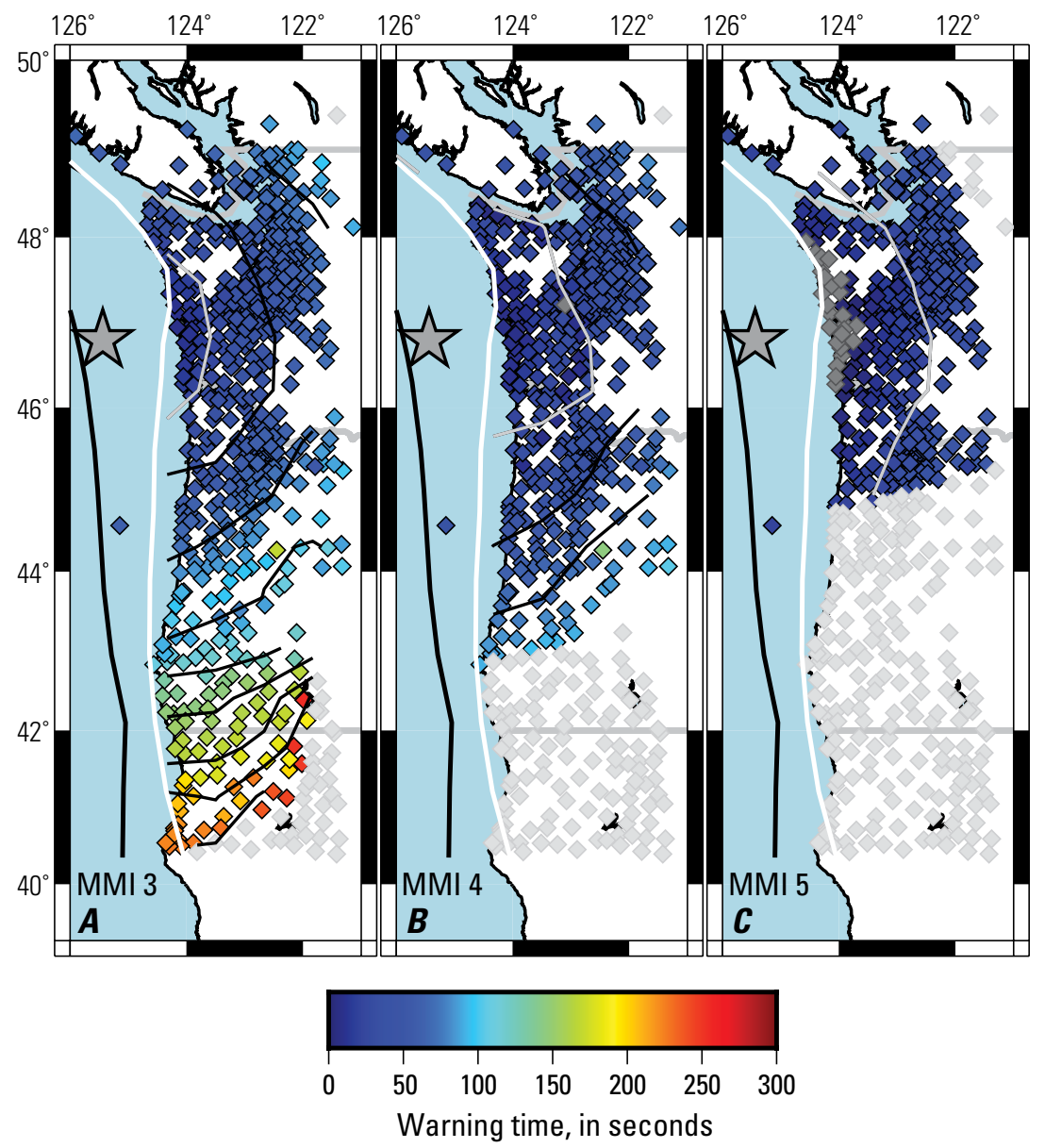

\section{The Future ShakeAlert Production System}

Figures 12-14 show simulations for an approximation of how ShakeAlert will perform once FinDer is updated to characterize earthquakes of M8-9. First, an expanded template set for the FinDer algorithm was employed that allows rupture lengths to reach a maximum length of $1,362 \mathrm{~km}$. This is equivalent to a maximum $M 9.0$ for the FinDer crustal magnitude-length scaling relation and a maximum $M 9.59$ for the FinDer subduction zone magnitude-length scaling relation. For these simulations, the subduction zone magnitude-length scaling relation was applied, whereas the crustal scaling relation was applied in figure 11 . Second, in figures 12-14, the maximum sample and hold time was also increased from 120 to 600 seconds to account for the longer rupture. Last, the tolerances in the solution aggregator module configuration were doubled to increase the probability of EPIC and FinDer alerts associating. Given these configuration changes, the maximum reported magnitude for the simulations is typically a little less than $M 9$; a $M 9$ event with subduction zone scaling would have an approximately 588-km-long rupture.

Figure 1.5 of appendix 1 shows the magnitude evolution in the five runs. The initial magnitudes are lower here than in the Tokachi-Oki, Nisqually, and Anchorage earthquakes and that discrepancy may result from the stochastic nature of the synthetic seismograms. As a result, in a real Cascadia megathrust earthquake, regions near the epicenter may be alerted to higher MMI levels earlier in the rupture than what is shown in figures 12-14. However, on the spatial scale of the subduction zone, the evolution of the earthquake rupture above about M6.5 determines much of the warning time behavior and these simulations appear to be excellent tests of the FinDer algorithm for tracking that evolution. Even with this expanded template set, the FinDer algorithm does not quite reach a large enough magnitude to alert all of Cascadia using the MMI 5 contour product before the end of the simulations (figs. 14 and 1.6 of appendix 1). Figures 12-14 show that the warning time at a particular location depends strongly on the locations of the earthquake's epicenter and the alerting criteria of the delivery mechanism. For locations throughout Cascadia, scenarios are possible where warning times are less than a minute, even for $M 9$ earthquakes. There are end-member cases where alerting for low shaking levels (MMI 3; fig. 12) produces about 3-4 minutes of warning at the far end of the rupture, but for these alerting levels, M8-9 megathrust earthquakes will contribute only about 1-4 percent of the ShakeAlert-powered alerts received at these locations (table 4). When alerting for moderate shaking levels (MMI 5; fig. 14), there can be significant late-alert zones near the epicenter and maximum warning times at the far end of the 

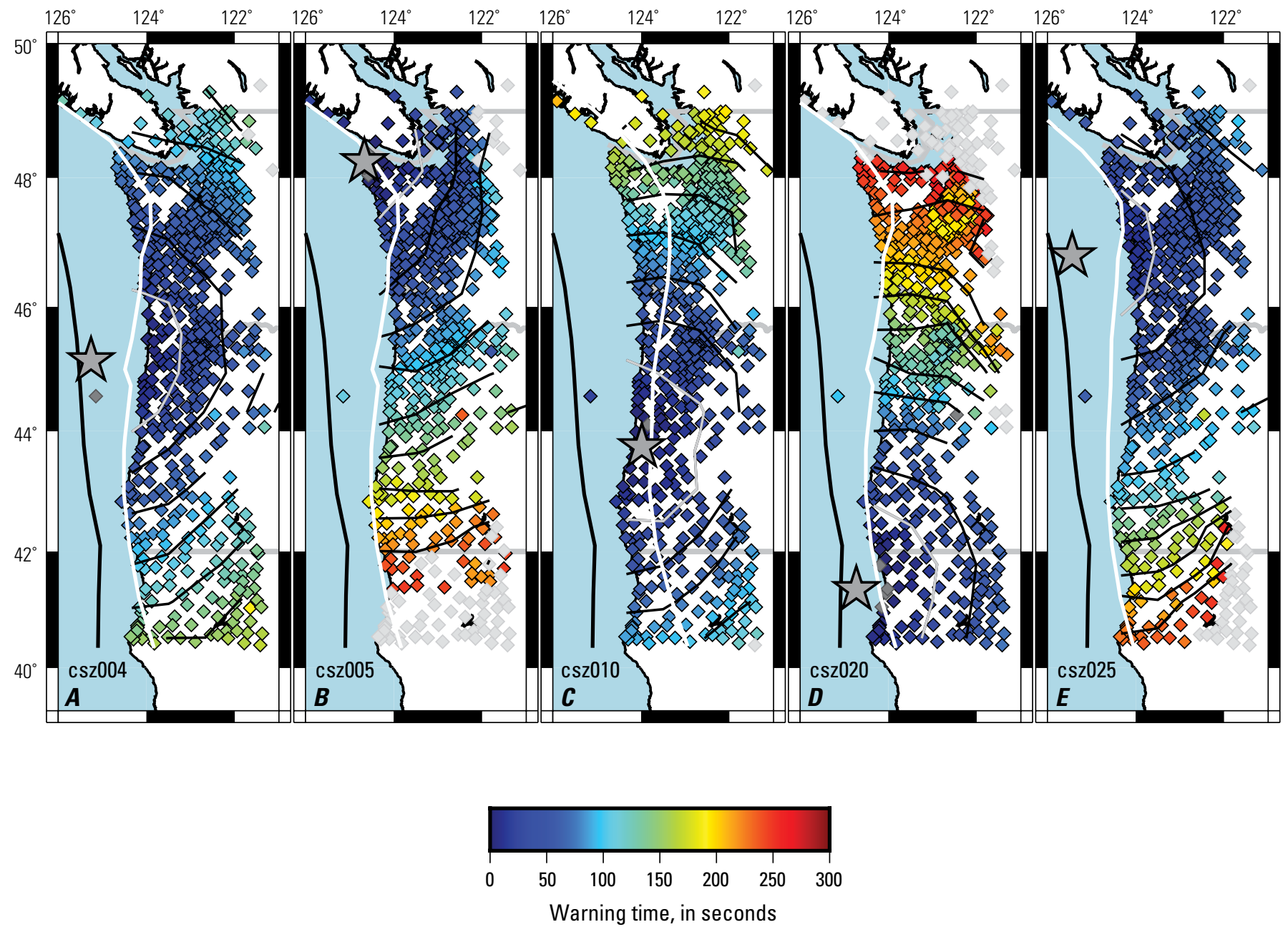

Figure 12. Maps of the western Cascadia region showing warning times for five magnitude 9 earthquake scenarios (see fig. 10) for one possible future version of the ShakeAlert system that uses a larger template set for the FinDer algorithm. The five scenarios shown are csz004 $(A), \operatorname{csz005}(B), \operatorname{csz010}(C), \operatorname{csz} 020(D)$, and csz025 $(E)$. Maximum possible warning times are shown for an alert threshold ( $M M I_{\text {alert }}$ ) of 2.5 and an observed ground-motion threshold $\left(M M I_{\text {tw }}\right)$ of 4.5, which corresponds to most cell phone app alerts and Android's be-aware alerts (table 1). Gray stars mark the epicenter of the rupture; thick black and white lines mark the updip and downdip limits of slip, respectively. Diamonds denote the locations of current or planned ShakeAlert seismic stations colored by the warning time. Light gray diamonds show locations that were outside of the alert polygons and as a result received no warning. Dark gray diamonds show locations that had already exceeded the shaking threshold before they were within the alerting area-late alerts. Contour lines are shown for every 25 seconds of warning time, starting from the gray line ( 25 seconds); subsequent contours are black. These warning times do not include data telemetry or alert delivery latencies. 

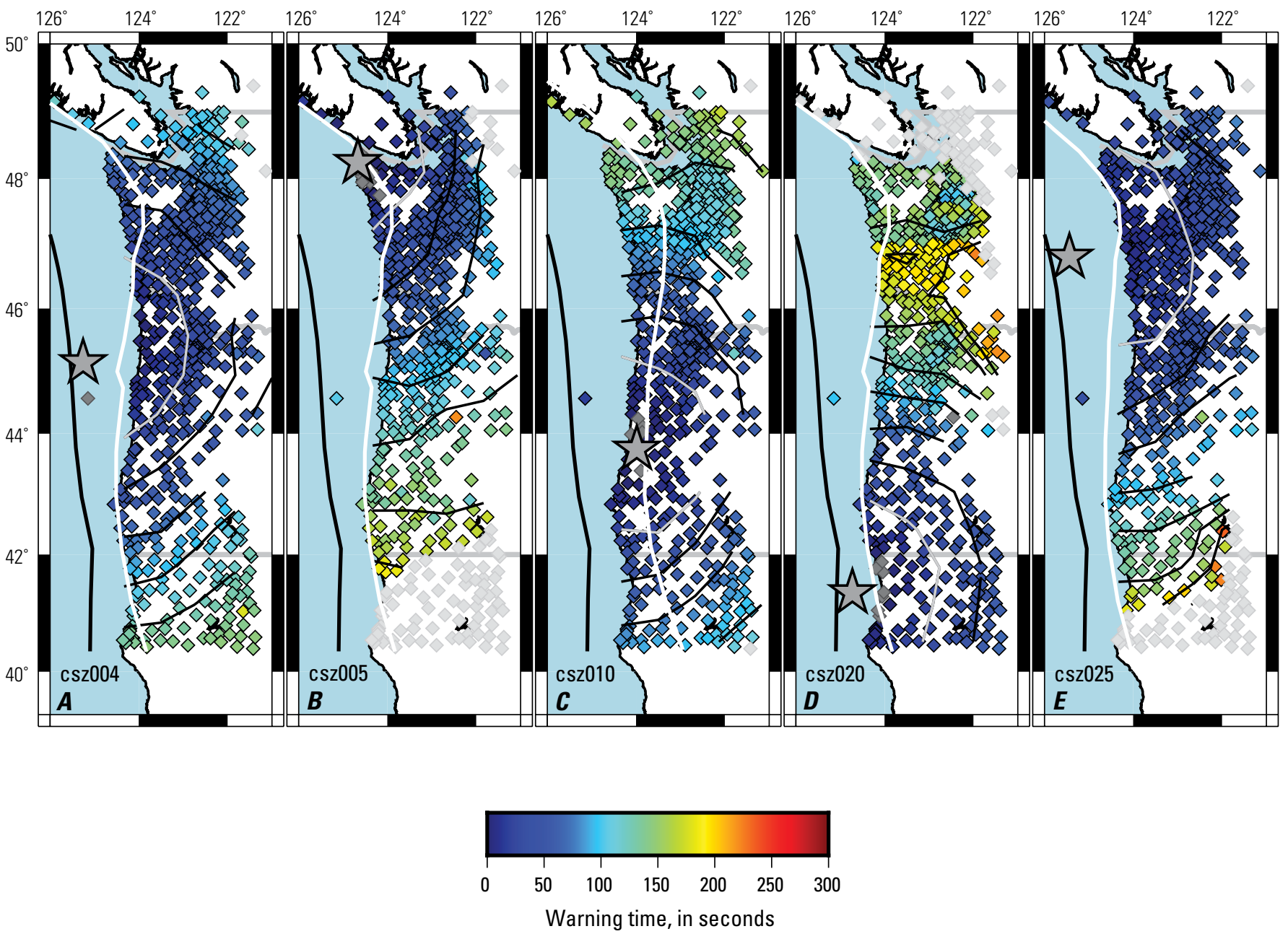

Figure 13. Maps of the western Cascadia region showing warning times for five magnitude 9 earthquake scenarios (see fig. 10) for one possible future version of the ShakeAlert system that uses a larger template set for the FinDer algorithm. The five scenarios shown are csz004 $(A), \operatorname{csz005}(B), \operatorname{csz} 010(C), \operatorname{csz} 020(D)$, and csz025 (E). Maximum possible warning times are shown for an alert threshold ( $M M I_{\text {alert }}$ ) of 3.5 and an observed ground-motion threshold $\left(M M I_{\text {tw }}\right.$ ) of 4.5, which corresponds to Wireless Emergency Alerts (WEA) and some cell phone app alerts (with user-adjustable alerting thresholds; table 1). Gray stars mark the epicenter of the rupture; thick black and white lines mark the updip and downdip limits of slip, respectively. Diamonds denote the locations of current or planned ShakeAlert seismic stations colored by the warning time. Light gray diamonds show locations that were outside of the alert polygons and as a result received no warning. Dark gray diamonds show locations that had already exceeded the shaking threshold before they were within the alerting area-late alerts. Contour lines are shown for every 25 seconds of warning time, starting from the gray line ( 25 seconds); subsequent contours are black. These warning times do not include data telemetry or alert delivery latencies. 

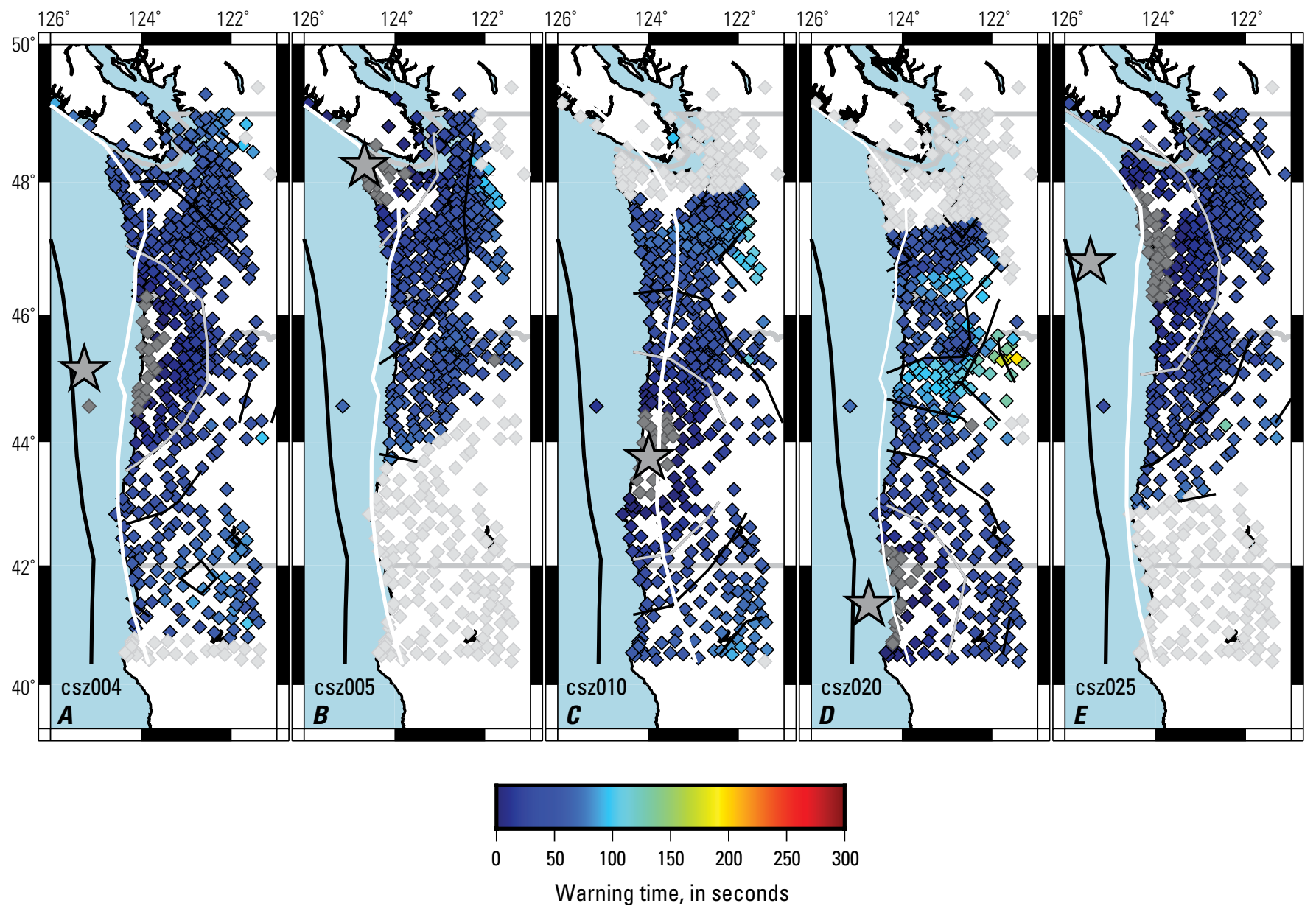

Figure 14. Maps of the western Cascadia region showing warning times for five magnitude 9 earthquake scenarios (see fig. 10) for one possible future version of the ShakeAlert system that uses a larger template set for the FinDer algorithm. The five scenarios shown are csz004 $(A), \operatorname{csz005}(B), \operatorname{csz} 010(C), \operatorname{csz020}(D)$, and csz025 $(E)$. Maximum possible warning times are shown for an alert threshold $\left(M M I_{\text {alert }}\right)$ of 4.5 and an observed ground-motion threshold ( $M M I_{\text {tww }}$ ) of 4.5, which corresponds to Android's take-action alerts and some cell phone app alerts (with user-adjustable alerting thresholds; table 1). Gray stars mark the epicenter of the rupture; thick black and white lines mark the updip and downdip limits of slip, respectively. Diamonds denote the locations of current or planned ShakeAlert seismic stations colored by the warning time. Light gray diamonds show locations that were outside of the alert polygons and as a result received no warning. Dark gray diamonds show locations that had already exceeded the shaking threshold before they were within the alerting area-late alerts. Contour lines are shown for every 25 seconds of warning time, starting from the gray line ( 25 seconds); subsequent contours are black. These times do not include data telemetry or alert delivery latencies.

rupture are much shorter-about 50-80 seconds. Regardless of the delivery mechanism they choose, ShakeAlert users in Cascadia should not expect multiple minutes of warning time even in the largest possible earthquakes.

There is a considerable difference in warning time behavior for large offshore megathrust earthquakes between the MMI 3 and MMI 5 alerting criteria. In the offline run of the Tokachi-Oki earthquake (figs. 8 and 1.4 of appendix 1), the offline runs of the synthetic Cascadia earthquakes using the current production system (fig. 11), and the offline runs of the synthetic Cascadia earthquakes using the potential future ShakeAlert system (fig. 12), the MMI 3 alerts (defined by $M M I_{\text {alert }}=2.5$ ) rapidly extend to very large distances when the magnitude estimate first reaches approximately the M6-7 range. This rapid expansion to alerting regions that span many hundreds of kilometers results in long warning times in the more distant alerted locations, commonly exceeding a minute or more (figs. 11 and 12). In contrast, the MMI 5 alerting polygons by definition do not include the area that receives strong shaking until the magnitude and length estimates approach the true values. Figure 1.7 of appendix 1 shows a composite view of the MMI 5 alerting polygon expansion for all five $M 9$ scenarios. Once the magnitude estimates start to exceed approximately $M 7.0$, the effective moveout velocity of the MMI 5 polygons is approximately 4-7 kilometers per second. This expansion velocity allows the MMI 5 alerting polygon to envelop the region that has already experienced MMI 5 shaking and start to provide useful warning times (figs. 8, 11, 14, and 1.4 and 1.8 of appendix 1) at greater distances. Communication, education, 
and outreach efforts in the Cascadia region will need to emphasize the effective difference between alerting thresholds (fig. 10 versus figs. 13 and 14). Although a $M 9$ earthquake will take 5 minutes or more to rupture the entire subduction zone, that does not mean that most EEW users will receive several minutes of warning. In fact, given that Android and WEA alerts are expected to be received by a larger portion of the population than cell phone app alerts, at least initially, the majority of users would receive significantly shorter warning times even during a $M 9$ earthquake (figs. 13 and 14), particularly after accounting for alert delivery latencies. EEW users who are concerned about damage from offshore megathrust earthquakes will need to evaluate the tradeoffs between alerting criteria, distance from the coast, and necessary warning times to take protective actions carefully, and additionally realize that the majority of ShakeAlert-powered alerts they receive will not be from large megathrust earthquakes (tables 2-4).

The results presented in figures 9-14 highlight the need for the ShakeAlert system to continue operating and producing alert updates for many minutes during a $M 9$ earthquake to ensure that all of Cascadia receives the appropriate warnings. ShakeAlert was designed with considerable redundancy to help ensure it would function well during large earthquakes (Given and others, 2018). However, peak performance in large earthquakes is far from guaranteed. As learned from the 2019 Ridgecrest earthquake sequence, large earthquakes can present challenges for data telemetry systems that can prevent ShakeAlert algorithms from tracking a large rupture (Chung and others, 2020; Stubailo and others, 2020). Some alert delivery mechanisms may also be affected during a megathrust earthquake. Considerable effort will be required over the coming years to ensure that ShakeAlert is able to achieve its peak performance during large earthquakes. Otherwise, alerts may arrive more slowly, or not at all, compared to the results presented in this study.

Peak performance in large offshore earthquakes will require continued research efforts focused on this problem. Our results for the $M 9$ earthquake simulations do not reflect the current state and configuration of the ShakeAlert system as of late 2020, but we expect that the system will soon be improved to handle events of this magnitude. The simulations of the TokachiOki earthquake represent something close to a current best case scenario for performance in a large offshore earthquake, where the initial magnitude estimates increase rapidly and the data continues to flow throughout the minute-long rupture, allowing FinDer to approach its current maximum magnitude of 8.0. The ShakeAlert team of researchers at the USGS and its university partners are continually working to advance the suite of ShakeAlert algorithms to produce faster and more accurate ground-motion forecasts. In particular, many efforts are currently underway to improve the algorithms that track the growth of large ruptures. It is very likely that ShakeAlert performance in large earthquakes will improve over the results shown in figures 11-14. For example, the maximum size templates used by FinDer may soon be increased to allow for $M 9$ earthquake ruptures. There is also the potential to add algorithms that use geodetic data (for example, Global Positioning System [GPS] data) (Crowell and others, 2012; Minson and others, 2014;
Murray and others, 2018) or offshore data streams (McGuire and others, 2008), both of which may help improve warning times in large ruptures. In great offshore megathrust earthquakes, real-time geodetic data should be able to better constrain the full size of the earthquake (for example, the seismic moment) (Crowell and others 2012; Minson and others, 2014), which could potentially be difficult to estimate from the accelerations measured solely by onshore seismic stations.

\section{Implications for EEW Users in the Pacific Northwest}

A few studies looking at theoretical possibilities for warning times in Cascadia have advertised very long times for offshore megathrust ruptures (Hartog and others, 2016; Ruhl and others, $2017,2019)$. These values were specific to very large ruptures (M8-9) that are expected to produce damaging shaking across a wide region, including inland cities such as Seattle, Tacoma, and Portland. They concluded that several minutes of warning are possible in Cascadia (Hartog and others, 2016) or that warning times of more than 100 seconds would be common at sites in Cascadia with moderate to severe shaking (Ruhl and others, 2019). These studies have set a high expectation for the effectiveness of EEW in Cascadia. However, Ruhl and others (2019) published a correction that substantially reduced the estimate of potential warning times for sites with strong to severe shaking in Cascadia. Moreover, their claims are in stark contrast to both theoretical (Minson and others, 2018) and retrospective studies of past earthquakes in Japan (Meier and others, 2020), which find that it is very difficult to provide long warning times for high intensity shaking. Meier and others (2020) showed that alerting at low predicted intensity levels in $M 8-9$ subduction zone earthquakes does allow many sites that eventually experience MMI 8-10 shaking to potentially achieve $10-40$ seconds of warning, which would be an excellent outcome for any EEW system. The key to understanding what any individual user's experience with EEW will be like in Cascadia is to understand the range of warning times that are achievable for different earthquake scenarios. Although warning times longer than a minute are possible in certain end-member cases (for example, fig. 12) these cannot be counted on as the most likely outcome in any particular location even for an $M 9$ offshore megathrust rupture.

To help users understand their likely experiences with ShakeAlert in Cascadia, we summarize a number of key results from this study.

- Residents in most locations throughout Cascadia, including Seattle, Portland, Tacoma, Newport, and Eureka, should expect that the majority of alerts they receive will be from nearby shallow crustal and intraslab earthquakes. The vast majority of these alerts will be for earthquakes smaller than M7. In these scenarios, ShakeAlert users that will experience strong (or worse) shaking should expect warning times less than 10 seconds before it becomes difficult to take protective actions. 
- There will be a region near the epicenter where shaking arrives before the alert, termed the late-alert zone (McBride and others, 2020). ShakeAlert end users should take protective actions as soon as they feel shaking whether they have received an alert yet or not.

- The late-alert zone can range from a few tens of kilometers around the epicenter for crustal earthquakes (Chung and others, 2020) to a potentially much larger region along the coast for offshore earthquakes (fig. 14). The exact dimensions of the late-alert zone depend on the details of the particular earthquake, station density near the epicenter, and alert delivery mechanism.

- Although intraslab earthquakes typically occur much deeper than crustal events, this does not imply longer warning times. Because of the greater depth, strong shaking from the S-wave reaches a broad region almost simultaneously. ShakeAlert end users should expect less than 10 seconds of warning from intraslab events in areas of strong shaking (figs. 6, 7, and 1.2 of appendix 1).

- Longer warning times are possible at more distant locations (>100 km) during M6-7 crustal and intraslab earthquakes, but those regions will generally experience only moderate to weak shaking (figs. 4, 5, and 1.2 of appendix 1).

- For $M 8$ offshore megathrust (plate-interface) earthquakes, the alerts received by end users who experience severe shaking will typically be less than 40 seconds but can be much shorter along the coast. These maximum times for the MMI 3 contour product (table 2), which corresponds to the threshold for generally felt shaking, are the best case even for inland areas (figs. 6 and 1.3 of appendix 1). The warning times will be shorter along the coast and for delivery mechanisms that use the MMI 4 or 5 contour products (figs. 6 and 1.3 of appendix 1).

- For $M 9$ earthquakes, the amount of time between when the earthquake starts and when a particular location experiences moderate shaking is highly variable and depends strongly on the epicenter location. Although users located more than $500 \mathrm{~km}$ from the epicenter will not experience moderate shaking until 4-5 minutes after the earthquake begins, this does not mean they will always receive that much warning time.

- For $M 9$ earthquakes, the warning time a particular location will receive depends strongly on the alert threshold and ShakeAlert system performance during the earthquake (figs. 11-14). For end users willing to be alerted at low levels of shaking (for example, the MMI 3 contour product; table 1 ) it is possible to have warning times of $2-3$ minutes at locations $500 \mathrm{~km}$ from the epicenter (figs. 12-14). However, at this level of shaking, offshore megathrust earthquakes are expected to account for less than 1-2 percent of alerts received at most locations (table 2).
- ShakeAlert users that only receive alerts for MMI 5 (that is, the threshold for very light damage; see fig. 9) will experience much shorter warning times in $M 8$ and 9 earthquakes than those who receive alerts at MMI 3 (figs. 12-14) - typically less than 30 seconds even in great $M 9$ earthquakes.

- Given the short expected warning times for crustal and instraslab earthquakes, warning messages should be brief. Warning strategies require short messages that earthquake shaking is imminent and suggest protective actions people should take to reduce injury. Easily understood, actionable alert messages that do not require more than a few seconds to read and comprehend should be further developed to help reduce injuries.

- Automated actions by technical users may continue to be effective at higher levels of shaking than the $M M I_{\mathrm{tw}}=4.5$ level used in most of the results presented here. As a result, these automated actions would receive somewhat longer useable warning times, particularly in large Cascadia megathrust earthquakes (figs. 1.3 and 1.7 of appendix 1).

- Technical end users who require 10 or more seconds to complete automated (machine-to-machine) processes that can be taken without undue consequence if shaking does not grow to become damaging should consider taking actions at an alerting threshold of MMI 3 to allow for maximum warning times.

ShakeAlert may not achieve peak performance in large earthquakes (Chung and others, 2020; Stubailo and others, 2020); therefore, warning times may be significantly shorter than the values reported here. ShakeAlert has the potential to provide actionable warning times for regions that experience strong to violent shaking in large earthquakes of all types throughout Cascadia because it alerts for weak to moderate shaking (table 1). However, ShakeAlert users should expect warning times to be short in cases where the shaking will be strongest and should take appropriate protective actions quickly.

The choice of which shaking level to alert for has a great effect on potential warning times in large earthquakes, as shown in figures $6,8,12,13$, and 14, and also a large effect on how often one will be alerted (tables 2-4). Alerting level preferences may vary for different types of users. For example, in automated (machine-to-machine) applications, the cost of taking a particular automated protective action can vary widely and may require different shaking levels for different applications. For public alerting in the United States, we do not yet have sufficient information to understand what level of alerting will be optimal to achieve the desired result of users taking protective actions when they receive an alert. Research conducted in New Zealand (Becker and others, 2020) found that respondents preferred to be alerted for MMI 6 or above, which is similar to findings in Japan (Nakayachi and others, 2019). It is important to note that people in both New Zealand and Japan have experienced large, damaging earthquakes in the last decade whereas there has been less seismic activity in the United States. The Becker and others (2020) and 
Nakayachi and others (2019) studies are being replicated in the Pacific Northwest, with results forthcoming. McBride and others (2020) note that alerting thresholds were lowered in response to widespread shaking felt during the 2019 Ridgecrest earthquakes after no alert was sent by a City of Los Angeles ShakeAlertpowered cell phone app.

Other hazards may assist in developing an alerting strategy. The flash-flood warning system managed by the U.S. National Weather Service also broadcasts WEA alerts via FEMA's IPAWS system. After a few years of experience and social science research, the National Weather Service changed its strategy to issue fewer and more targeted flash-flood messages that had clearer text in the hope of improving public response to the warnings (Cappucci, 2020; Roman, 2020). Those alerts now focus on users for whom the threat is deemed to be considerable or catastrophic (Cappucci, 2020).

The ShakeAlert system is currently in a testing phase that includes social science research on effective alerting, and the system may evolve over time as more is understood about how to make EEW alerts more effective (for example, Cochran and others, 2018; Cochran and Husker, 2019).

\section{Effects on Protective Actions and the ShakeAlert Warning Message}

The findings of this study have implications for the ongoing development, testing, and implementation of ShakeAlert messaging utilized by alert distribution partners. ShakeAlert distinguishes itself from the other Advanced National Seismic System information products and tools because of the level of activity required during very short times. Public safety can only be optimized if alerts that are powered by data from the ShakeAlert system are supported by effective social science research, education, training, and messaging (Cochran and others, 2018); to be most effective, these activities must be tailored to specific alert distribution pathways (for example, WEA, cell phone apps and operating systems, public address systems, and data casting over radio and television frequencies).

Two major theories from social science have aided in the development of alert messages for ShakeAlert: the (1) protective action decision model and (2) emergent norm theory. The protective action decision model explores what factors are required for integration and processing of information for people to take action to protect themselves when faced with a risk or a warning. Emergent norm theory, first introduced by Turner and Killian (1957) but fully explored in terms of warnings by Wood and others (2018), focuses more on milling processes (that is, when people stand or walk around as they consider what to do next), and suggests that people require secondary confirmation of an alert in order to take action. The alert itself may not be sufficient to take action, which is another reason to constrain message lengths so people have time to confirm that the alert is correct and take action.

Given the importance of milling and the lag time it may take for people to take protective actions, as explained by these two theories, one consideration in designing an optimal EEW message is length. Although FEMA's IPAWS allows for WEA messages of as many as 360 characters, WEA messages currently sent by ShakeAlert are only 90 characters. This decision was based partly on the need for users to quickly process the information and take the appropriate protective action. Sutton and Kuligowski (2019) argue that the time required for cognitive processing of novel information and initiation of a physical response requires short and simple messaging. The other consideration is that, by keeping messages short, there is less risk of encountering technical issues that may delay message delivery. Finally, an EEW alert alone may not be sufficient motivation for some people to take action; thus, by distributing shorter messages people may have more time to confirm the alert is correct and take action (Becker and others, 2020). People confirm warning messages through social norming (watching other people), milling for information (either searching online platforms or media outlets), or waiting for another alert or follow-up information (Wood and others, 2018). Studies of human behavior as well as the physical limitations of the system suggest that WEA messages should be as simple as possible, and contain only basic information about pending ground shaking and protective actions that people should take.

Exploring how injuries occur during or after earthquakes is a critical step in understanding what information is needed in an EEW alert message. Evidence suggests that most injuries occur from movement just after shaking begins (Peek-Asa and others, 2003; Johnston and others, 2014; McBride and others, 2019; Horspool and others, 2020). In one of the few studies about injuries in the Pacific Northwest, Kano (2005) showed that during the 2001 Nisqually earthquake, the main reason for reported injuries was falls (1 death, 400 injuries). Additional injuries occurred from bricks falling just outside of buildings (staff of the Pacific Northwest Seismic Network, 2001; Kano, 2005). In California earthquakes, such as the 1987 Whittier Narrows, 1989 Loma Prieta, and 1994 Northridge earthquakes, studies found that injuries sustained while exiting a building and from falls accounted for the majority of injuries (Shoaf and others, 1998; Peek-Asa and others, 2003). According to Shoaf and others (1998), who studied a decade of earthquakes in California, people who moved during shaking were twice as likely to be injured as those who did not. Although more evidence is required for the Pacific Northwest, existing research suggests that staying stationary is one of the most constructive protective actions.

Because most injuries occur when people try to move during earthquake shaking, drop, cover, and hold on (illustrated in fig. 15) has been adopted as the preferred method to reduce injuries in the United States (Jones and Benthien, 2011; Porter and Jones, 2018). It is important to note that drop, cover, and hold on is a suite of protective actions, included as step 5 in the 7 steps to earthquake safety (Earthquake Country Alliance, 2021). Drop, cover, and hold on recommendations also include protective actions for people who use wheelchairs, canes, and walkers (fig. 15). Situationdependent actions, including what to do if one feels shaking or receives an alert while in bed or driving a car, are also described. For current information on protective actions to take during an earthquake, visit https://community.fema.gov/ProtectiveActions/s/ topic/0TOt0000000Gzy6GAC/earthquake. 

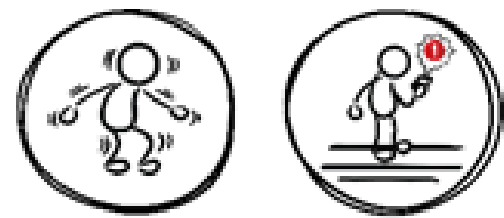

If you FEEL SHAKING or GET AN ALERT...

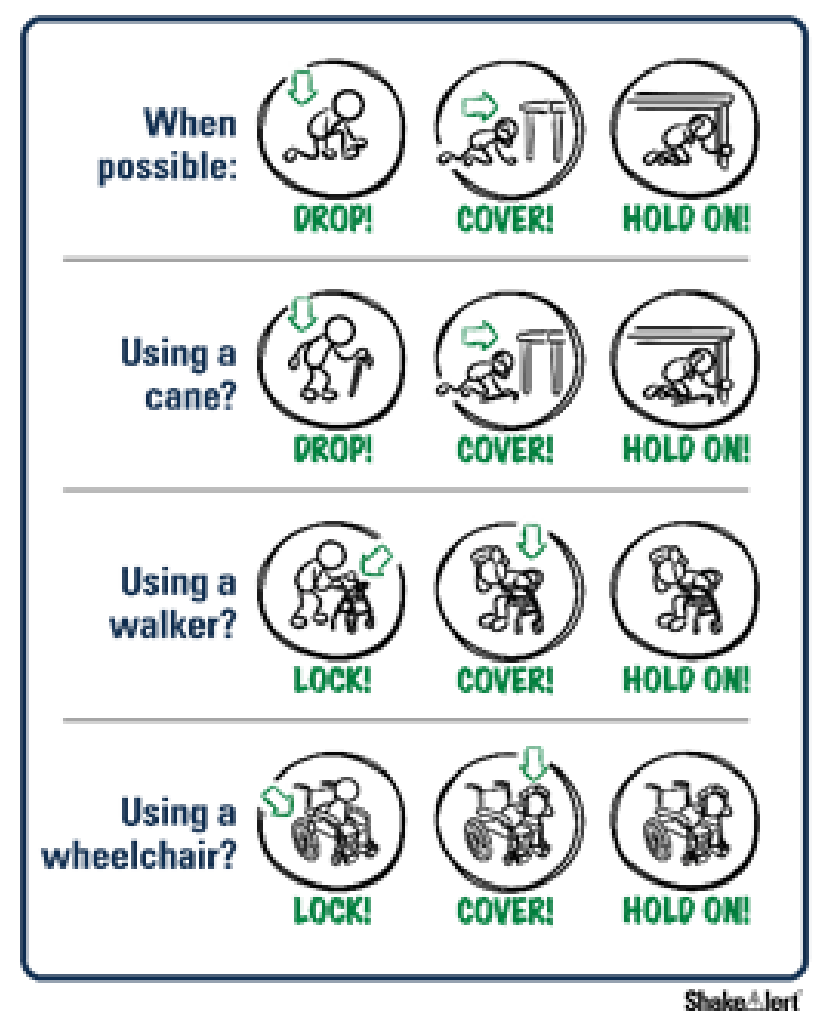

Figure 15. Schematic cartoon created for ShakeAlert's public education campaign showing a suite of actions included in drop, cover, and hold on actions.

Public education is a critical component to helping people understand what protective actions to take when they receive an alert. The Great ShakeOut is an earthquake drill practiced around the world in more than 50 countries that teaches people to drop, cover, and hold on (McBride and others, 2019). Videos could be used to educate people about appropriate protective actions to take when they feel shaking or receive an EEW alert (Sutton and others, 2020). Teaching people about building safety issues for the types of structures they live and work in would facilitate successful implementation of protective actions. Internationally, it is suggested that public education campaigns and information could encourage situational awareness among people in different settings and countries by providing basic earthquake safety principles, which can in turn assist people making the best choices for their specific situation (GeoHazards International, 2018, p. 5-6, 20).

Additional questions remain regarding protective actions, particularly in the Cascadia region. The ShakeAlert Joint Committee for Communication, Education, and Outreach
(JCCEO) provides messaging guidelines on protective actions to ShakeAlert delivery partners in California, Oregon, and Washington. The USGS and JCCEO manage an ongoing effort to optimize the content of EEW alert messages, with special attention to alerts delivered to cell phones and other personal wireless devices. Extensive work also continues on messaging used in institutional settings, such as alerts delivered via a public address system at a school. In 2019, the JCCEO convened a team of State emergency managers, social scientists, geoscientists, FEMA officials, and structural engineers to develop the ShakeAlert Protective Actions Guidelines (McBride and Bruce, 2020). These guidelines recommend that the drop, cover, and hold on suite of actions (fig. 15) are the most effective protective actions to be communicated to end users for the ShakeAlert system in California, Oregon, Washington. However, there may be special circumstances where additional or alternative protective actions are more appropriate to a particular setting (for example, an end user working on a powerline or in a hazardous environment).

\section{Conclusions}

The Cascadia region presents both difficult challenges and opportunities for success in EEW. Offshore megathrust earthquakes present one of the greatest potential gains from EEW because of the time it takes these ruptures to propagate along hundreds of kilometers of a plate-interface fault and the extensive region where EEW users can benefit from the warning. EEW was originally developed in Mexico and Japan, where megathrust earthquakes contribute substantially to earthquake hazards, and the expansion of ShakeAlert from California into Oregon and Washington builds on experience with EEW in all these regions. The potential exists for long warning times before strong to severe shaking in great megathrust earthquakes for many, but not all, ShakeAlert users. The expected warning times are highly variable depending on the details of the earthquake, the user's location, and the alert delivery mechanism. Alert delivery times, although not included in our calculations, are improving and recent tests of internet-based delivery, either directly to Wi-Fi-connected cell phones or for machine-to-machine applications, have shown that very rapid delivery (about 1 second) is possible. Thus, the warning times shown in figures 8 and 11-14 are likely realizable for many ShakeAlert users. Although megathrust earthquakes are rare in Cascadia, large ones will be devastating over a wide region. The sheer scale of these events makes them some of the best opportunities for ShakeAlert to help mitigate impacts and reduce injuries. Given the complexities involved and the various types of earthquakes that could occur in the Pacific Northwest, simple, clear, and consistent messaging is preferable so that users know what actions to take in most situations. Studies support this approach and indicate that drop, cover, and hold on actions are the most appropriate protective actions to take in most cases. For this reason, drop, cover, and hold on is already practiced 
widely in seismically active areas throughout the world, including in California, Oregon, and Washington.

As ShakeAlert rolls out in Oregon and Washington in 2021, ShakeAlert users there should expect that the majority of alerts they receive will be from relatively close earthquakes and that the amount of time they have to take protective actions after receiving an alert is short - on the order of 10 seconds or less in most cases for regions experiencing strong shaking. Offshore megathrust earthquakes are infrequent in Cascadia but are expected to cause significant damage over a wide area and offer longer warning times for users far from the earthquake epicenter. As the ShakeAlert system improves, it is expected to offer longer warning times for many of the earthquake sources in Cascadia and elsewhere. ShakeAlert end users should take immediate protective actions as soon as they feel shaking, whether they have received an alert or not. Because there may be long times between alerts in Cascadia, given the paucity of earthquakes in the region, developing a long-term public education plan for this area is complex. The use of frequent or annual drills, earthquake roadshows, or other outreach activities could be useful in raising awareness of the ShakeAlert system, so that people are not confused when they receive an alert. The ShakeAlert system will continue to improve over time and our understanding of potential warning times will become more complete as the underlying algorithms are improved and the alert delivery latencies are better understood.

\section{References Cited}

Allen, R.M., and Melgar, D., 2019, Earthquake early warning-Advances, scientific challenges, and societal needs: Annual Review of Earth and Planetary Sciences, v. 47 , p. $361-388$.

Atwater, B.F., Musumi-Rokkaku, S., Satake, K., Tsuji, Y., Ueda, K., and Yamaguchi, D.K., 2005, The orphan tsunami of 1700Japanese clues to a parent earthquake in North America: U.S. Geological Survey Professional Paper 1707, 133 p.

Becker, J.S., Potter, S.H., Vinnell, L.J., Nakayachi, K., McBride, S.K., and Johnston, D.M., 2020, Earthquake early warning in Aotearoa New Zealand-A survey of public perspectives to guide warning system development: Humanities and Social Sciences Communications, v. 7, no. 138, 12 p., https://doi. org/10.1057/s41599-020-00613-9.

Böse, M., Felizardo, C., and Heaton, T.H., 2015, Finite-fault Rupture Detector (FinDer) - Going real-time in California ShakeAlert warning system: Seismological Research Letters, v. 86, p. 1,692-1,704, https://doi.org/10.1785/0220150154.

Böse, M., Heaton, T.H., and Hauksson, E., 2012, Real-time Finite Fault Rupture Detector (FinDer) for large earthquakes: Geophysical Journal International, v. 191, p. 803-812, https:// doi.org/10.1111/j.1365-246X.2012.05657.x.
Böse, M., Smith, D.E., Felizardo, C., Meier, M.-A., Heaton, T.H., and Clinton, J.F., 2018, FinDer v.2-Improved real-time ground-motion predictions for M2-M9 with seismic finitesource characterization: Geophysical Journal International, v. 212, p. 725-742, https://doi.org/10.1093/gji/ggx430.

Bostock, M.G., Christensen, N.I., and Peacock, S.M., 2019, Seismicity in Cascadia: Lithos, v. 332-333, p. 207-225.

Brocher, T.M., Blakely, R.J., and Sherrod, B.L., 2017, Evaluating spatial and temporal relations between an earthquake cluster near Entiat, central Washington and the large December 1872 Entiat earthquake: Bulletin of the Seismological Society of America, v. 107, p. 2,380-2,393.

Cappucci, M., 2020, Those shrieking flash-flood alerts on your phone? Expect fewer of them: The Washington Post, January 10, 2020, accessed March 4, 2021, at https://www. washingtonpost.com/weather/2020/01/10/those-shriekingflash-flood-alerts-your-phone-expect-fewer-them.

Chiou, B.S.-J., and Youngs, R.R., 2008, An NGA model for the average horizontal component of peak ground motion and response spectra: Earthquake Spectra, v. 24, no. 1, p. 173-215.

Chung, A.I., Henson, I., and Allen, R.M., 2019, Optimizing earthquake early warning performance-ElarmS-3: Seismological Research Letters, v. 90, no. 2A, p. 727-743.

Chung, A.I., Meier, M., Andrews, J., Böse, M., Crowell, B., McGuire, J.J., and Smith, D.E., 2020, ShakeAlert earthquake early warning system performance during the 2019 Ridgecrest earthquake sequence: Bulletin of the Seismological Society of America, v. 110, p. 1,904-1,923.

Cochran, E.S., Aagaard, B.T., Allen, R.M., Andrews, J., Baltay, A.S., Barbour, A.J., Bodin, P., Brooks, B.A., Chung, A., Crowell, B.W., Given, D.D., Hanks, T.C., Hartog, J.R., Hauksson, E., Heaton, T.H., McBride, S., Meier, M-A., Melgar, D., Minson, S.E., Murray, J.R., Strauss, J.A., and Toomey, D., 2018, Research to improve ShakeAlert earthquake early warning products and their utility: U.S. Geological Survey Open-File Report 2018-1131, 17 p., https://doi.org/10.3133/ofr20181131.

Cochran, E.S., and. Husker, A.L., 2019, How low should we go when warning for earthquakes?: Science, v. 366, p. 957-958, https://doi.org/10.1126/science.aaz6601.

Crowell, B.W., Bock, Y., and Melgar, D., 2012, Real-time inversion of GPS data for finite fault modeling and rapid hazard assessment: Geophysical Research Letters, v. 39, 6 p., https://doi.org/10.1029/2012GL051318.

Dewey, J.W., Reagor, B.G., Dengler, L., and Moley, K., 1995, Intensity distribution and isoseismal maps for the Northridge, California, earthquake of January 17, 1994: U.S Geological Survey Open-File Report 95-92, 35 p. 
Earthquake Country Alliance, 2021, Seven steps to earthquake safety: Earthquake Country Alliance, accessed March 3, 2021, at https://www.earthquakeauthority.com/California-EarthquakeRisk/Personal-Preparedness/Seven-Steps-to-Earthquake-Safety/ Seven-Steps-to-Earthquake-Safety.pdf.

Frankel, A., Chen, R., Petersen, M., Moschetti, M., and Sherrod, B., 2019, 2014 update of the Pacific Northwest portion of the U.S. National Seismic Hazard Maps: Earthquake Spectra, v. 31, p. S131-S148, https://doi.org/10.1193/111314EQS193M.

Frankel, A., Wirth, E., Marafi, N., Vidale, J., and Stephenson, W., 2018, Broadband synthetic seismograms for magnitude 9 earthquakes on the Cascadia megathrust based on 3D simulations and stochastic synthetics, Part 1-Methodology and overall results: Bulletin of the Seismological Society of America, v. 108, p. 2,347-2,369.

GeoHazards International, 2018, Developing messages for protective actions to take during earthquake shaking: GeoHazards International Protective Actions Manual, 71 p., accessed December 31, 2020, at https://www.geohaz.org/fromthe-field.

Given, D.D., Allen, R.M., Baltay, A.S., Bodin, P., Cochran, E.S., Creager, K., de Groot, R.M., Gee, L.S., Hauksson, E., Heaton, T.H., and Hellweg, M., 2018, Revised technical implementation plan for the ShakeAlert system - An earthquake early warning system for the West Coast of the United States: U.S. Geological Survey Open-File Report 2018-1155, 42 p., https://doi. org/10.3133/ofr20181155.

Given, D.D., Cochran, S.E., Heaton, T., Hauksson, E., Allen, R., Hellweg, P., Vidale, J., and Bodin, P., 2014, Technical implementation plan for the ShakeAlert production systemAn earthquake early warning system for the West Coast of the United States: U.S. Geological Survey Open-File Report 2014-1097, 25 p., https://doi.org/10.3133/ofr20141097.

Goldfinger, C., Nelson, C.H., Morey, A.E., Johnson, J.E., Patton, J.R., Karabanov, E., Gutiérrez-Pastor, J., Eriksson, A.T., Gràcia, E., Dunhill, G., Enkin, R.J., Dallimore, A., and Vallier, T., 2012, Turbidite event history - Methods and implications for Holocene paleoseismicity of the Cascadia subduction zone: U.S. Geological Survey Professional Paper 1661-F, 170 p.

Hartog, J.R., Kress, V.C., Malone, S.D., Bodin, P., Vidale, J.E., and Crowell, B.W., 2016, Earthquake Early Warning-ShakeAlert in the Pacific Northwest: Bulletin of the Seismological Society of America, v. 106, no. 4, p. 1875-1886.

Horspool, N., Elwood, K., Johnston, D., Deely, J., and Ardagh, M., 2020 , Factors influencing casualty risk in the 14th November 2016 Mw7. 8 Kaikōura, New Zealand earthquake: International Journal of Disaster Risk Reduction, v. 51, 8 p.

Johnston, D.M., Standring, S., Ronan, K.R., Lindell, M., Wilson, T., Cousins, J., and Jensen, S., 2014, The 2010/2011 Canterbury earthquakes - Context and cause of injury: Natural Hazards, v. 73, p. 627-637.
Jones, L.M., and Benthien, M., 2011, Preparing for a "Big One"-The great southern California ShakeOut: Earthquake Spectra, v. 27, p. 575-595.

Kano, M., 2005, Characteristics of earthquake-related injuries treated in emergency departments following the 2001 Nisqually earthquake in Washington: Journal of Emergency Management, v. 3, p. 33-45.

Kohler, M.D., Cochran, E.S., Given, D., Guiwits, S., Neuhauser, D., Henson, I., Hartog, R., Bodin, P., Kress, V., Thompson, S., Felizardo, C., Brody, J., Bhadha, R., and Schwarzand, S., 2018, Earthquake Early Warning ShakeAlert System-West Coast Wide Production Prototype: Seismological Research Letters, v. 89, no. 1, p. 99-107.

Kohler, M.D., Smith, D.E., Andrews, J., Chung, A.I., Hartog, R., Henson, I., Given, D.D., de Groot, R., and Guiwits, S., 2020, Earthquake Early Warning ShakeAlert 2.0-Public Rollout: Seismological Research Letters, v. 91, no. 3, p. 1,763-1,775, https://doi.org/10.1785/0220190245.

McBride, S.K., Becker, J.S., and Johnston, D.M., 2019, Exploring the barriers for people taking protective actions during the 2012 and 2015 New Zealand ShakeOut drills: International Journal of Disaster Risk Reduction, v. 37, 11 p., https://doi.org/10.1016/j. ijdrr.2019.101150.

McBride, S.K., Bostrom, A., Sutton, J., de Groot, R.M., Baltay, A.S., Terbush, B., Bodin, P., Dixon, M., Holland, E., Arba, R., Laustsen, P., Liu, S., and Vinci, M., 2020, Developing post-alert messaging for ShakeAlert, the earthquake early warning system for the West Coast of the United States of America: International Journal of Disaster Risk Reduction, v. $50,11 \mathrm{p}$.

McBride, S.K., and Bruce, J., 2020, ShakeAlert protective actions guidelines: ShakeAlert Technical Partner Resource Center web page, 7 p., accessed March 8, 2021, at https://www.shakealert. org/education-outreach/tprc.

McGuire, J.J., de Groot, R.M., and Wald, L.A., 2019, What if the ShakeAlert Earthquake Early Warning System had been operating during the M6.9 1989 Loma Prieta earthquake: U.S. Geological Survey Natural Hazards webpage, October 17, 2019, accessed March 3, 2021, at https://www.usgs.gov/centernews/what-if-shakealert-earthquake-early-warning-system-hadbeen-operating-during-m69-1989.

McGuire, J.J., Simons, F.J., and Collins, J.A., 2008, Analysis of seafloor seismograms of the 2003 Tokachi-Oki earthquake sequence for earthquake early warning: Geophysical Research Letters, v. 35, 5 p., https://doi.org/10.1029/2008GL033986.

Meier, M.-A., Kodera, Y., Böse, M., Chung, A., Hoshiba, M., Cochran, E., Minson, S., Hauksson, E., and Heaton, T., 2020, How often can Earthquake Early Warning systems alert sites with high-intensity ground motion?: Journal of Geophysical Research Solid Earth, v. 125, 17 p., https://doi. org/10.1029/2019JB017718. 
Minson, S.E., Meier, M.-A., Baltay, A.S., Hanks, T.C., and Cochran, E.S., 2018, The limits of earthquake early warning-Timeliness of ground motion estimates: Science Advances, v. 4, 11 p., https://doi.org/10.1126/sciadv. aaq0504.

Minson, S.E., Murray, J.R., Langbein, J.O., and Gomberg, J.S., 2014, Real-time inversions for finite fault slip models and rupture geometry based on high-rate GPS data: Journal of Geophysical Research Solid Earth, v. 119, p. 3,2013,231, https://doi.org/10.1002/2013JB010622.

Murray, J.R., Crowell, B.W., Grapenthin, R., Hodgkinson, K., Langbein, J.O., Melbourne, T., Melgar, D., Minson, S.E., and Schmidt, D.A., 2018, Development of a geodetic component for the U.S. West Coast earthquake early warning system: Seismological Research Letters, v. 89 p. 2,322-2,336, https://doi.org/10.1785/0220180162.

Nakayachi, K., Becker, J.S., Potter, S.H., and Dixon, M., 2019, Residents' reactions to earthquake early warnings in Japan: Risk Analysis, v. 39, p. 1,723-1,740.

Nelson, A.R., Johnson, S.Y., Kelsey, H.M., Wells, R.E., Sherrod, B.L., Pezzopane, S.K., Bradley L.-A., Koehler, R.D., and Bucknam, R.C., 2003, Late Holocene earthquakes on the Toe Jam Hill fault, Seattle fault zone, Bainbridge Island, Washington: Geological Society of America Bulletin, v. 115, p. 1,388-1,403.

Nelson, A.R., Kelsey, H.M., and Witter, R.C., 2006, Great earthquakes of variable magnitude at the Cascadia subduction zone: Quaternary Research, v. 65, p. 354-365.

Peek-Asa, C., Ramirez, M., Seligson, H., and Shoaf, K.I., 2003, Seismic, structural, and individual factors associated with earthquake related injury: Injury Prevention, v. 9, p. 62-66.

Petersen, M.D., Moschetti, M.P., Powers, P.M., Mueller, C.S., Haller, K.M., Frankel, A.D., Zeng, Y., Rezaeian, S., Harmsen, S.C., Boyd, O.S., Field, N., Chen, R., Rukstales, K.S., Luco, N., Wheeler, R.L., Williams, R.A., and Olsen, A.H., 2014, Documentation for the 2014 update of the United States national seismic hazard maps: U.S. Geological Survey Open-File Report 2014-1091, 243 p., https://doi.org/10.3133/ofr20141091.

Petersen, M.D., Shumway, A.M., Powers, P.M., Mueller, C.S., Moschetti, M.P., Frankel, A.D., Rezaeian, S., McNamara, D.E., Luco, N., Boyd, O.S., Rukstales, K S., Jaiswal, K.S., Thompson, E.M., Hoover, S.M., Clayton, B.S., Field, E.H., and Zeng, Y., 2019, The 2018 update of the US National Seismic Hazard Model-Overview of model and implications: Earthquake Spectra, v. 36, p. 5-41, https:// doi.org/10.1177/8755293019878199.
Porter, K.A., and Jones, J.L., 2018, How many injuries can be avoided in the HayWired scenario through earthquake early warning and drop, cover, and hold on?, chap. Q of Detweiler, S.T., and Wein, A.M., eds., The HayWired earthquake scenario-Engineering implications: U.S. Geological Survey Scientific Investigations Report 20175013-I-Q, 429 p., https://doi.org/10.3133/sir20175013v2.

Roman, D., 2020, Simplifying and clarifying National Weather Service (NWS) flood products via the NWS Hazard Simplification Project [abs.]: Annual meeting of the American Meteorological Society, 100th, January 15, 2020, accessed March 3, 2021 at https://ams.confex.com/ams/2020Annual/ meetingapp.cgi/Paper/367496.

Ruhl, C.J., Melgar, D., Grapenthin, R., and Allen, R.M., 2017, The value of real-time GNSS to earthquake early warning: Geophysical Research Letters, v. 44, p. 8,311-8,319, https://doi. org/10.1002/2017GL074502.

Ruhl, C.J., Melgar, D., Chung, A.I., Grapenthin, R., and Allen, R.M., 2019, Quantifying the value of real-time geodetic constraints on earthquake early warning using a global seismic and geodetic dataset: Journal of Geophysical Research Solid Earth, v. 124, no. 4, p. 3,819-3,837, https://doi. org/10.1029/2018JB016935.

Satake, K., Wang, K., and Atwater, B.F., 2003, Fault slip and seismic moment of the 1700 Cascadia earthquake inferred from Japan tsunami descriptions: Journal of Geophysical Research Solid Earth, v. 108, 17 p., https://doi. org/10.1029/2003JB002521.

Shoaf, K.I., Nguyen, L.H., Sareen, H.R., and Bourque, L.B., 1998, Injuries as a result of California earthquakes in the past decade: Disasters, v. 22, no. 3, p. 218-235.

Staff of the Pacific Northwest Seismograph Network, 2001, Preliminary report on the $\mathrm{Mw}=6.8$ Nisqually, Washington earthquake of 28 February 2001: Seismological Research Letters, v. 72, no. 3, p. 352-361, https://doi.org/10.1785/ gssrl.72.3.352.

Stover, C.W., and Coffman, J.L., 1993, Seismicity of the United States, 1568-1989 (revised): U.S. Geological Survey Professional Paper 1527, $418 \mathrm{p}$.

Stubailo, I., Alvarez, M., Biasi, G., Bhadha, R., and Hauksson, E., 2020, Latency of waveform data delivery from the Southern California seismic network during the 2019 Ridgecrest earthquake sequence and its effect on ShakeAlert: Seismological Research Letters, v. 92, p. 170-186, https://doi. org/10.1785/0220200211.

Sutton, J., Fischer, L., James, L.E., and Sheff, S.E., 2020, Earthquake early warning message testing - Visual attention, behavioral responses, and message perceptions: International Journal of Disaster Risk Reduction, v. 49, 9 p., https://doi. org/10.1016/j.ijdrr.2020.101664. 
Sutton, J., and Kuligowski, E.D., 2019, Alerts and warnings on short messaging channels - Guidance from an expert panel process: Natural Hazards Review, v. 20, 10 p.

Thakoor, K., Andrews, J., Hauksson, E., and Heaton, T., 2019, From earthquake source parameters to ground-motion warnings near you - The ShakeAlert earthquake information to ground-motion (eqInfo2GM) method: Seismological Research Letters, v. 90, p. 1,243-1,257.

Turner, R.H., and Killian, L.M., 1957, Collective behavior: Englewood Cliffs, New Jersey, Prentice-Hall, v. 3, 547 p.

Wald, D.J., 2020, Practical limitations of earthquake early warning: Earthquake Spectra, v. 36, p. 1,412-1,447, https:// doi.org/10.1177/8755293020911388.

Wang, K., and Tréhu, A.M., 2016, Invited review paperSome outstanding issues in the study of great megathrust earthquakes - The Cascadia example: Journal of Geodynamics, v. 98, p. 1-18, https://doi.org/10.1016/j. jog.2016.03.010.

Wirth, E.A., and Frankel, A.D., 2019, Impact of down-dip rupture limit and high-stress drop subevents on coseismic land-level change during Cascadia megathrust earthquakes: Bulletin of the Seismological Society of America, v. 109, p. 2,187-2,197.
Wirth, E.A., Frankel, A.D., Marafi, N., Vidale, J.E., and Stephenson, W.J., 2018, Broadband synthetic seismograms for magnitude 9 earthquakes on the Cascadia megathrust based on 3D simulations and stochastic synthetics, Part 2-Rupture parameters and variability: Bulletin of the Seismological Society of America, v. 108, no. 5A, p. 2,370-2,388.

Wirth, E.A., Grant, A., Marafi, N.A., and Frankel, A.D., 2020, Ensemble ShakeMaps for magnitude 9 earthquakes on the Cascadia subduction zone: Seismological Research Letters, v. 92, 13 p., https://doi.org/10.1785/0220200240.

Witter, R.C., Zhang, Y.J., Wang, K., Priest, G.R., Goldfinger, C., Stimely, L., English, J.T., and Ferro, P.A., 2013, Simulated tsunami inundation for a range of Cascadia megathrust earthquake scenarios at Bandon, Oregon, USA: Geosphere, v. 9, 21 p.

Wood, M.M., Mileti, D.S., Bean, H., Liu, B.F., Sutton, J., and Madden, S., 2018, Milling and public warnings: Environment and Behavior, v. 50, p. 535-566.

Worden, C.B., Gerstenberger, M.C., Rhoades, D.A., and Wald, D.J., 2012, Probabilistic relationships between groundmotion parameters and modified Mercalli intensity in California: Bulletin of the Seismological Society of America, v. 102, p. 204-221. 


\section{Appendix 1}

In this appendix, we present alternative versions of several figures from the main text for different combinations of the ground motion threshold, $M M I_{\mathrm{tw}}$, and alert threshold,
$M M I_{\text {alert }}$. We also present alternative versions of tables 2-4 that include the shallow crustal earthquake sources separated by fault type, as published in the National Seismic Hazard Maps.

Table 1.1. Probability of exceeding peak ground acceleration (PGA) of $0.045 g$ at the indicated return time for three earthquake types.

[PGA of $0.045 \mathrm{~g}$ corresponds to the Modified Mercalli Intensity (MMI) 5 contour product. $g$, gravitational acceleration; \%, percent; yr, year]

\begin{tabular}{|c|c|c|c|c|c|}
\hline Location & Return time (yr) & $\begin{array}{c}\text { Megathrust } \\
\text { earthquake (\%) }\end{array}$ & $\begin{array}{l}\text { Deep intraslab } \\
\text { earthquake (\%) }\end{array}$ & $\begin{array}{c}\text { Shallow crustal } \\
\text { earthquake without } \\
\text { specific faults }(\%)\end{array}$ & $\begin{array}{l}\text { Shallow crustal } \\
\text { earthquake with } \\
\text { specific faults (\%) }\end{array}$ \\
\hline Seattle & 24 & 6 & 54 & 36 & 4 \\
\hline Portland & 91 & 26 & 15 & 52 & 7 \\
\hline Newport & 117 & 39 & 12 & 22 & $26^{\mathrm{a}}$ \\
\hline
\end{tabular}

${ }^{a}$ The Yaquina Fault is only 1 kilometer from Newport, Oreg.

Table 1.2. Probability of exceeding peak ground acceleration (PGA) of $0.013 g$ at the indicated return time for three earthquake types.

[PGA of $0.013 g$ corresponds to the Modified Mercalli Intensity (MMI) 4 contour product. $g$, gravitational acceleration; \%, percent; yr, year]

\begin{tabular}{lccccc}
\hline Location & Return time (yr) & $\begin{array}{c}\text { Megathrust } \\
\text { earthquake (\%) }\end{array}$ & $\begin{array}{c}\text { Deep intraslab } \\
\text { earthquake (\%) }\end{array}$ & $\begin{array}{c}\text { Shallow crustal } \\
\text { earthquake without } \\
\text { specific faults (\%) }\end{array}$ & $\begin{array}{c}\text { Shallow crustal } \\
\text { earthquake with } \\
\text { specific faults (\%) }\end{array}$ \\
\hline Seattle & 8 & 2 & 49 & 46 \\
Tacoma & 8 & 2 & 49 & 46 & 3 \\
Portland & 25 & 8 & 25 & 63 & 5 \\
Newport & 50 & 17 & 13 & 54 & 74 \\
Eureka & 4 & 1 & 5 & 15 \\
\hline
\end{tabular}

Table 1.3. Probability of exceeding peak ground acceleration (PGA) of $0.003 g$ at the indicated return time for three earthquake types.

[PGA of $0.013 \mathrm{~g}$ corresponds to the Modified Mercalli Intensity (MMI) 3 contour product. $g$, gravitational acceleration; \%, percent; yr, year]

\begin{tabular}{lccccc}
\hline Location & Return time (yr) & $\begin{array}{c}\text { Megathrust } \\
\text { earthquake (\%) }\end{array}$ & $\begin{array}{c}\text { Deep intraslab } \\
\text { earthquake (\%) }\end{array}$ & $\begin{array}{c}\text { Shallow crustal } \\
\text { earthquake without } \\
\text { specific faults (\%) }\end{array}$ & $\begin{array}{c}\text { Shallow crustal } \\
\text { earthquake with } \\
\text { specific faults (\%) }\end{array}$ \\
\hline Seattle & 3.5 & 1 & 35 & 63 & 1 \\
Tacoma & 4 & 1 & 37 & 60 & 2 \\
Portland & 7 & 2 & 30 & 63 & 71 \\
Newport & 12 & 4 & 11 & 51 & 13 \\
Eureka $(0.005 \mathrm{~g}$ threshold) & 2 & 1 & 4 & 14 \\
\hline
\end{tabular}



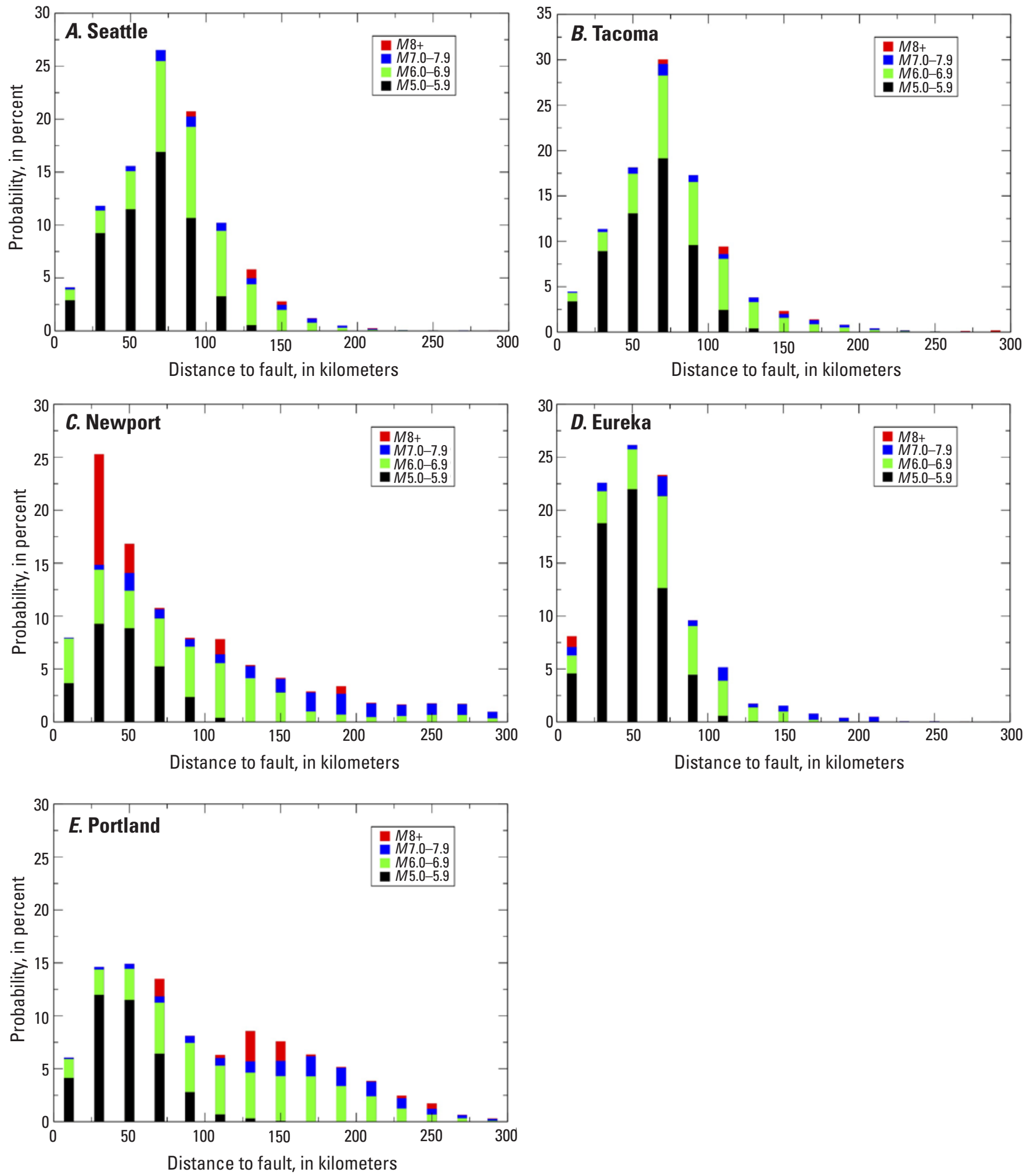

Figure 1.1. Plots showing the probability of generating a ShakeAlert Message as a function of the closest distance to the fault that ruptured during the earthquake for the hazard deaggregation calculations in table 3 of the main text for Seattle $(A)$, Tacoma $(B)$, Newport $(C)$, Eureka $(D)$, and Portland $(E)$. The disaggregation calculations are for a Modified Mercalli Intensity 4 contour product, an observed ground-motion threshold $\left(M M I_{\text {tw }}\right)$ of 4.5, and an alert threshold ( $M M I_{\text {alert }}$ ) of 3.5. Compare with figure 3 of the main text. Note the distance is the distance tabulated in the National Seismic Hazard Maps, which is the distance to the closest point on the fault $\left(R_{\text {rup }}\right)$, not the distance to the epicenter. Colors show the contribution of different magnitude ranges to the probabilities. $M$, magnitude. 

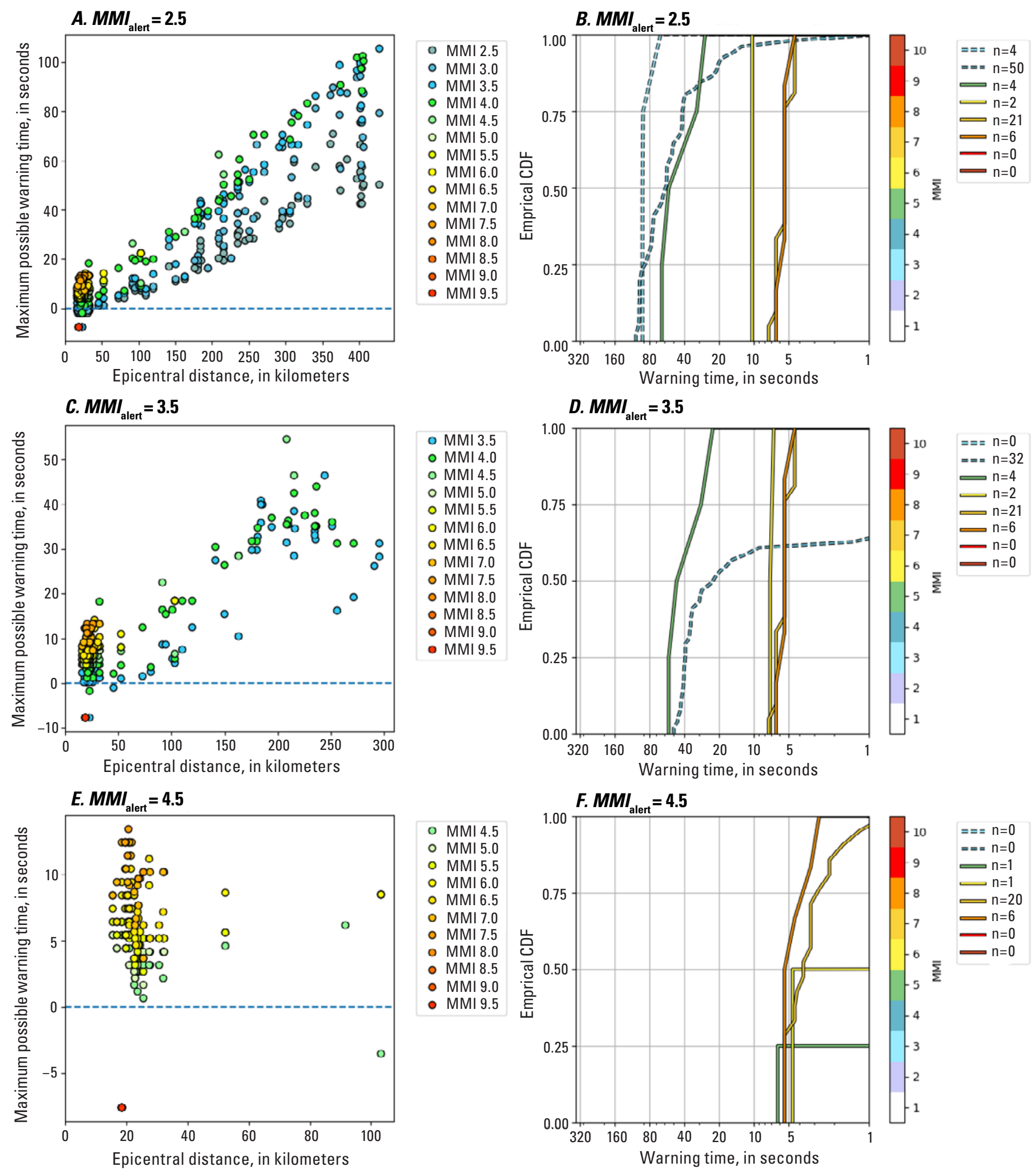

Figure 1.2. Plots showing warning times from the ShakeAlert system for the 2018 moment magnitude 7.1 Anchorage earthquake in Alaska. The left column shows warning time as as a function of epicentral distance for three different alert thresholds $\left(M M I_{\text {alen }}\right)$, which correspond to different delivery mechanisms (table 1 of the main text). Only seismic stations that exceeded an instrumental Modified Mercalli Intensity (MMI) of 2.5 are shown. The right column shows the cumulative distribution functions (CDF) of warning times. Warning times are for a ground-motion threshold $\left(M M I_{\mathrm{tw}}\right)$ of 4.5 in all plots. The number ( $\mathrm{n}$ ) of alerts that have warning times $>1$ second for each $\mathrm{MMI}$ level is shown. These are maximum possible warning times because they do not include the data telemetry latency (approximately 1-2 seconds) or the variable time to deliver the alert via different mechanisms. Therefore, actual warning times will be shorter by at least a few seconds. Compare to figures 5 and 7 in the main text. 

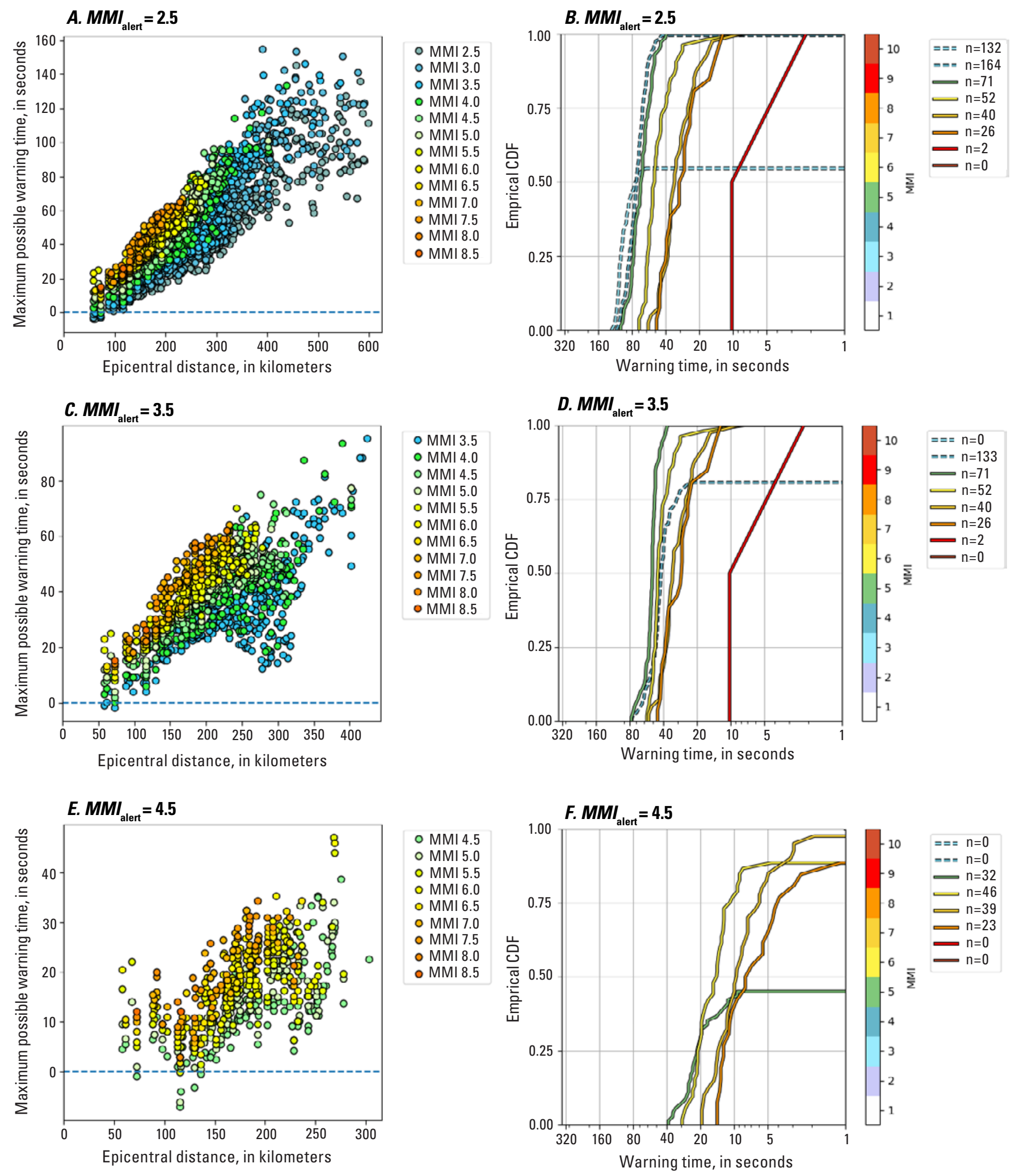

Figure 1.3. Plots showing warning times from the ShakeAlert system for the 2003 moment magnitude 8.3 Tokachi-Oki earthquake in Japan. The left column shows warning time as a function of epicentral distance for three different alert thresholds ( $M M I_{\text {alert }}$, which correspond to different delivery mechanisms (table 1 of the main text). Only seismic stations that exceeded an instrumental Modified Mercalli Intensity of 4.5 are shown. The right column shows the cumulative distribution functions (CDF) of warning times. Warning times are for a ground-motion threshold ( $M M I_{\mathrm{tw}}$ ) of 4.5 in all plots. The number $(\mathrm{n})$ of alerts that have warning times $>1$ second for each $\mathrm{MMl}$ level is shown. Many sites would have an additional $10-20$ seconds of warning time beyond what is shown in this figure for applications that are better described by $M M I_{\mathrm{tw}}=7(A, C, E)$. These are maximum possible warning times because they do not include the data telemetry latency (approximately 1-2 seconds) or the variable time to deliver the alert via different mechanisms. Therefore, actual warning times will be shorter by at least a few seconds. Compare to figures 5 and 7 in the main text. 

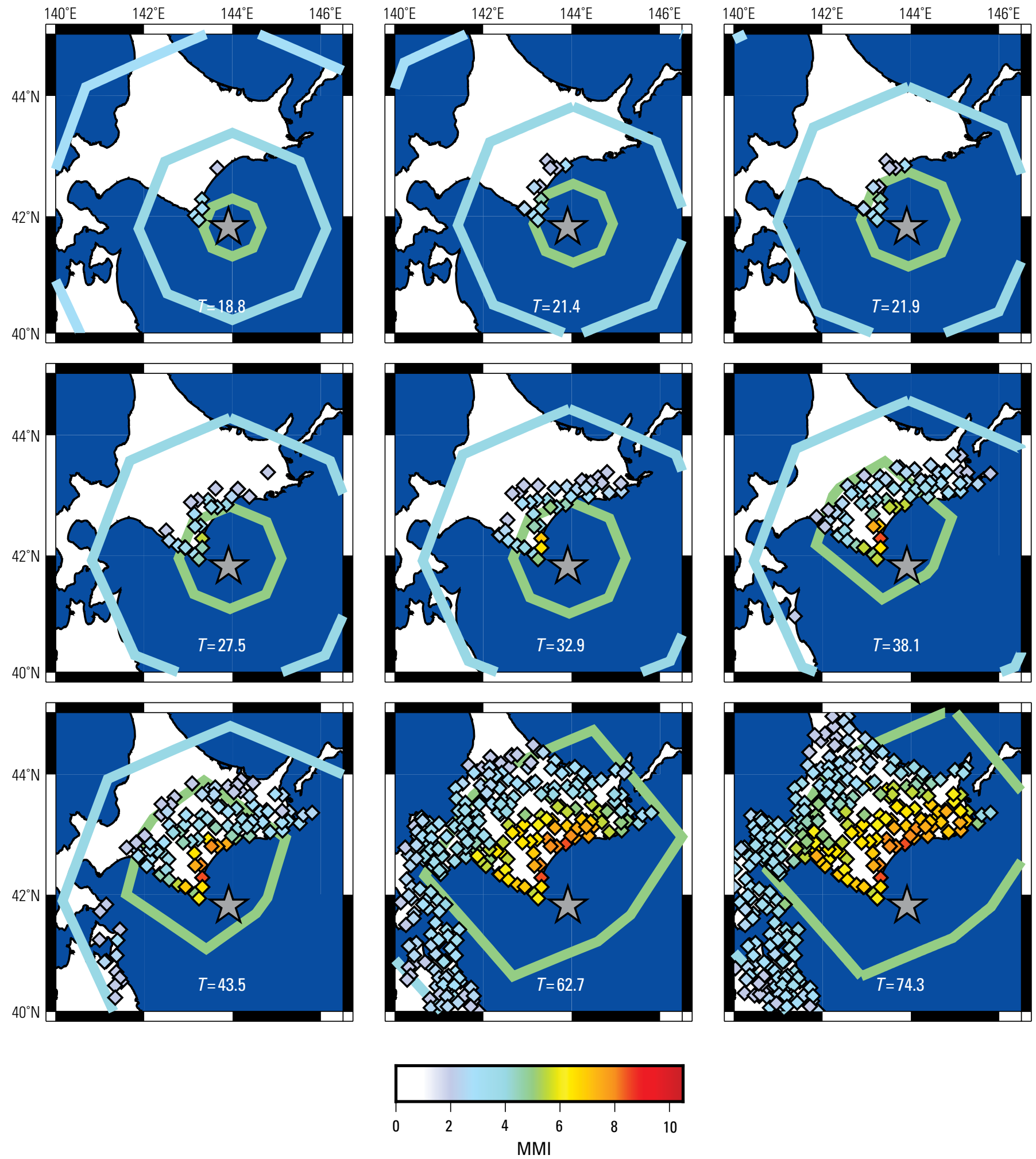

Figure 1.4. Maps of Hokkaido, Japan, showing the alert polygons for a Modified Mercalli Intensity (MMI) of 3 (light blue), 4 (cyan), and 5 (green) ShakeAlert Message contour products and observed shaking levels (colored diamonds) at different times during the 2003 magnitude 8.3 Tokachi-Oki earthquake simulation. Each map shows a time when the ShakeAlert solution aggregator issues a new alert in response to an increase in the estimated earthquake magnitude. Times $(T)$ are given in seconds after origin. The three alert polygons are colored according to $\mathrm{MMI}$ level, but after $T=21.9$ seconds, the MMI 3 contour product extends beyond the scale of these maps. Each map shows the seismic stations (diamonds colored by shaking level at that time) that have exceeded MMI 2 shaking at the time step. Gray star marks the earthquake epicenter. 


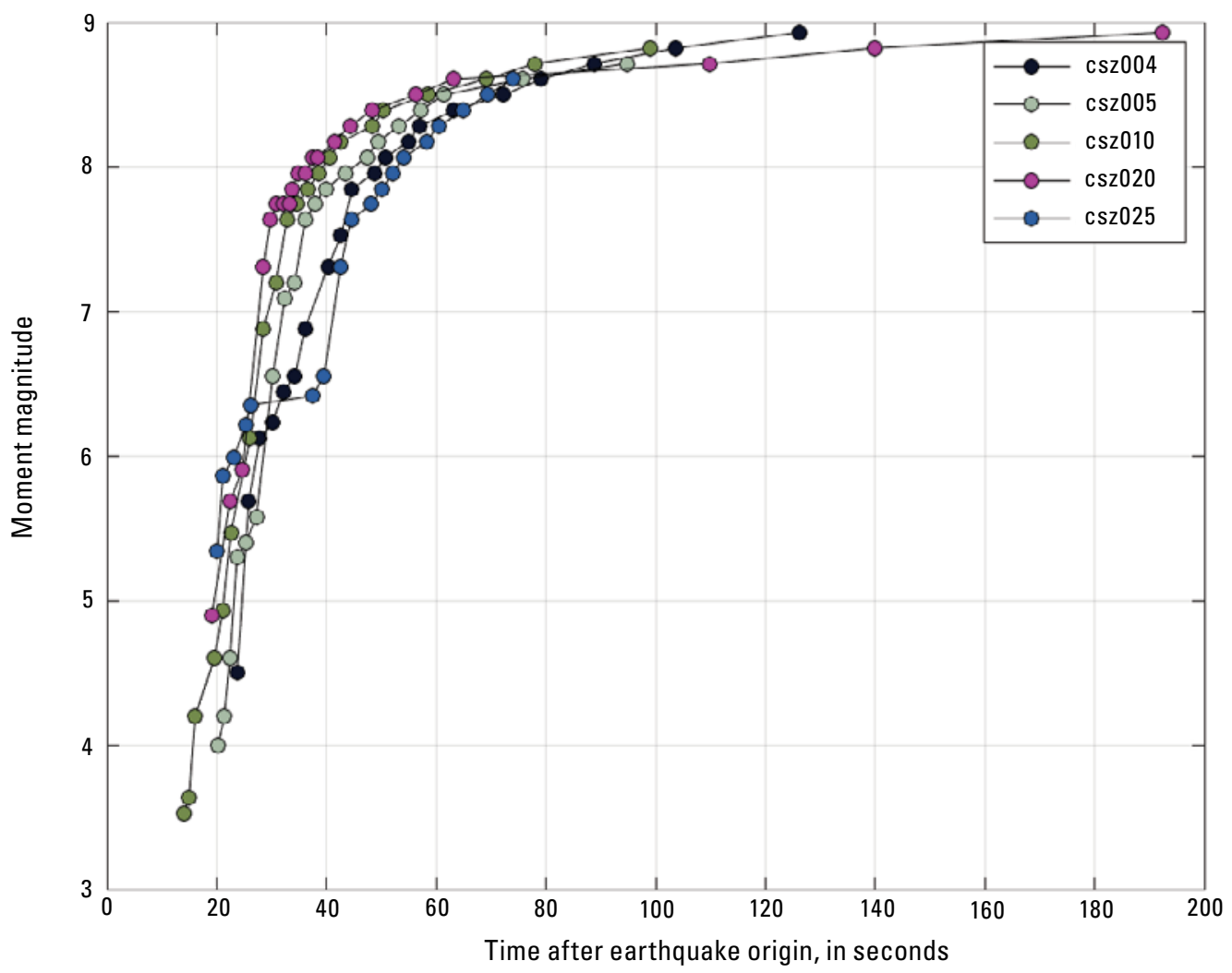

Figure 1.5. Plot showing the evolution of magnitude through time as determined by ShakeAlert for five magnitude 9 Cascadia megathrust earthquake simulations calculated by using the expanded FinDer template set.

Figure 1.6. Maps of the western Cascadia region showing alert times-the difference between the time an ShakeAlert Message is issued and the initiation time of the earthquake, which is not the same as warning time-for five magnitude 9 earthquake scenarios. The five scenarios (from left to right) are csz004, csz005, csz010, csz020, and csz025. Maps show results for three different alert thresholds $\left(M M I_{\text {alert }}\right): M M I_{\text {alert }}=2.5$ (top row), $M M I_{\text {alert }}=3.5$ (middle row), $M M I_{\text {alert }}=4.5$ (bottom row). Gray star marks the epicenter of the rupture. Thick black and white lines mark the updip and downdip limits of slip, respectively. Diamonds denote the locations of current or planned ShakeAlert seismic stations colored by the alert time. The color scale repeats at 75 seconds after the earthquake origin time. Light gray diamonds show locations that were outside of the alert polygons and as a result received no warning. 

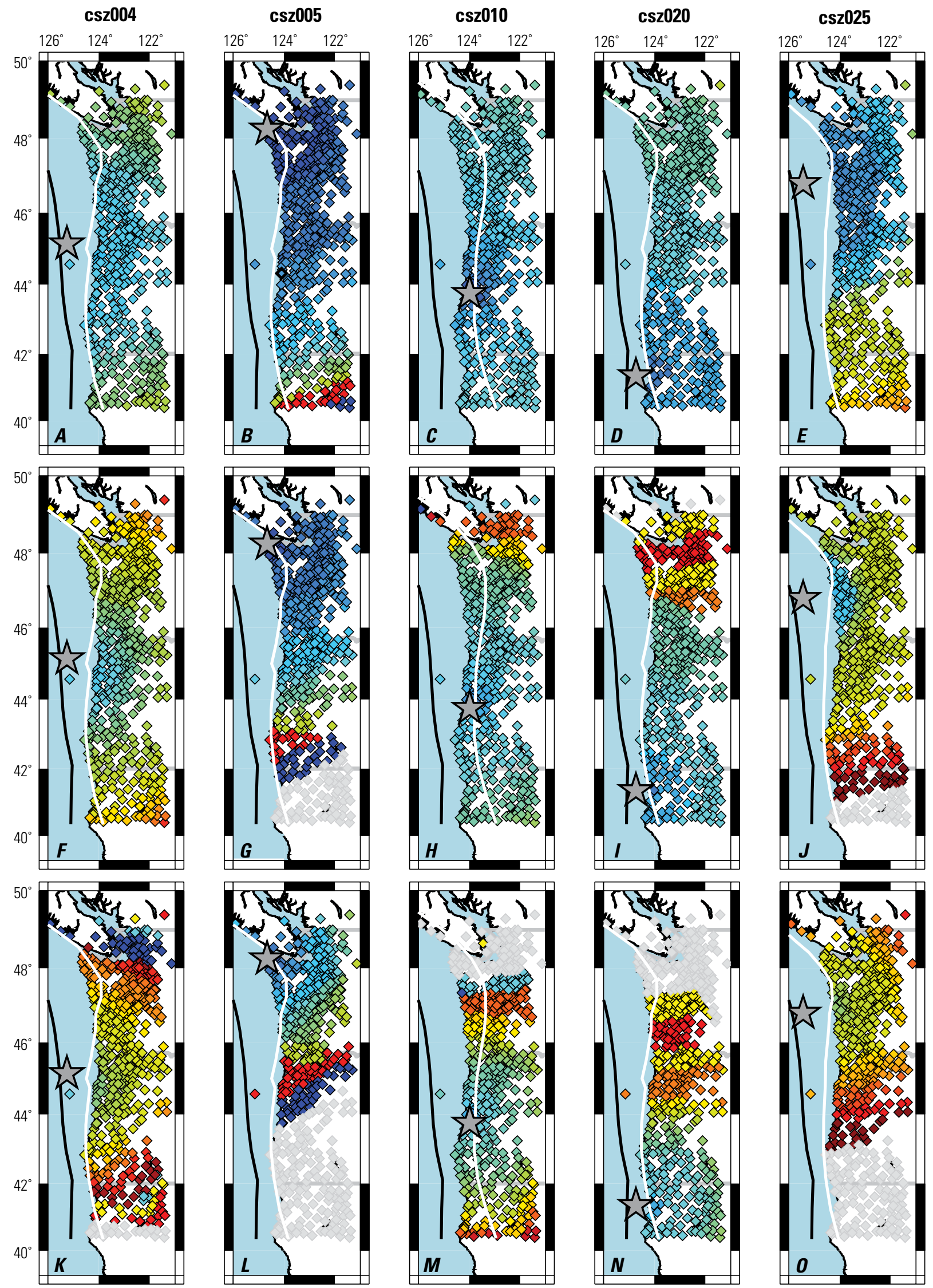


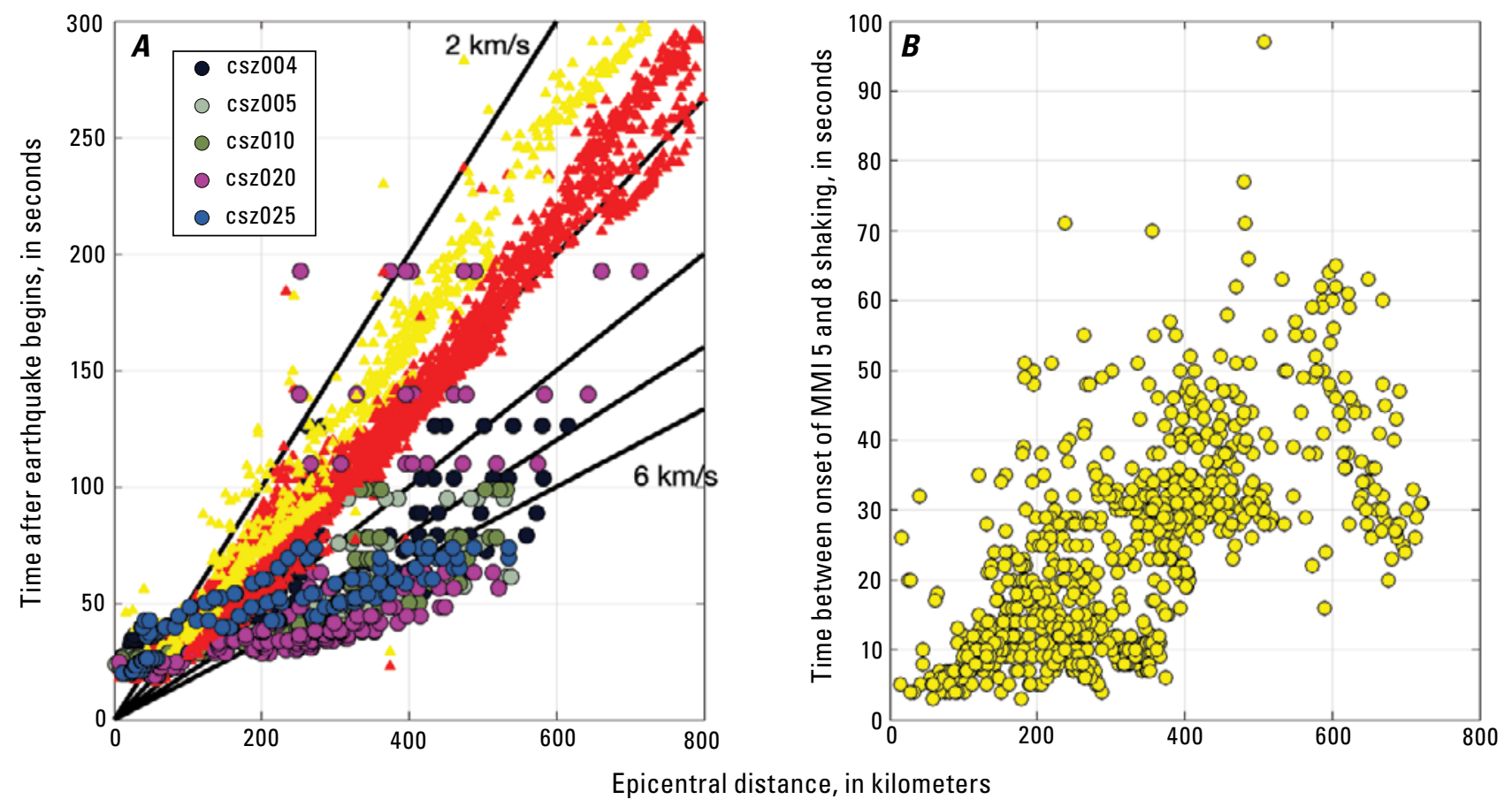

Figure 1.7. A, Plot showing instrumental Modified Mercalli Intensity (MMI) exceedance times for five magnitude 9 earthquake scenarios in the Cascadia region calculated by using the expanded FinDer template set. Red and yellow triangles denote the time a particular location exceeded MMI 4.5 and 7.5, respectively. Colored circles show the vertices that define the MMI 5 contour product alert polygons for all alerts. The colors correspond to the different earthquake simulations. For reference, black lines show rates of 2, 3, 4, 5, and 6 kilometers per second $(\mathrm{km} / \mathrm{s})$. $B$, Plot showing the difference between when MMI 4.5 and 7.5 level shaking is exceeded for the five earthquake simulations as a function of epicentral distance. At distances greater than 300 kilometers, the difference typically corresponds to the difference between the S-wave and surface wave arrivals in these synthetic simulations.

Figure 1.8. Plots showing empirical cumulative distribution functions (CDF) of warning times for five magnitude 9 Cascadia megathrust earthquake scenarios for three different alert threshold $\left(M M I_{\text {alert }}\right)$ levels. In the left column $M M I_{\text {alert }}=2.5$, middle column $M M I_{\text {alert }}=3.5$, and right column $M M I_{\text {alert }}=4.5$. Plots $A-C$ show results for scenario csz004, $D-F$ show scenario csz005, $G-I$ show scenario csz010, $J-L$ show scenario csz020, and $M-O$ show scenario csz025. Warning times are for a groundmotion threshold ( $M M I_{\text {tw }}$ ) of 4.5 in all plots. These are not true CDFs because the distribution of seismic stations used for the calculation is non-uniform. Compare to figures 5 and 7 of the main text. 
Appendix 1
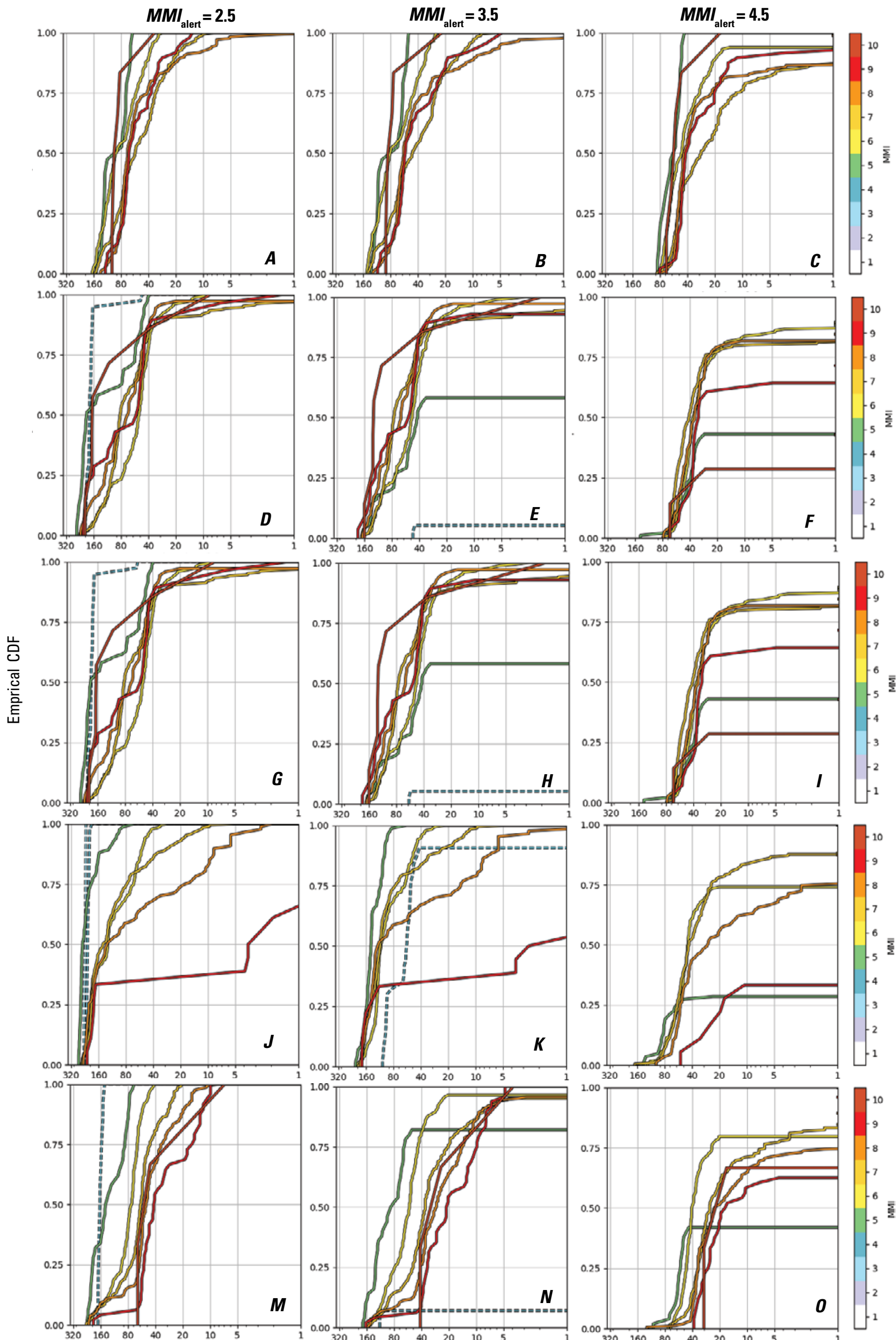

Moffett Field Publishing Service Center, California

Manuscript approved March 9, 2021

Edited by Monica Erdman

Layout by Cory Hurd 
旁

웅

i

증

蛋 